\title{
RELATIONSHIP OF SHALE DEWATERING AND SMECTITE DEHYDRATION TO UNDERCOMPACTION OCCURRENCE
}

Final Report

October 1995 - September 1996

John T. Leftwich, Jr.

Geological Sciences Program

Old Dominion University

Norfolk, Virginia 23529

December 1996

PREPARED FOR THE U.S. DEPARTMENT OF ENERGY

UNDER GRANT NUMBER DOE-FG05-96FE63870 


\section{DISCLAIMER}

This report was prepared as an account of work sponsored by an agency of the United States Government. Neither the United States Government nor any agency thereof, nor any of their employees, make any warranty, express or implied, or assumes any legal liability or responsibility for the accuracy, completeness, or usefulness of any information, apparatus, product, or process disclosed, or represents that its use would not infringe privately owned rights. Reference herein to any specific commercial product, process, or service by trade name, trademark, manufacturer, or otherwise does not necessarily constitute or imply its endorsement, recommendation, or favoring by the United States Government or any agency thereof. The views and opinions of authors expressed herein do not necessarily state or reflect those of the United States Government or any agency thereof. 


\section{DISCLAIMER}

Portions of this document may be illegible in electronic image products. Images are produced from the best available original document. 
Introduction 1

Virginia State University Student Research...................................................2

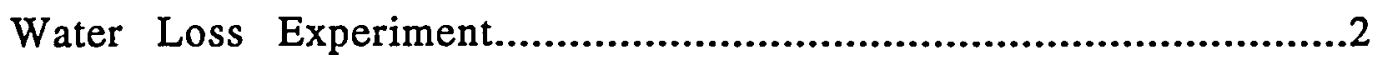

Methylene Blue Experiment......................................................9

Old Dominion University Research......................................................16

Semi-quantitative X-ray analysis for clay and other minerals in shales from Maguire Oil's Rupp \#1 well Ann Mag Field, South Texas..................16

Semi-quantitative X-ray analysis for clay and other minerals in shales from Humble Oil East Flour Bluff D-9 and Standard Oil of Texas State Tract 883, Well \#, South Texas.

Relationship of hydrocarbon zones to the tops of abnormal pressure and the zone of undercompaction in the Ann Mag and El Paistle Fields........58

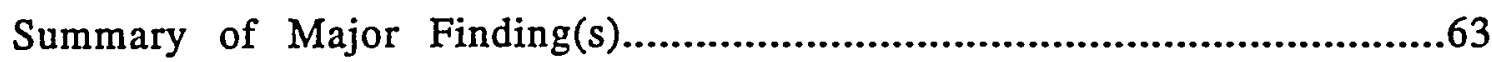

Student Development and Education....................................................64

Computer Equipment for Virginia State University and for Old Dominion university....66

Appendix A Paper by Leftwich et.al., The Correlaation between interlayer Water Content in Shale and Abnormal Pressure in the Ann Mag Field, South Texas ...67

Appendix B Preparation procedure for a semi-quantitative analysis of clay minerals from analysis of shale chips. Described methods for X-raying cuttings from Maguire Oil Company's Rupp \#1 well. Technique modified from methods by Dr. Dennis Darby. 


\section{INTRODUCTION}

The cause(s) of abnormal fluid pressures in sedimentary basins are not clearly understood. One step in determining the mechanism(s) of abnormal pressure generation in sedimentary basins is to develop an understanding of the relationship among undercompacted shale, abnormal pressure, and temperature. Our research focused on understanding undercompaction and how it related to smectite-illite conversion. A series of carefully designed experiments were used to help clarify and evaluate the relationship of smectite-illite transformation to undercompaction.

Research was done at Old Dominion University, (Norfolk, Virginia) and Virginia State University, (Petersburg, Virginia). The student research was done at Virginia State University and the remainder was done at Old Dominion.

The research was initiated by making a planning trip to Virginia State University in March 1996. This was an introductory/planning meeting held in the Department of Geology at Virginia State University. I met with the three undergraduate students who were identified to work on the project, Dr. G. Jagannadham (department chairman), and Dr. Constance Hill (faculty member who agreed to help supervise the students). The Virginia State University students that worked on this project were Kelly Doswell, Delano King, and Miyoshi Stith. 


\section{WATER LOSS VERSUS DEPTH FOR THE HUMBLE OIL EAST FLOUR BLUFF D-9 WELL EAST FLOUR BLUFF FIELD, NUECES COUNTY, TEXAS}

\section{INTRODUCTION}

Leftwich, 1993 and Leftwich, Engelder, and Kacandes (1996) (see paper in Appendix A) demonstrated the usefulness of water loss techniques in evaluating the mechanism of undercompaction. All of the water loss experiments that they performed involved experiments on wells (Sullivan $\mathrm{K}-1, \mathrm{M}-1$, and Rupp 1 in Ann Mag field, Figures 1-3) that only penetrated 1000 to 1500 feet below the top of the undercompacted zone. In these wells it was very obvious as to the trend of the water loss above and down through the top of the undercompacted zone, but the wells were generally not deep enough to clearly show the trend well into the zone of undercompaction.

The purpose of this study was to plot a water loss curve on a relatively deep well and examine the deep water loss trend.

\section{METHODS AND DATA}

The methods used in this study are the same as those outlined in Leftwich, 1993 and Leftwich, Engelder, and Kacandes (1996) (see paper in Appendix A). The well chosen for this study was the Humble Oil East Flour Bluff D-9 well, which is located in the E. Flour Bluff field in Nueces County, Texas. The well was drilled to a total depth of 12,000 feet and 122 cuttings samples were studies which ranged in depth from about 4000 feet to the 12,000 foot total depth of the well. Sample depths and the calculated water loss is shown in Table 1. A graph of the water loss versus depth is shown in Figure 4.

\section{OBSERVATIONS}

When we examine the three shallow wells fro the Ann Mag field (Figures 1-3) we can see the gradual decrease in water loss (smectite dehydration) with depth down to the top of the undercompacted zone. The fact that these wells are shallow makes it impossible to say what happens to the trend deep into the zone of undercompaction. When we examine the water loss curve on the deep Flour Bluff D-9 well it becomes apparent what happens to this trend down deep. It shows that once we get into the undercompacted zone the overall trend becomes vertical. The water loss is about the same. There is some variation but the trend is vertical meaning that the value remains about the same.

Thus we observe a sudden change in the slope of the water loss curve at the top of the zone of undercompaction (see Figure 4).

\section{CONCLUSIONS}

The change in slope marks the point at which most of the smectite has been converted to illite. This is defined as the "smectite to illite transformation point". The slope change is coincident with the top of undercompaction therefore it suggest that undercompaction is closely related to smectite to illite transformation. 


\section{REFERENCES}

Leftwich Jr., J. T., 1993, The Development of Zones of Undercompacted Shale Relative to Abnormal Subsurface Pressures in Sedimentary Basins. Ph.D. diss., The Pennsylvania State University.

Leftwich, J. T., Engelder, T., and Kacandes G.H., 1996, The Correlation between Interlayer Water content in Shale and Abnormal Pressure in the Ann Mag Field, South Texas: Clay Minereals, (in press). 


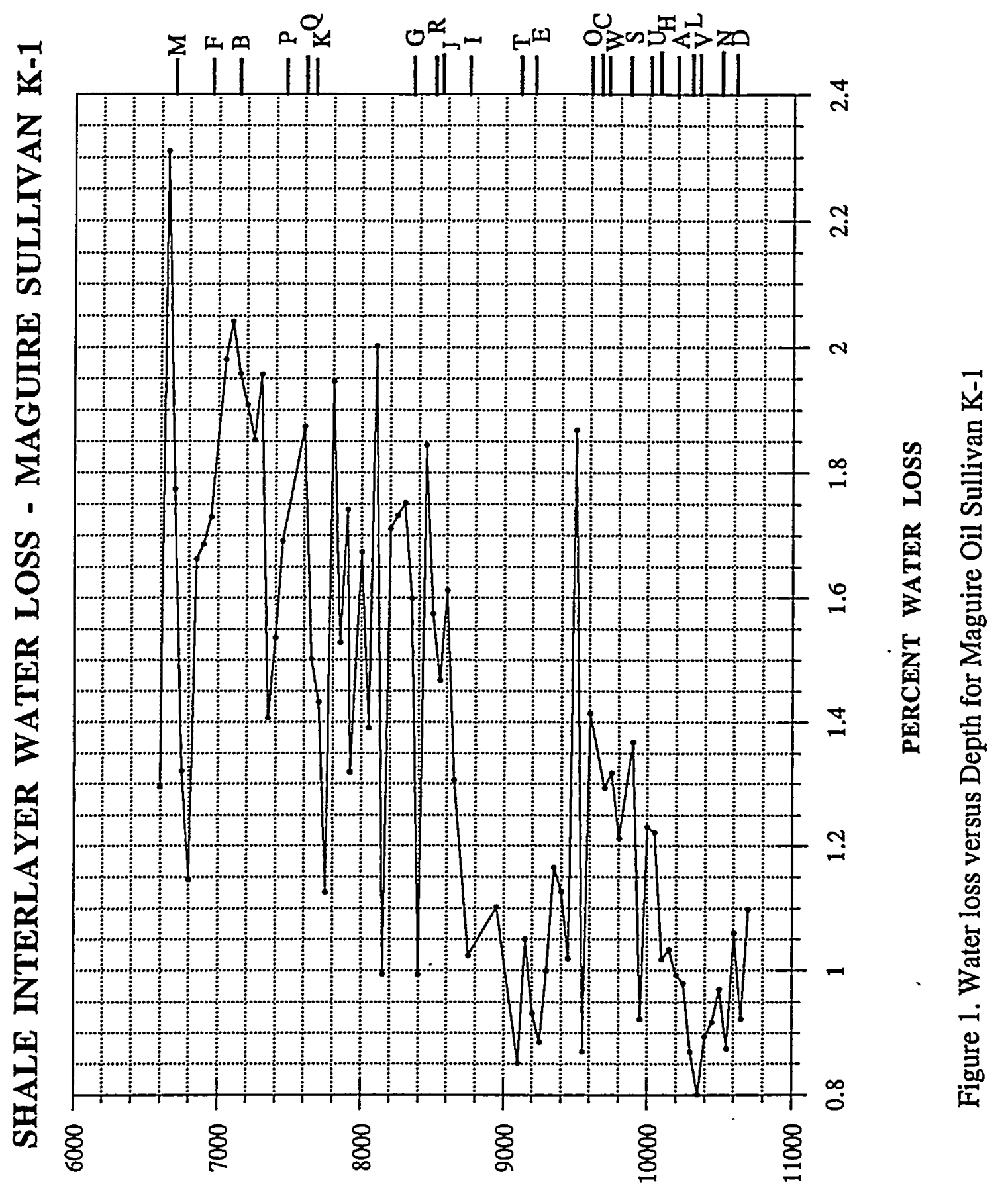

（IH） HLAG 


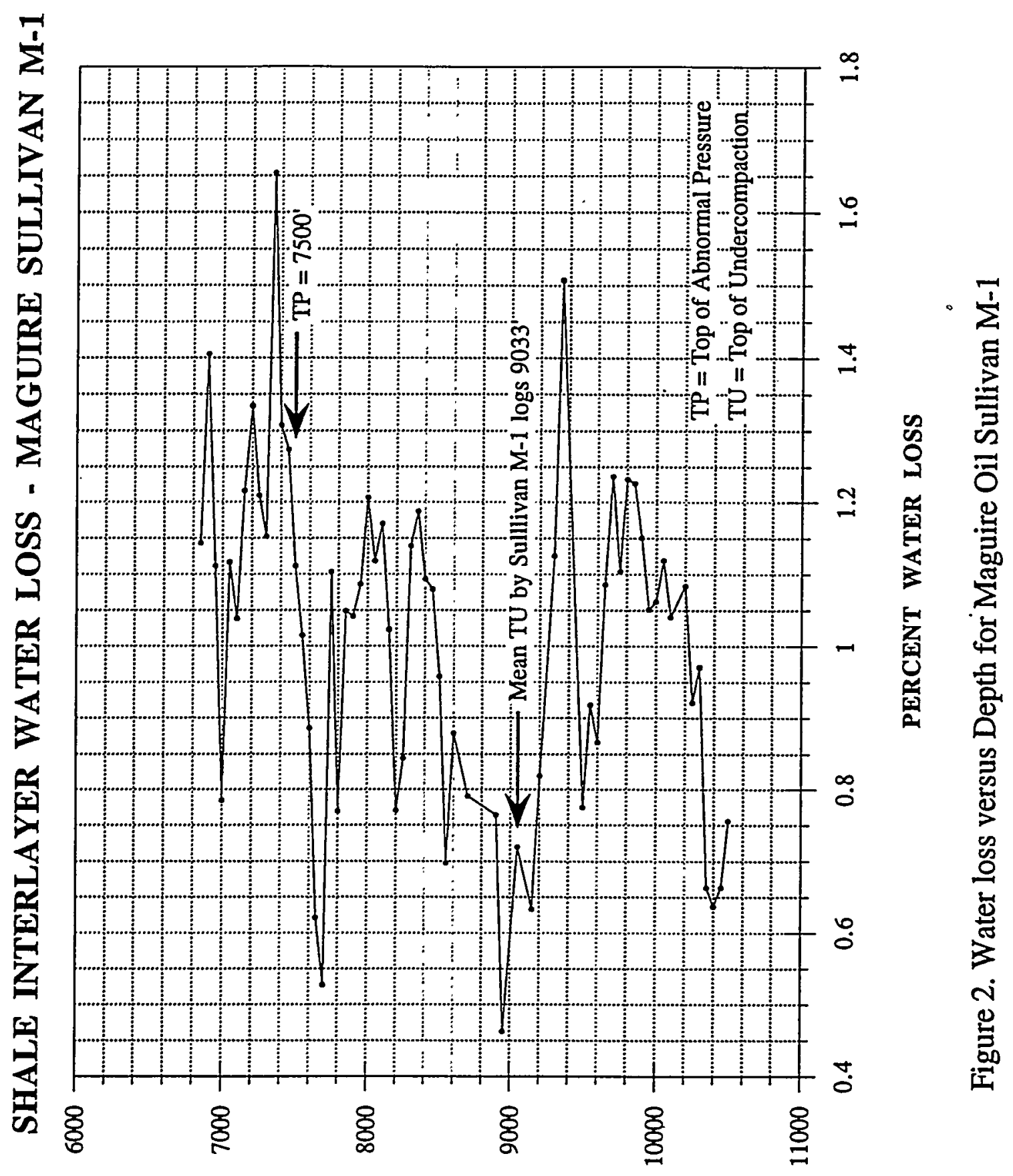

(IA) HLdHA 


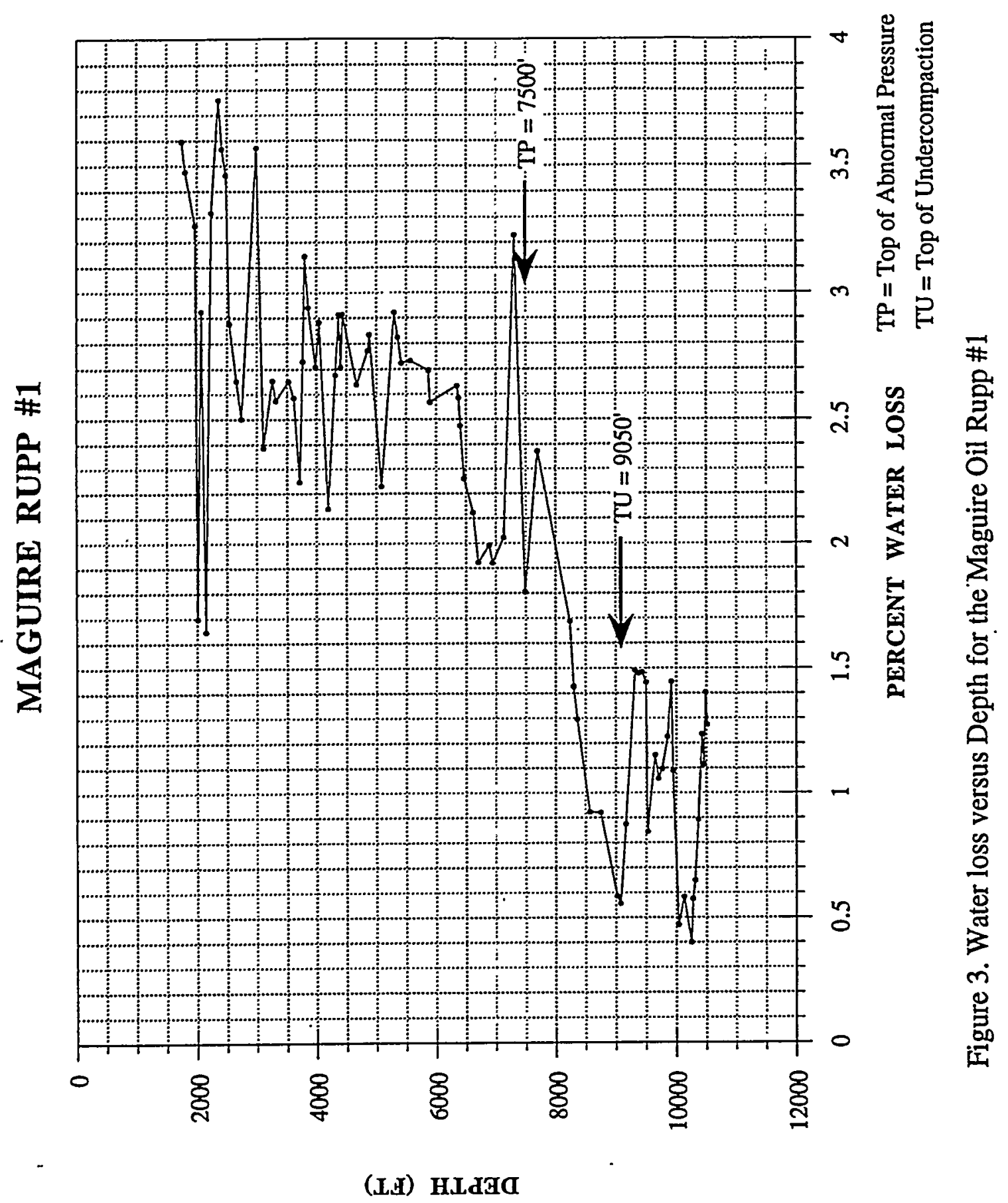


Table 1. Water loss versus depth data for Humble Oil East Flour Bluff D-9 Well

\begin{tabular}{|r|r|r|}
\hline & DEPTH(FI) & WATERLOSS \\
\hline 0 & 4013.0 & 6.8398 \\
\hline 1 & 4061.0 & 6.4439 \\
\hline 2 & 4121.0 & 6.3229 \\
\hline 3 & 4211.0 & 6.4153 \\
\hline 4 & 4271.0 & 6.2682 \\
\hline 5 & 4331.0 & 6.3222 \\
\hline 6 & 4391.0 & 6.3289 \\
\hline 7 & 4452.0 & 6.3708 \\
\hline 8 & 4511.0 & 6.2161 \\
\hline 9 & 4571.0 & 6.4041 \\
\hline 10 & 4631.0 & 6.2415 \\
\hline 11 & 4691.0 & 6.1547 \\
\hline 12 & 4752.0 & 6.0404 \\
\hline 13 & 4811.0 & 6.3119 \\
\hline 14 & 4871.0 & 5.5213 \\
\hline 15 & 4899.0 & 5.3920 \\
\hline 16 & 4961.0 & 5.5261 \\
\hline 17 & 5021.0 & 5.7342 \\
\hline 18 & 5081.0 & 5.4943 \\
\hline 19 & 5141.0 & 5.8047 \\
\hline 20 & 5201.0 & 5.9713 \\
\hline 21 & 5261.0 & 5.6695 \\
\hline 22 & 5318.0 & 5.4033 \\
\hline 23 & 5381.0 & 5.2567 \\
\hline 24 & 5441.0 & 4.9434 \\
\hline 25 & 5502.0 & 4.9275 \\
\hline 26 & 5561.0 & 5.7308 \\
\hline 27 & 5621.0 & 5.8309 \\
\hline 28 & 5681.0 & 5.8746 \\
\hline 29 & 5741.0 & 5.9540 \\
\hline 30 & 5796.0 & 5.7151 \\
\hline 31 & 5852.0 & 5.3380 \\
\hline 32 & 5941.0 & 5.3926 \\
\hline 33 & 6002.0 & 5.2404 \\
\hline 34 & 6061.0 & 5.4055 \\
\hline 35 & 6121.0 & 5.4099 \\
\hline 36 & 6181.0 & 5.4839 \\
\hline 37 & 6241.0 & 4.9202 \\
\hline 38 & 6301.0 & 5.9023 \\
\hline 39 & 6361.0 & 5.6305 \\
\hline 40 & 6421.0 & 5.6313 \\
\hline 41 & 6481.0 & 5.8419 \\
\hline 42 & 6541.0 & 5.4999 \\
\hline 43 & 6631.0 & 5.9326 \\
\hline 44 & 6691.0 & 5.8928 \\
\hline 45 & 6752.0 & 5.1584 \\
\hline
\end{tabular}

\begin{tabular}{|r|r|r|}
\hline & DEPTH(FI) & WATER LOSS \\
\hline 47 & 6871.0 & 5.0121 \\
\hline 48 & 6931.0 & 4.3337 \\
\hline 49 & 6991.0 & 5.2729 \\
\hline 50 & 7052.0 & 4.6027 \\
\hline 51 & 7111.0 & 5.2291 \\
\hline 52 & 7171.0 & 5.3516 \\
\hline 53 & 7231.0 & 5.2252 \\
\hline 54 & 7291.0 & 5.2833 \\
\hline 55 & 7352.0 & 4.4706 \\
\hline 56 & 7411.0 & 4.5639 \\
\hline 57 & 7471.0 & 4.5593 \\
\hline 58 & 7531.0 & 4.4765 \\
\hline 59 & 7591.0 & 3.8134 \\
\hline 60 & 7741.0 & 3.8317 \\
\hline 61 & 7790.0 & 4.2828 \\
\hline 62 & 7845.0 & 4.1476 \\
\hline 63 & 7905.0 & 3.9235 \\
\hline 64 & 7965.0 & 4.3451 \\
\hline 65 & 8025.0 & 3.6374 \\
\hline 66 & 8085.0 & 3.5347 \\
\hline 67 & 8145.0 & 2.9340 \\
\hline 68 & 8205.0 & 4.1172 \\
\hline 69 & 8295.0 & 3.6459 \\
\hline 70 & 8355.0 & 4.0422 \\
\hline 71 & 8415.0 & 3.0688 \\
\hline 72 & 8475.0 & 4.5062 \\
\hline 73 & 8535.0 & 3.6575 \\
\hline 74 & 8595.0 & 3.9698 \\
\hline 75 & 8645.0 & 4.0786 \\
\hline 76 & 8705.0 & 3.5569 \\
\hline 77 & 8765.0 & 4.0727 \\
\hline 78 & 8845.0 & 3.4859 \\
\hline 79 & 8905.0 & 2.4717 \\
\hline 80 & 8995.0 & 4.0678 \\
\hline 81 & 9505.0 & 3.7319 \\
\hline 82 & 9535.0 & 2.9075 \\
\hline 83 & 9595.0 & 3.9491 \\
\hline 84 & 9655.0 & 3.8479 \\
\hline 85 & 9805.0 & 3.3076 \\
\hline 86 & 9835.0 & 3.5674 \\
\hline 87 & 9895.0 & 4.0154 \\
\hline 88 & 9955.0 & 4.1339 \\
\hline 89 & 10015 & 3.7011 \\
\hline 90 & 10075 & 4.5549 \\
\hline 91 & 10125 & 4.3657 \\
\hline 92 & 10185 & 3.9033 \\
\hline
\end{tabular}

\begin{tabular}{|c|c|c|}
\hline & DEPTH(FI) & WATERLOSS \\
\hline 94 & 10305 & 3.3874 \\
\hline 95 & 10365 & 3.8852 \\
\hline 96 & 10415 & 3.7650 \\
\hline 97 & 10475 & 3.6970 \\
\hline 98 & 10535 & 3.4933 \\
\hline 99 & 10595 & 2.7842 \\
\hline 100 & 10665 & 2.7895 \\
\hline 101 & 10725 & 3.2715 \\
\hline 102 & 10795 & 3.0076 \\
\hline 103 & 10845 & 3.4076 \\
\hline 104 & 10905 & 3.1713 \\
\hline 105 & 10995 & 3.3489 \\
\hline 106 & 11058 & 3.6005 \\
\hline 107 & 11125 & 3.8248 \\
\hline 108 & 11185 & 4.4032 \\
\hline 109 & 11245 & 4.1724 \\
\hline 110 & 11305 & 4.0868 \\
\hline 111 & 11365 & 2.9996 \\
\hline 112 & 11425 & 3.6097 \\
\hline 113 & 11485 & 3.9707 \\
\hline 114 & 11545 & 3.5068 \\
\hline 115 & 11605 & 3.6573 \\
\hline 116 & 11695 & 3.7839 \\
\hline 117 & 11755 & 3.4891 \\
\hline 118 & 11815 & 3.7331 \\
\hline 119 & 11875 & 3.9874 \\
\hline 120 & 11965 & 3.5036 \\
\hline 121 & 11990 & 3.5668 \\
\hline
\end{tabular}




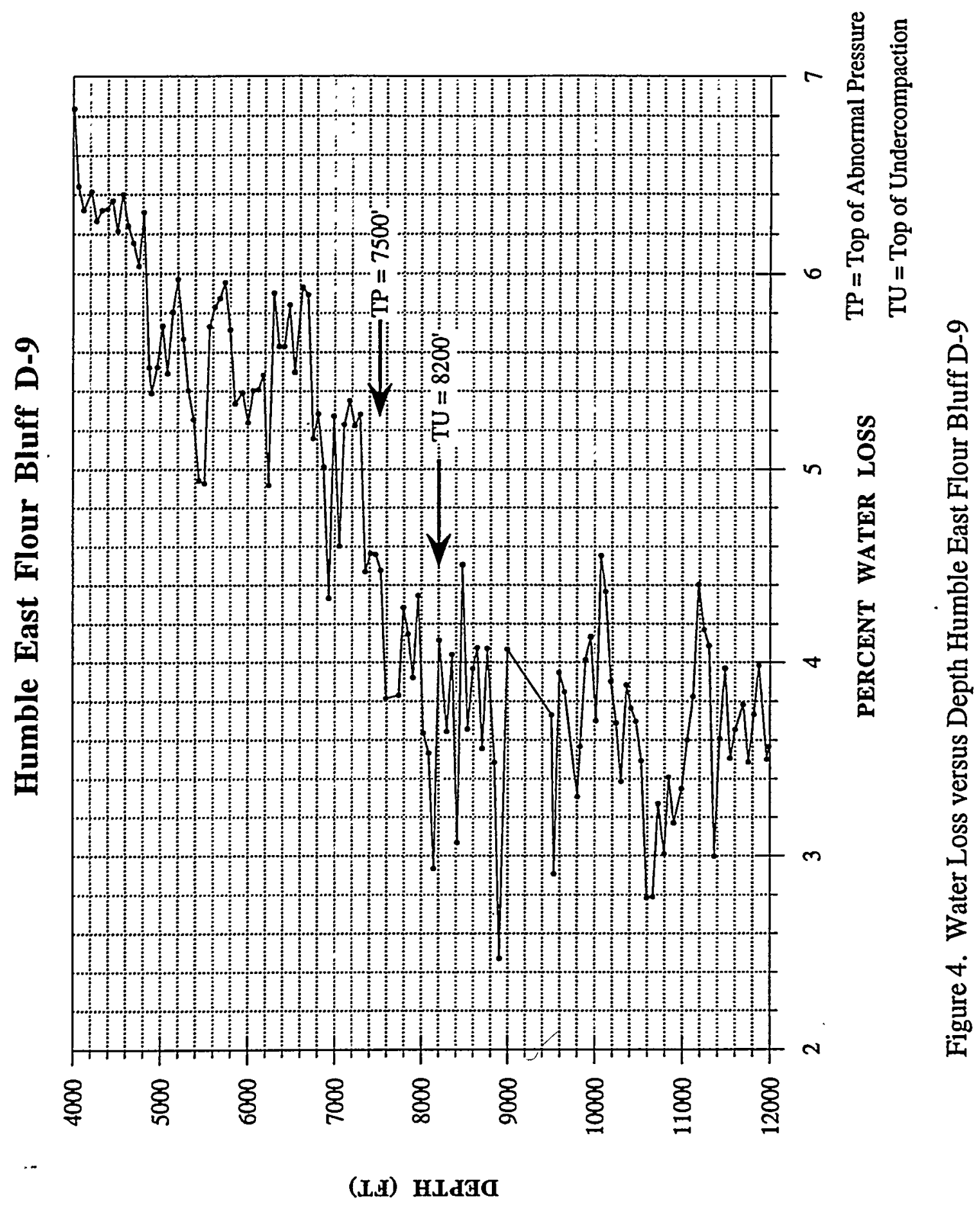


SHALE FACTOR BY METHYLENE BLUE VERSUS SHALE WATER LOSS

by

Kelley Doswell, Delano King, and Miyoshi Stith

\section{INTRODUCTION}

The purpose of this investigation was to determine how closely a plot of "shale factor" versus depth would correlate with a water loss curve (as prepared by Leftwich and Engelder, 1993) for the same well. The subject well of this study is Maguire Oil Company's Rupp \#1 located in the Ann Mag field of Brooks County, Texas.

Our research was important in helping to evaluate Dr. Leftwich's overall hypothesis that undercompaction phenomenon is related to smetite-illite transformation.

Shale Factor (Gill and Weintritt, 1971) is similiar to cation exchange capacity (CEC), which is the ability to exchange cations in clay minerals ( e.g., smetite, illite, kaolinite, etc.). The cation exchange capacity is commonly expressed in milliequivalents per $100 \mathrm{~g}$ of clay.

\section{HYPOTHESIS}

We developed and proceeded to test the following subhypothesis which was developed in the following way.

Premise 1: Leftwich and Engelder (1993) demonstrated that water loss versus depth is related to smetite-illite versus depth.

Premise 2: Since Methylene blue testing (shale factor) can be used to detect smectite directly a plot of shale factor versus depth should resemble a water loss versus depth curve on the same well.

Subhypothesis:

If undercompaction is controlled by smectite-illite transformation, then a plot of "shale factor" should identify undercompaction.

In order to help evaluate Dr. Leftwich's overall hypothesis that undercompaction phenomenon is the same as, or is controlled by smetite-illite transformation.

\section{LABORATORY METHODS}

The procedure for the determination of "shale factor" by methylene blue testing is outlined below:

Each dried cuttings sample was removed from their individual envelope. The cuttings that were seleeted were representative of the new formation. A mortar and pestle were used to grind the samples finely. After grinding each sample, the powders were placed in separate vials.

$0.5 \mathrm{~g}$ of each powdered sample was weighed on a balance. The $0.5 \mathrm{~g}$ of powder was placed in a evaporating dish. The evaporating dish was placed on a hot plate with a few drops of distilled water and sulphuric acid $(5 \mathrm{~N})$ were added. The suspension was stirred continuously as it heated to a boil. 
The methylene blue solution ( 0.01 milliequivalent) was added drop by drop taking one drop of the mixture at regular intervals and placing it on a sheet of filter paper. If the color

- remained in the center of the spot obtained, the equilibrium point had not yet been reached, but if the color followed the enlargement of the spot and formed an aureole around its periphery, the volume of methylene blue used was noted. The volume of methylene blue noted was determined by the number of drops used. For each cutting sample, the equation below was used to calculate the shale factor:

\author{
Shale Factor $=100 / \mathrm{W} * \mathrm{~V} * \mathrm{~N}$ \\ where, $W=$ Weight of powdered rock (gram) \\ $\mathrm{V}=$ Volume of methylene blue used $(\mathrm{ml})$ \\ $\mathrm{N}=$ Methylene blue concentration
}

\title{
DATA AND OBSERVATIONS
}

Table 1 shows the shale factor data obtained for each sample. Using the shale factor information a graph was sketched showing shale factor versus depth (Figure 1).

A plot of water loss versus depth for the Maguire Oil Rupp \#1 was provided by Dr. Leftwich and is shown in Figure 2.

We are amazed to see that a comparison of the the two plots show an almost perfect correlation.

\section{DISCUSSION}

The strong correlation between the water loss versus depth curve and the shale factor versus depth curve confirms that the water loss of Leftwich, 1993 and Leftwich, et.al., 1996, is mainly associated with interlayer water rather than just variations in pore water.

Taking the aforementioned conclusion into account and knowing that water loss curves on deep wells (e.g., water loss curve on Humble East Flour Bluff D-9 shown as Figure 3 on page 15 of this report) show a change in slope at the top of the zone of undercompaction strongly suggest that smectite-illite transformation point and the top of undercompaction are synonomous.

\section{CONCLUSION}

Water loss versus depth is associated with interlayer water and is essentially related to smectiteillite transformation, which defines undercompaction.

\section{REFERENCES}

Gill, G. A., and Weintritt, D. J., 1971, Shale Factor: A Diagnostic Tool for Formation Logging. The Log Analyst.

Leftwich Jr., J. T., 1993, The Development of Zones of Undercompacted Shale Relative to Abnormal Subsurface Pressures in Sedimentary Basins. Ph.D. diss., The Pennsylvania State University. 
Leftwich, J.T., and Engelder, T., 1995, The characteristics of geopressure profiles in the Gulf of Mexico Basin: in Orteleva, P., ed., Pressure Compartments, American Association of Petroleum Geologists Memoir, (in press).

Leftwich, J. T.; Engelder, T., and Kacandes G.H., 1995, The Correlation between Interlayer Water content in Shale and Abnormal Pressure in the Ann Mag Field, South Texas: Clay Minereals, (in press). 
Table 1. Shale Factor Determination Maguire Oil Co. Rupp \#1 Well

\begin{tabular}{|c|c|c|c|c|}
\hline $\begin{array}{l}\text { SAMPLE } \\
\text { NUMBERS }\end{array}$ & $\begin{array}{l}\text { DEPTH } \\
\text { (FT) }\end{array}$ & $\begin{array}{l}\text { METHYLENE } \\
\text { BLUE } \\
\text { DROPS } \\
\end{array}$ & $\begin{array}{l}\text { SHALE } \\
\text { FACTOR } \\
100 / W * V * N \\
\end{array}$ & $\begin{array}{l}\text { TOTAL OF } \\
\text { SHALE } \\
\text { FACTOR } \\
\end{array}$ \\
\hline 1 & 1750 & 85 & $100 / .5 * 8.5 \mathrm{ml} * 5$ & 8500 \\
\hline 2 & 1995 & 63 & $100 / .5 * 6.3 \mathrm{ml} * 5$ & 6300 \\
\hline 3 & 2455 & 68 & $100 / .5 * 6.8 \mathrm{ml}^{*} 5$ & 6800 \\
\hline 27 & 2700 & 59 & $100 / .5 * 5.9 \mathrm{ml}^{*} 5$ & 5900 \\
\hline 23 & 3145 & 54 & $100 / .5 * 5.4 \mathrm{ml}^{*} 5$ & 5400 \\
\hline 26 & 3595 & 37 & $100 / .5 * 3.7 \mathrm{ml}^{* 5}$ & 3700 \\
\hline .25 & 3805 & 50 & $100 / .5 * 5.0 \mathrm{ml}^{*} 5$ & 5000 \\
\hline 28 & 4285 & 40 & $100 / .5 * 4.0 \mathrm{ml}^{*} * 5$ & 4000 \\
\hline 29 & 4675 & 34 & $100 / .5 * 3.4 \mathrm{ml}^{* 5}$ & 3400 \\
\hline 6 & 4885 & 29 & $100 / .5 * 2.9 \mathrm{ml}^{*} 5$ & 2900 \\
\hline 4 & 5545 & 10 & $100 / .5 * 1.0 \mathrm{ml}^{* 5}$ & 1000 \\
\hline 30 & 5875 & 47 & $100 / .5 * 4.7 \mathrm{ml} * 5$ & 4700 \\
\hline 5 & 6380 & 28 & $100 / .5 * 2.8 \mathrm{ml}^{*} 5$ & 2800 \\
\hline 7 & 6985 & 25 & $100 / .5 * 2.5 \mathrm{ml} * 5$ & 2500 \\
\hline 8 & 7465 & 40 & $100 / .5^{*} 4.0 \mathrm{ml} * 5$ & 4000 \\
\hline 9 & 7675 & 27 & $100 / .5 * 2.7 \mathrm{ml} * 5$ & 2700 \\
\hline 10 & 8245 & 30 & $100 / .5 * 3.0 \mathrm{ml}^{* 5}$ & 3000 \\
\hline 11 & 8365 & 8 & $100 / .5 * .80 \mathrm{ml}^{* 5}$ & 800 \\
\hline 12 & 8643 & 14 & $100 / .5 * 1.4 \mathrm{ml} * 5$ & 1400 \\
\hline 13 & 8815 & 6 & $100 / .5^{*} .60 \mathrm{ml}^{* 5}$ & 600 \\
\hline$\overline{14}$ & 9055 & 8 & $100 / .5^{*} .80 \mathrm{ml} * 5$ & 800 \\
\hline 15 & 9085 & 3 & $100 / .5 * .30 \mathrm{ml}^{* 5}$ & 300 \\
\hline 24 & 9295 & 22 & $100 / .5 * 2.2 \mathrm{ml} * 5$ & 2200 \\
\hline 16 & 9325 & 29 & $100 / .5 * 2.9 \mathrm{ml} * 5$ & 2900 \\
\hline 17 & 9535 & 12 & $100 / .5 * 1.2 \mathrm{ml} * 5$ & 1200 \\
\hline 8 & 9655 & 40 & $100 / .5 * 4.0 \mathrm{ml}^{*} 5$ & 4000 \\
\hline 19 & 9985 & 21 & $100 / .5 * 2.1 \mathrm{ml} * 5$ & 2100 \\
\hline 21 & 10285 & 20 & $100 / .5 * 2.0 \mathrm{ml}^{*} 5$ & 2000 \\
\hline 20 & 10375 & 21 & $100 / .5 * 2.1 \mathrm{ml} * 5$ & 2100 \\
\hline$\overline{22}$ & 10525 & 51 & $100 / .5 * 5.1 \mathrm{ml} * 5$ & 5100 \\
\hline
\end{tabular}




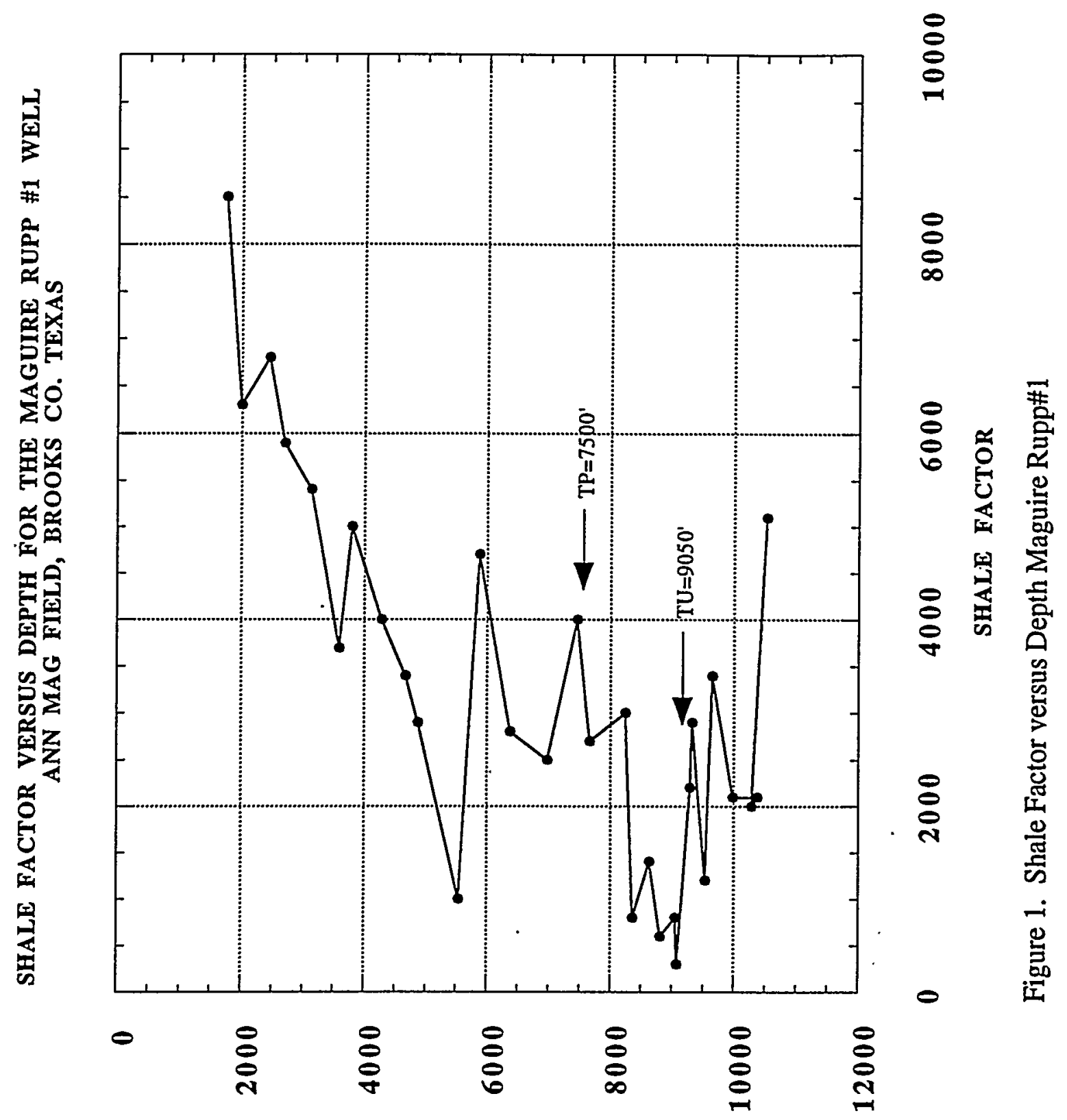

(LA) HLdGa 


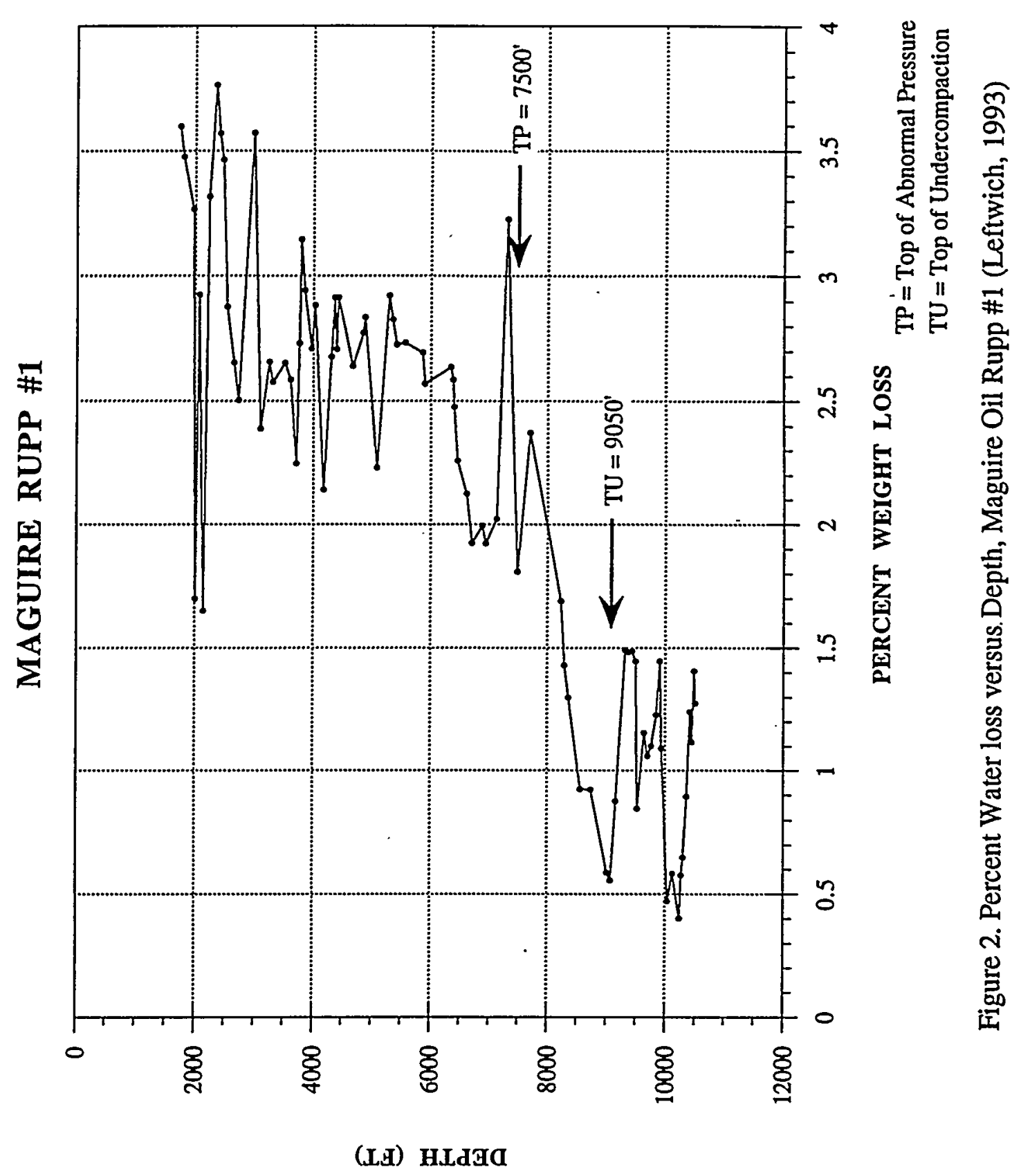




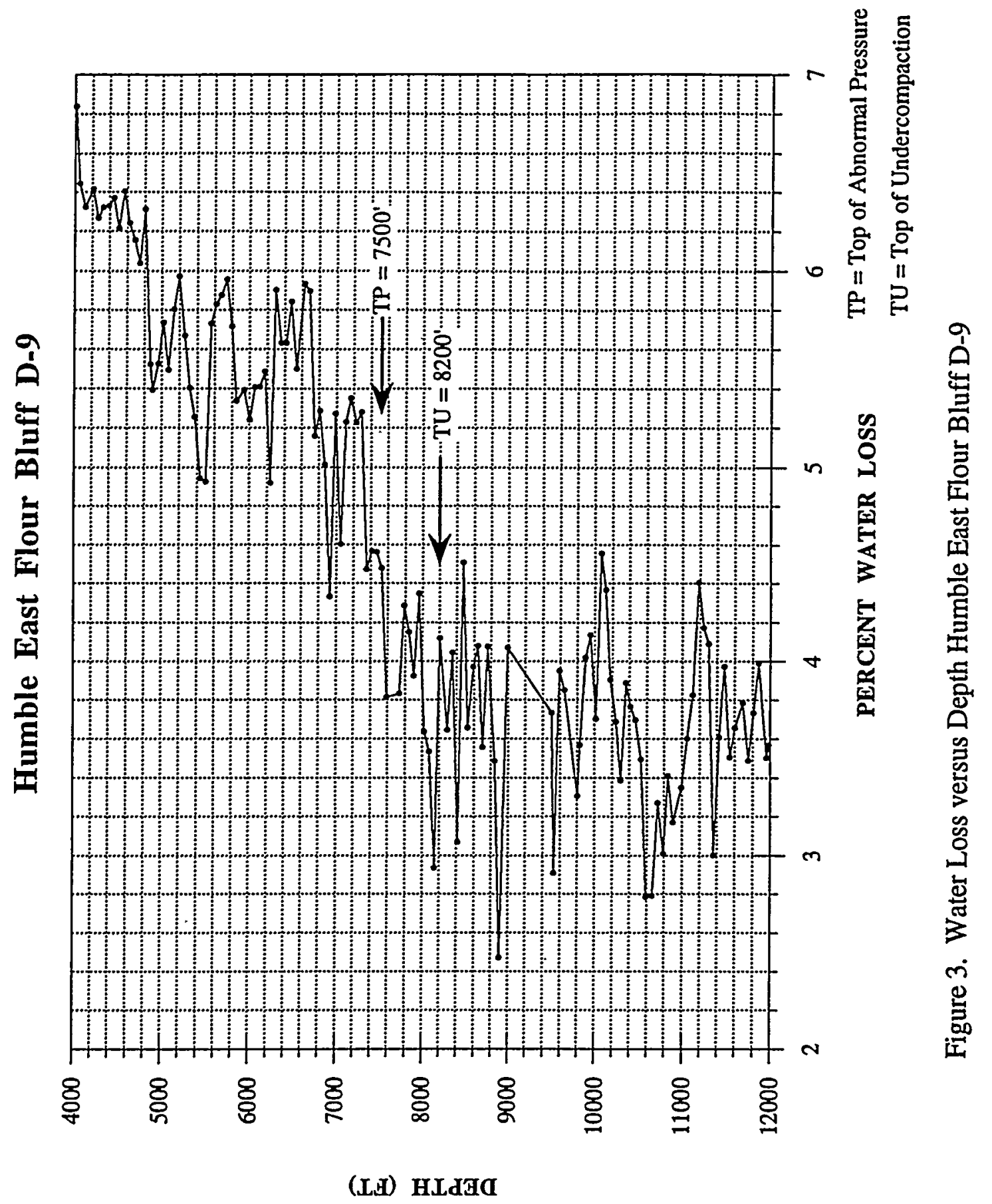




\section{SEMI-QUANTITATIVE X-RAY ANALYSIS FOR CLAY AND OTHER MINERALS IN SHALES FROM MAGUIRE OIL COMPANY'S RUPP \# 1 WELL, ANN MAG FIELD, SOUTH TEXAS}

\section{INTRODUCTION}

Investigations of geopressure and undercompaction in Gulf Coast fields (Leftwich, 1993; and Leftwich and Engelder, 1995) have revealed that the top of abnormal pressure and the top of undercompaction do not always occur at the same depth.

Leftwich, Engelder, and Kacandes (1996) (see Appendix A) demonstrated that a zone of illite-rich shale interrupts a gradual dehydration of smectite with depth of burial. The contact between this illite-rich zone and underlying smectite rich shale is the top of the shale density reversal signaling undercompacted shale.

The purpose of this research was to determine if a correlation exists between mineral trends with depth and the tops of abnormal pressure and undercompaction in the Ann Mag field, Brooks County, Texas. In addition to defining changes in smectite-illite proportions at the top of undercompaction this study investigated the distribution of other minerals (i.e., chlorite, kaolinite, vermiculite, quartz, feldspar, calcite, dolomite and amphibole) relative to the tops of abnormal pressure and undercompaction.

\section{METHODS AND DATA}

Semi-quantitative XRD analysis was performed on 26 shale cuttings samples from the Maguire Oil Rupp 1 well (Detailed methodology and a complete record of the data for the Rupp \#1 is shown in Appendix B). The samples range in depth from $533 \mathrm{~m}$ (1750 $\mathrm{ft}$ ) to $3194 \mathrm{~m}(10,480 \mathrm{ft})$ and were analyzed for relative amounts of illite, smectite, and other minerals. These data were then used to construct mineral abundance versus depth trends for each mineral (Figures 1 -14). The mineral trend data were then compared to the depths to the tops of abnormal pressure and undercompaction and studied to determine relationships.

\section{OBSERVATIONS}

Results indicate that there are distinct changes in mineralogy that can be correlated with both the tops of abnormal pressure and undercompaction. The study confirms the zone of illite rich shale that occurs above the top of the zone of undercompaction. The following is a more detailed summary of our observations.

Amphibole shows up just at the top of abnormal pressure (Figure 1). Dolomite shows a significant increase at the top of abnormal pressure but no real change at the top of undercompaction (Figure 2).

Quartz gradually increases with depth and shows an anomalous increase just above the top of abnormal pressure. Below the top of pressure quartz drops back to the baseline and continues to increase through the top of undercompaction (Figure 3).

There is a significant increase in feldspar percent at the top of abnormal pressure and a smaller increase in the component at the top of undercompaction (Figure 4). 
There is an increase in illite and decrease in smectite with depth with a very large illite anomaly at the top of abnormal pressure. There is a drop in illite and corresponding increase in smectite in the undercompacted zone (Figure 6).

Calcite and feldspar both show similar trends they both increase at the top of abnormal pressure (Figure 7).

Vermiculite first shows up at the depth of the top of pressure (Figure 10).

There is a drop in chlorite with depth above the top of abnormal pressure, then the chlorite increases in the abnormal pressured section. Minor changes in chlorite can be observed at the top of undercompaction (Figure 12).

Kaolinite increases in the abnormally pressured section of the well (Figure 13).

\section{CONCLUSIONS}

Based on observations in the Rupp \#1 well where the tops of abnormal pressure and undercompaction are separated we reach the following conclusions:

1.) Most of the significant changes in mineral trends studied occur at or near the top of abnormal pressure rather than near the top of undercompaction.

2.) The smectite to illite transformation point as defined by the change in slope of the water loss curve is coincident with the top of undercompaction.

\section{REFERENCES}

Leftwich Jr., J. T., 1993, The Development of Zones of Undercompacted Shale Relative to Abnormal Subsurface Pressures in Sedimentary Basins. Ph.D. diss., The Pennsylvania State University.

Leftwich, J.T., and Engelder, T., 1995, The characteristics of geopressure profiles in the Gulf of Mexico Basin: in Orteleva, P., ed., Pressure Compartments, American Association of Petroleum Geologists Memoir, (in press).

Leftwich, J. T., Engelder, T., and Kacandes G.H., 1995, The Correlation between Interlayer Water content in Shale and Abnormal Pressure in the Ann Mag Field, South Texas: Clay Minereals, (in press).

A paper discussing these findings was presented at the 1996 Annual Meeting of the Geological Society of America, which was held in Denver, Colorado (October). See abstract on following page. 
MINERAL TRENDS WITH DEPTH VERSUS THE TOPS OF ABNORMAL SUBSURFACE PRESSURE AND THE ZONE OF UNDERCOMPACTION IN THE ANN MAG FIELD, SOUTH TEXAS

LEFTWICH, John T., Jr., Department of Geological Sciences, Old Dominion

University, Norfolk, Virginia 23529, JTL100F@Giraffe.tech.odu.edu.

Investigations of geopressure and undercompaction in Gulf Coast fields (Leftwich, 1993; and Leftwich and Engelder, 1995) have revealed that the top of abnormal pressure and the top of undercompaction do not always occur at the same depth.

Leftwich, Engelder, and Kacandes (1993) demonstrated that a zone of illite-rich shale interrupts a gradual dehydration of smectite with depth of burial. The contact between this illite-rich zone and underlying smectite rich shale is the top of the shale density reversal signaling undercompacted shale.

The purpose of this research was to determine if a correlation exists between mineral trends with depth and the tops of abnormal pressure and undercompaction in the Ann Mag field, Brooks County, Texas. In addition to defining changes in smectite-illite proportions at the top of undercompaction this study investigates the distribution of other minerals (i.e., chlorite, kaolinite, vermiculite, quartz, feldspar, calcite, dolomite and amphibole) relative to the tops of abnormal pressure and undercompaction.

Semi-quantitative XRD analysis was performed on 26 shale cuttings samples from the Maguire Oil Rupp 1 well. The samples range in depth from $533 \mathrm{~m}$ (1750 ft) to $3194 \mathrm{~m}$ $(10,480 \mathrm{ft})$ and were analyzed for relative amounts of illite, smectite, and other minerals. These data were then used to construct mineral abundance versus depth trends for each mineral. The mineral trend data were then compared to the depths to the tops of abnormal pressure and undercompaction and studied to determine relationships.

Results indicate that there are distinct changes in mineralogy that can be correlated with both the tops of abnormal pressure and undercompaction. The study confirms the zone of illite rich shale that occurs above the top of the zone of undercompaction. Results also suggest that major changes in the trends of the other minerals occur at the top of abnormal pressure. 


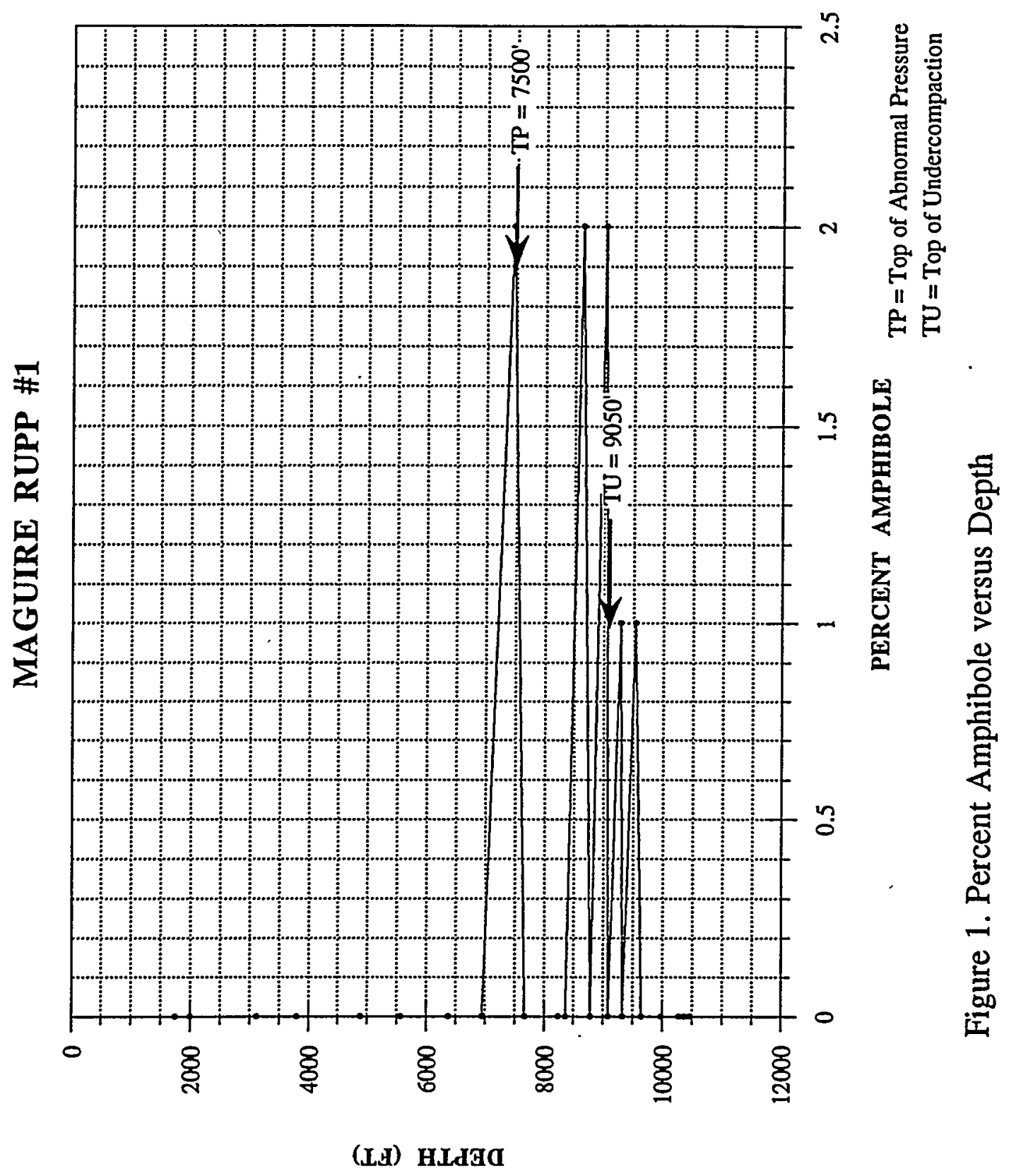



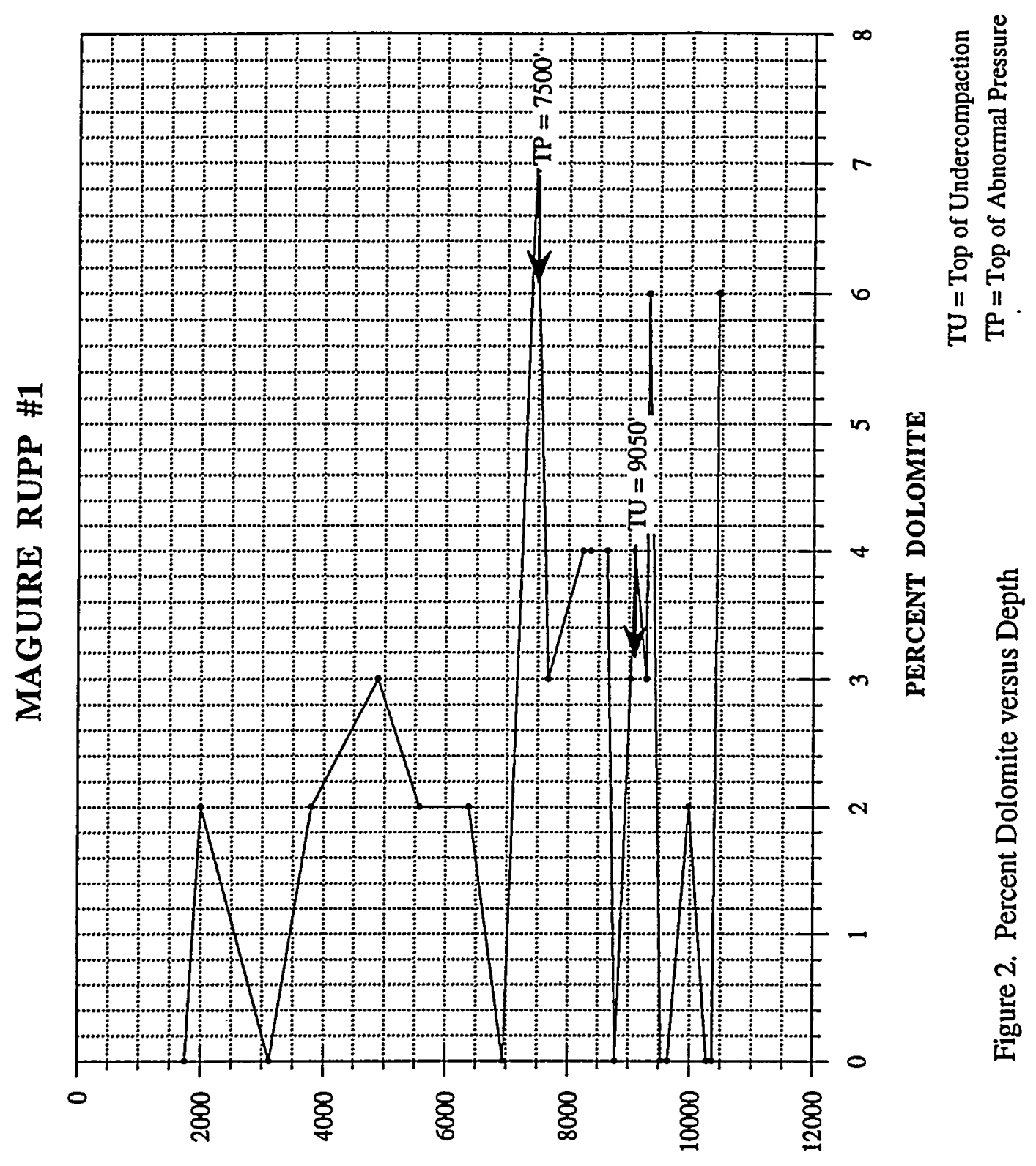



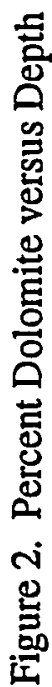

(IA) HLdG 

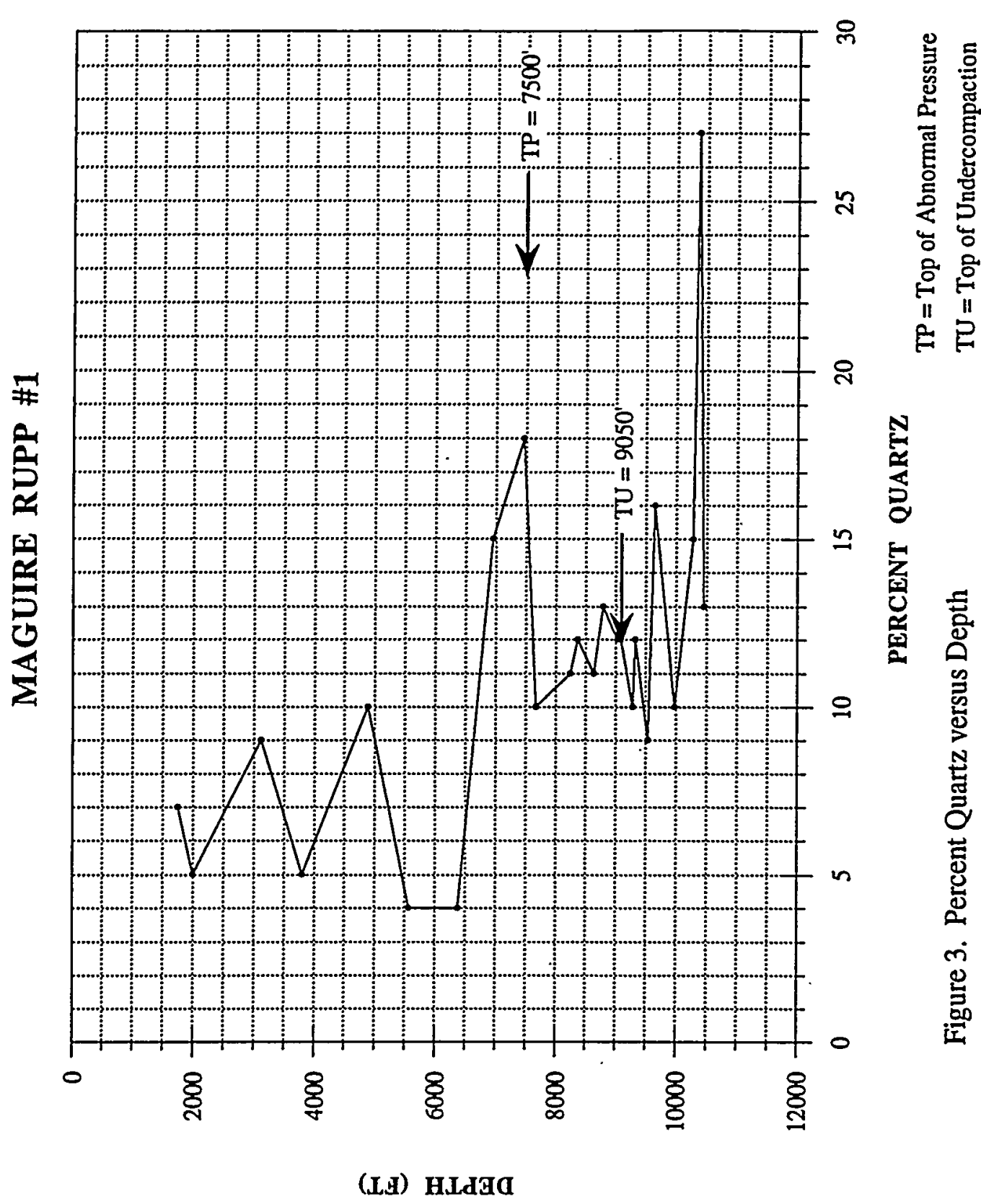


\section{MAGUIRE RUPP \#1}

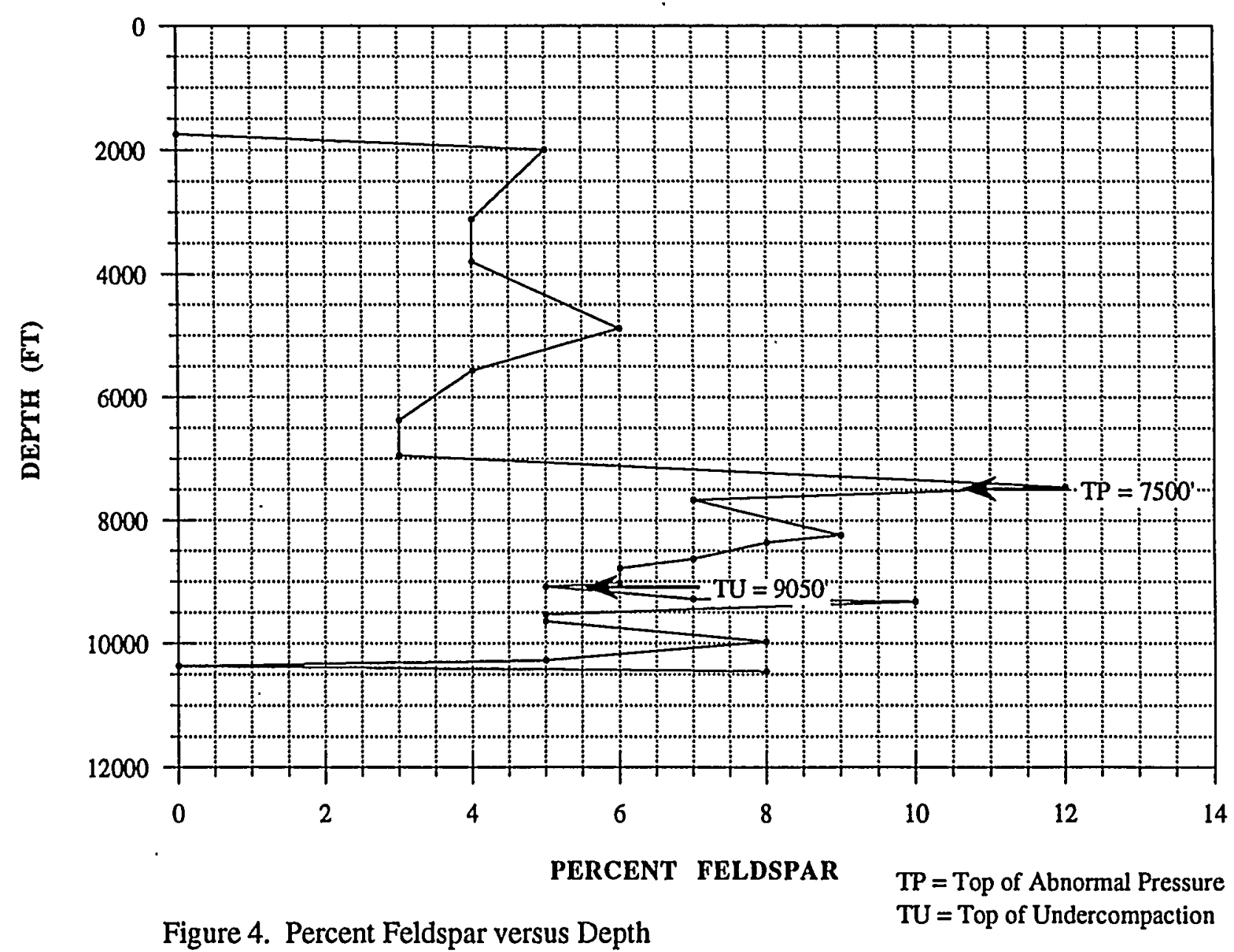




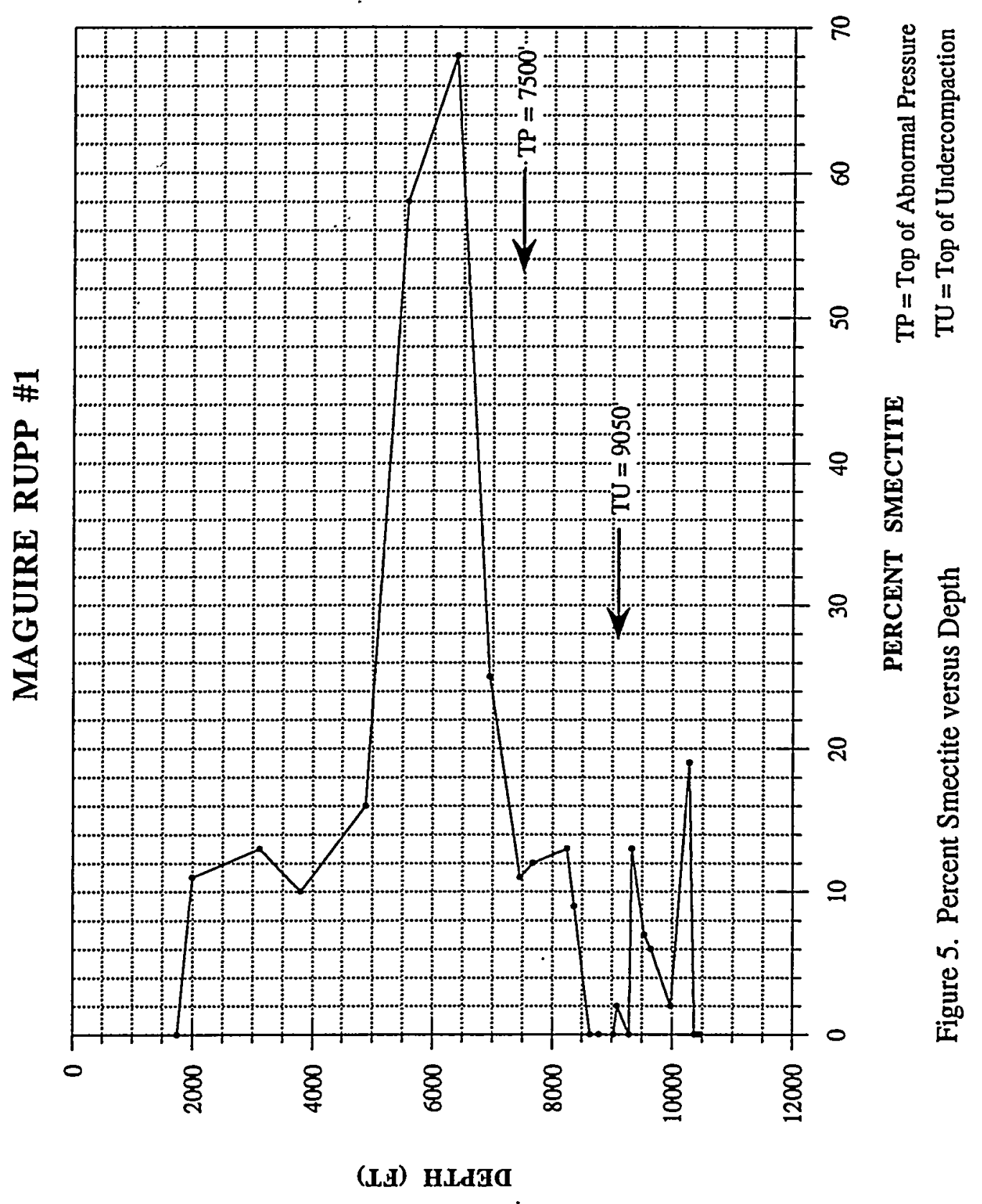




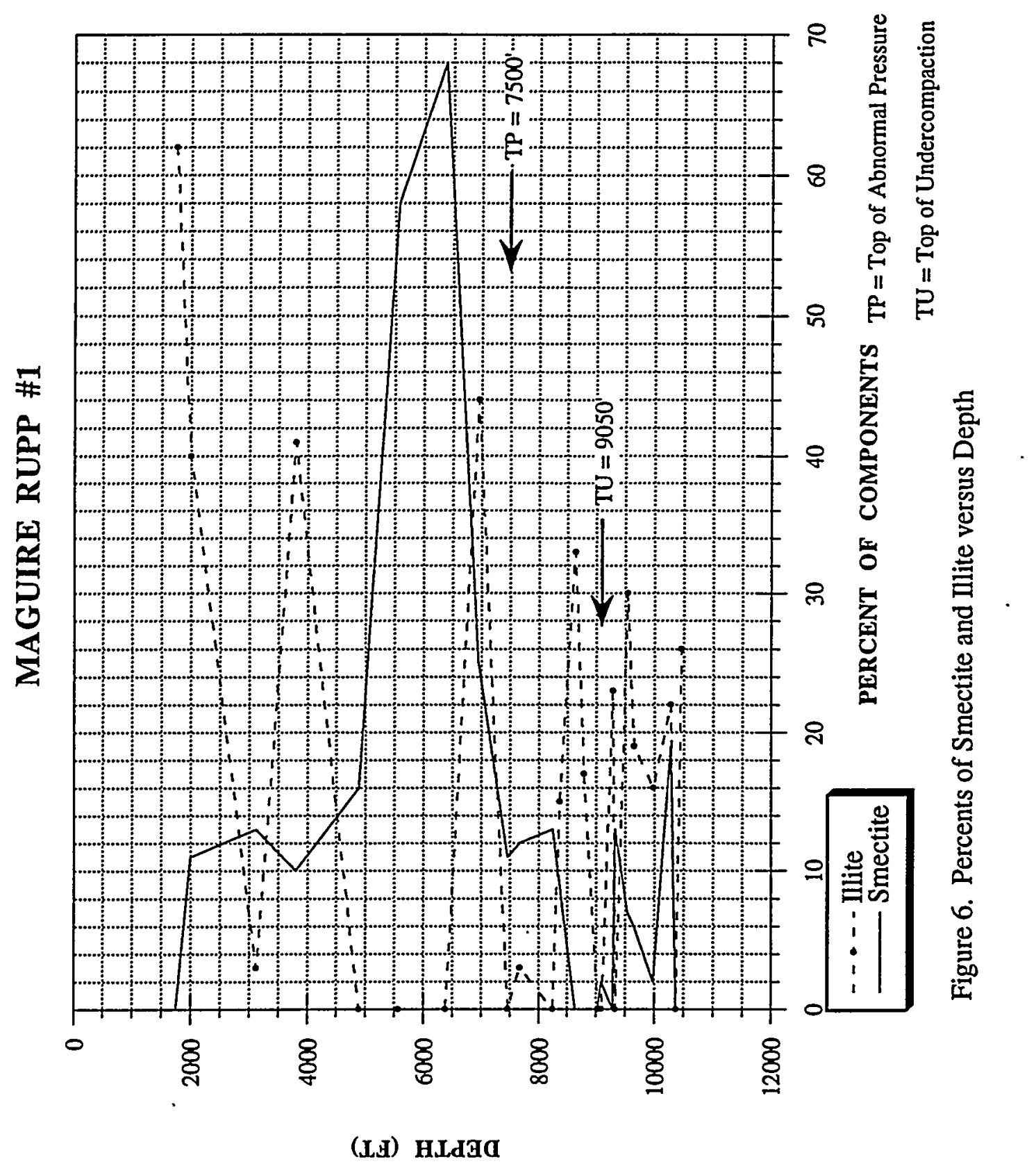




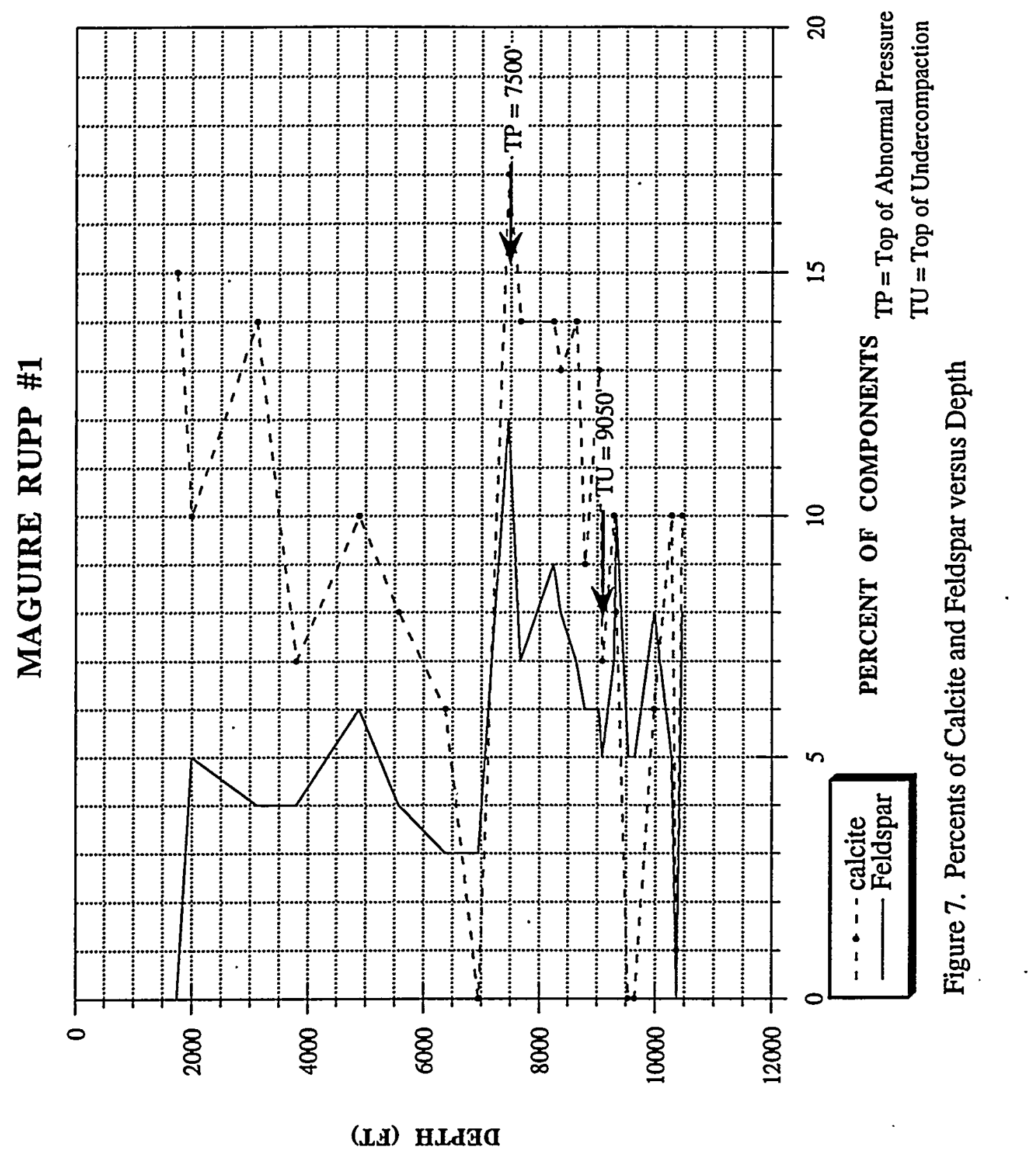




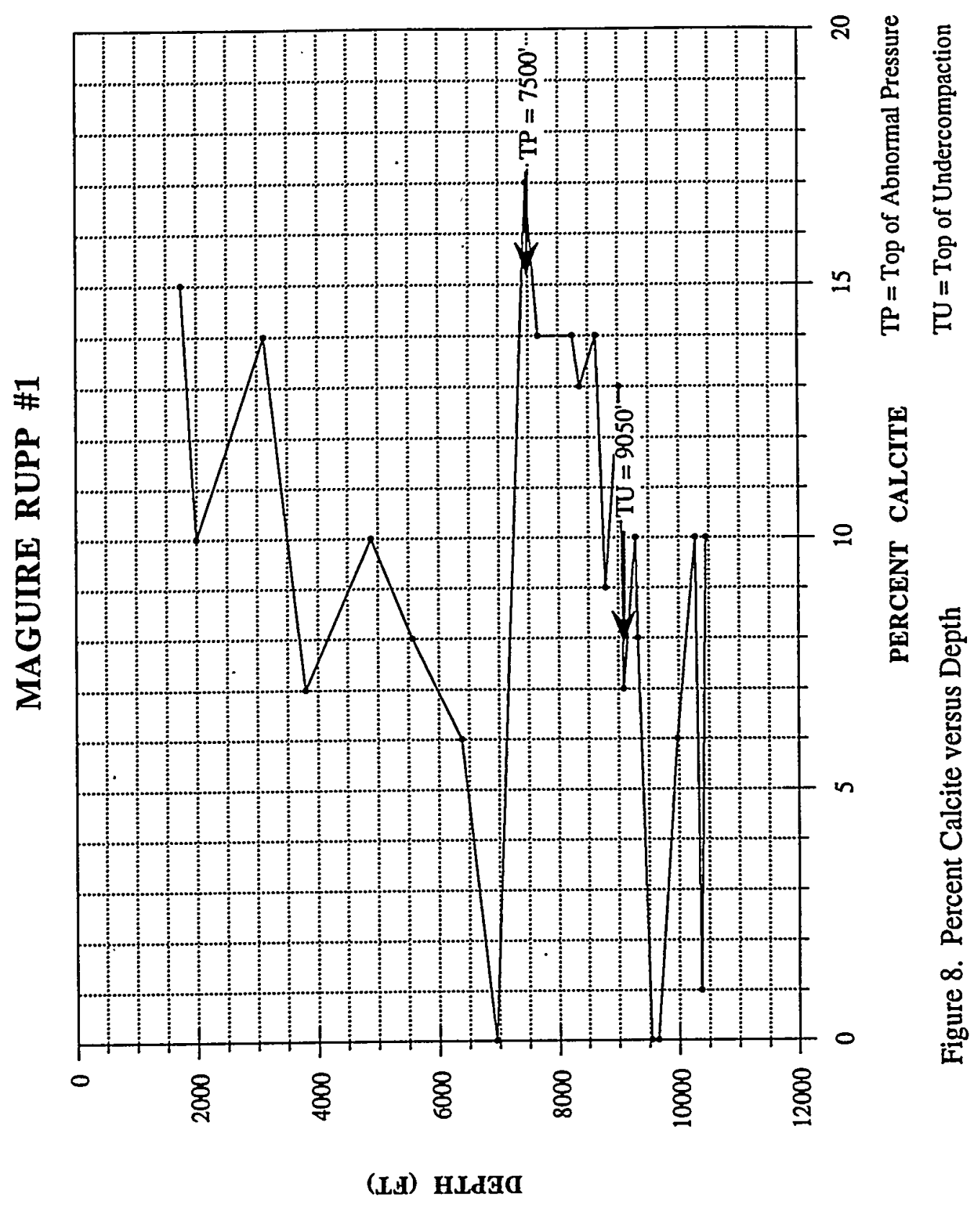




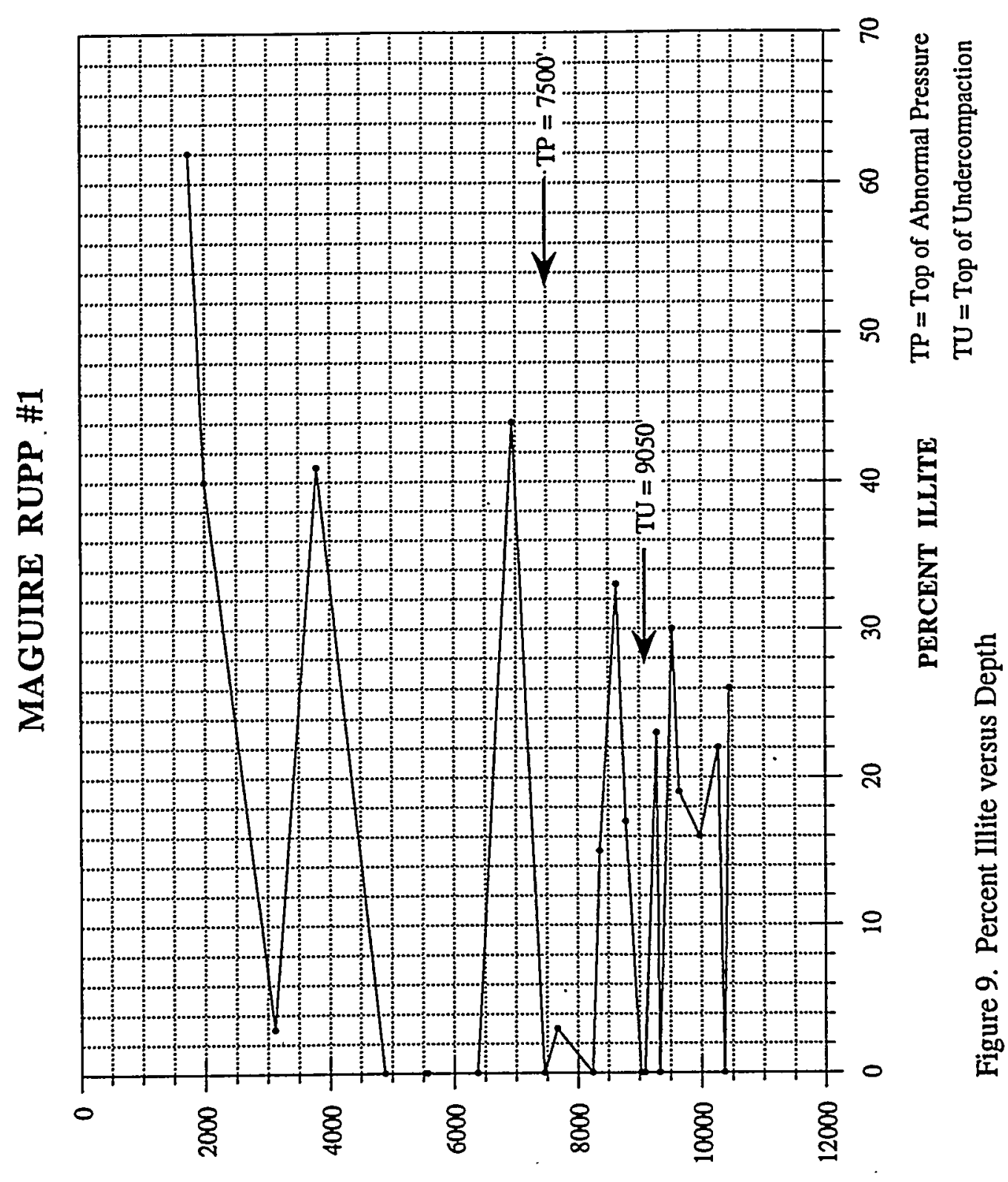

(I, HIdGa 


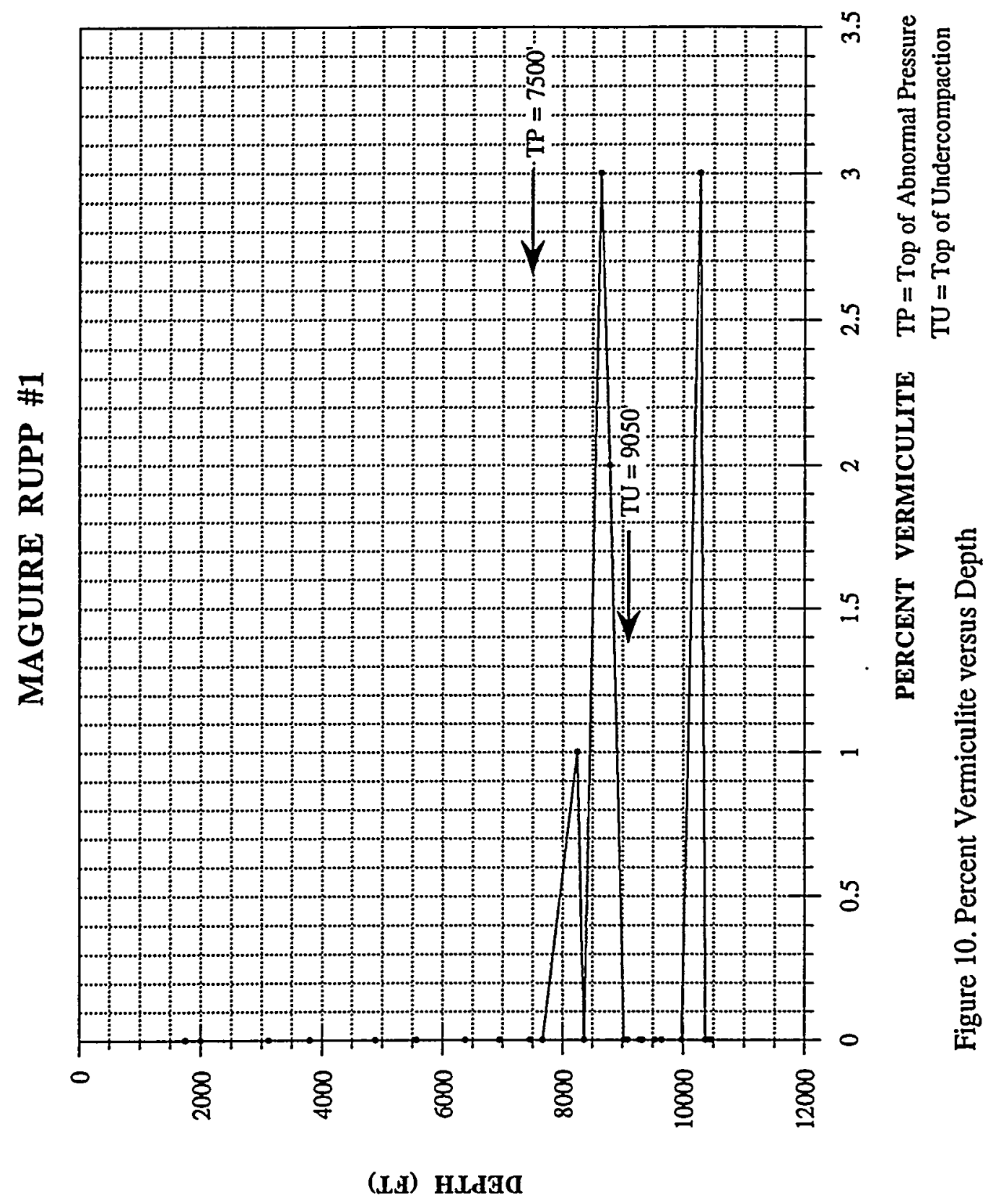




\section{MAGUIRE RUPP \#1}

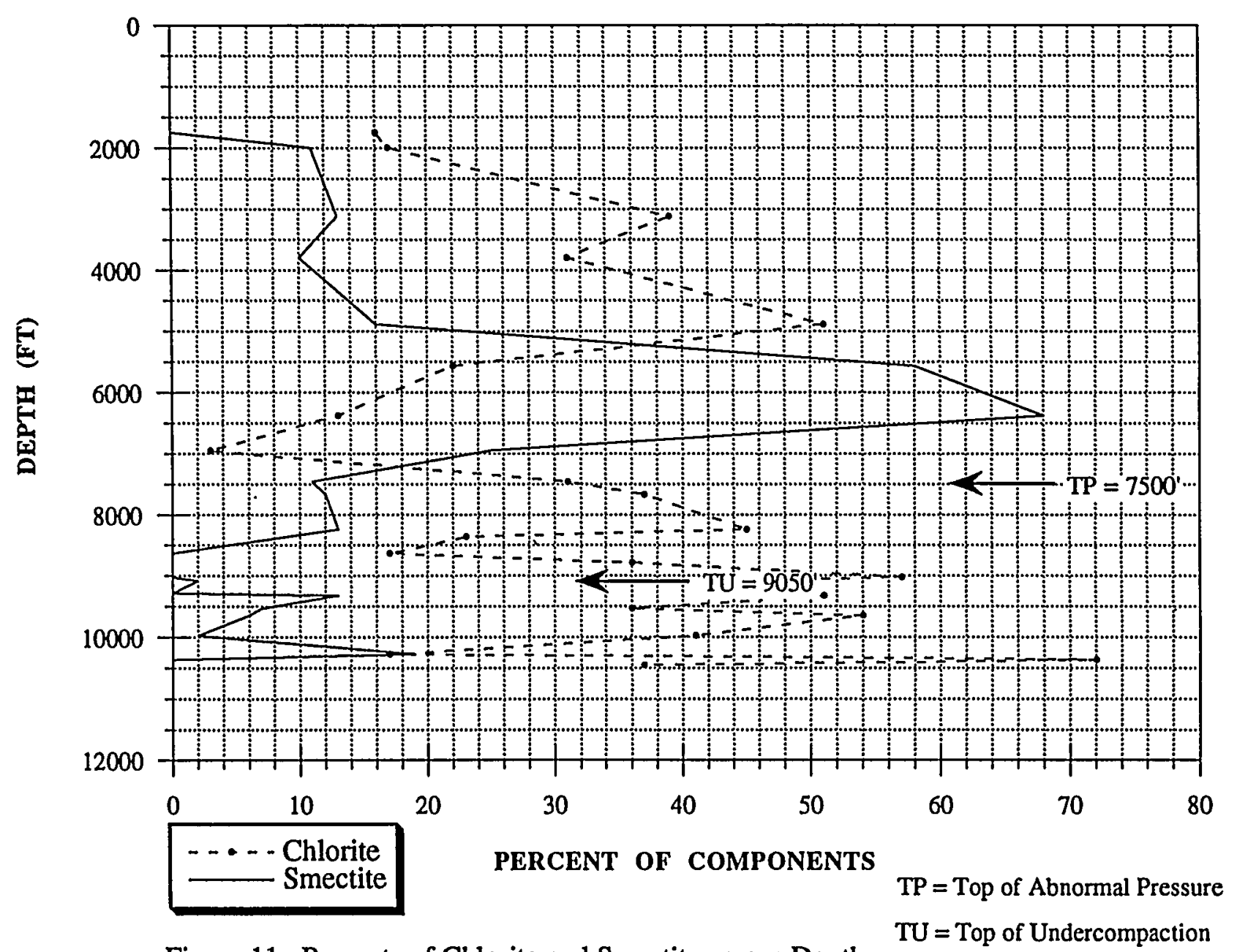

Figure 11. Percents of Chlorite and Smectite versus Depth 


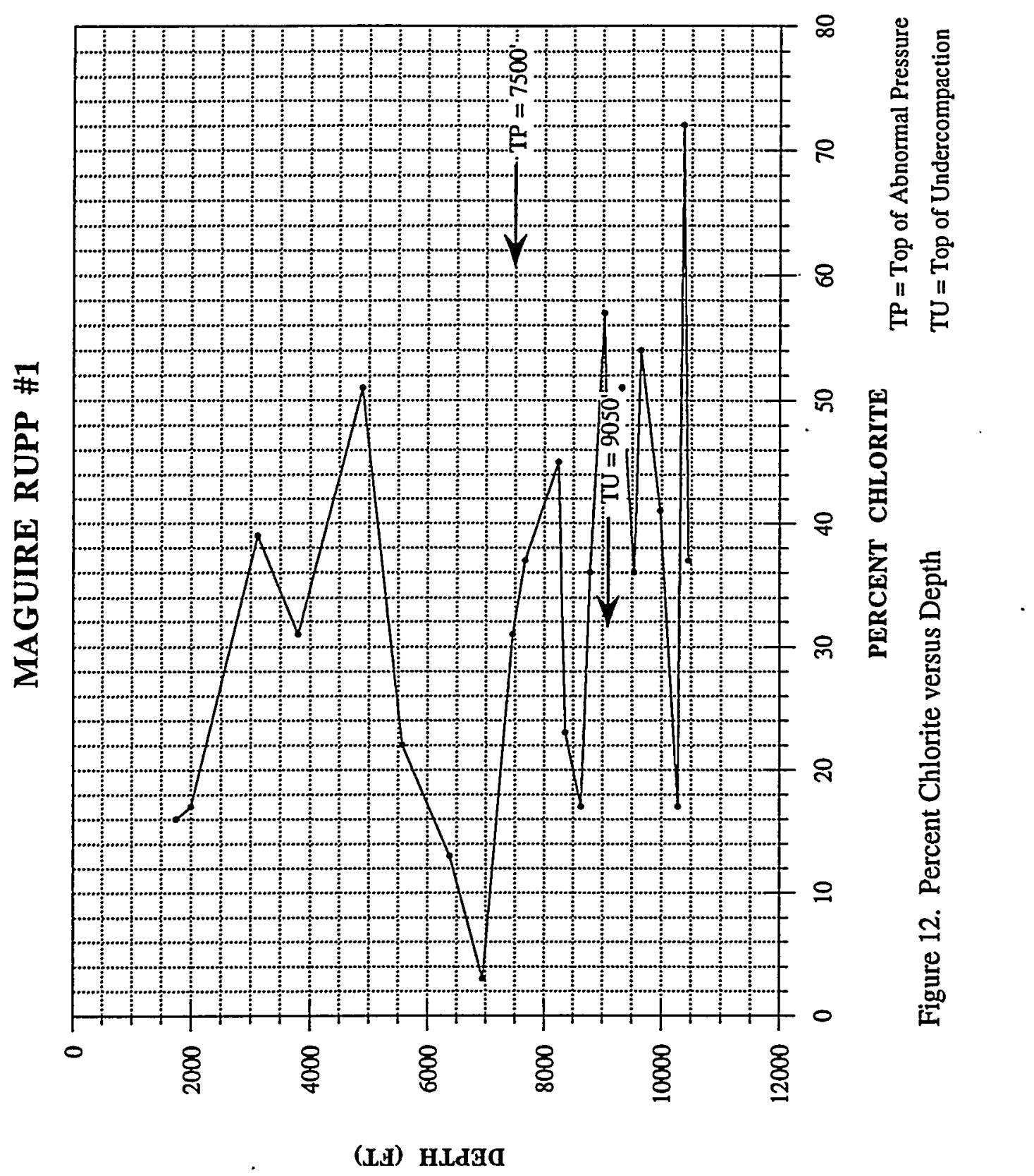




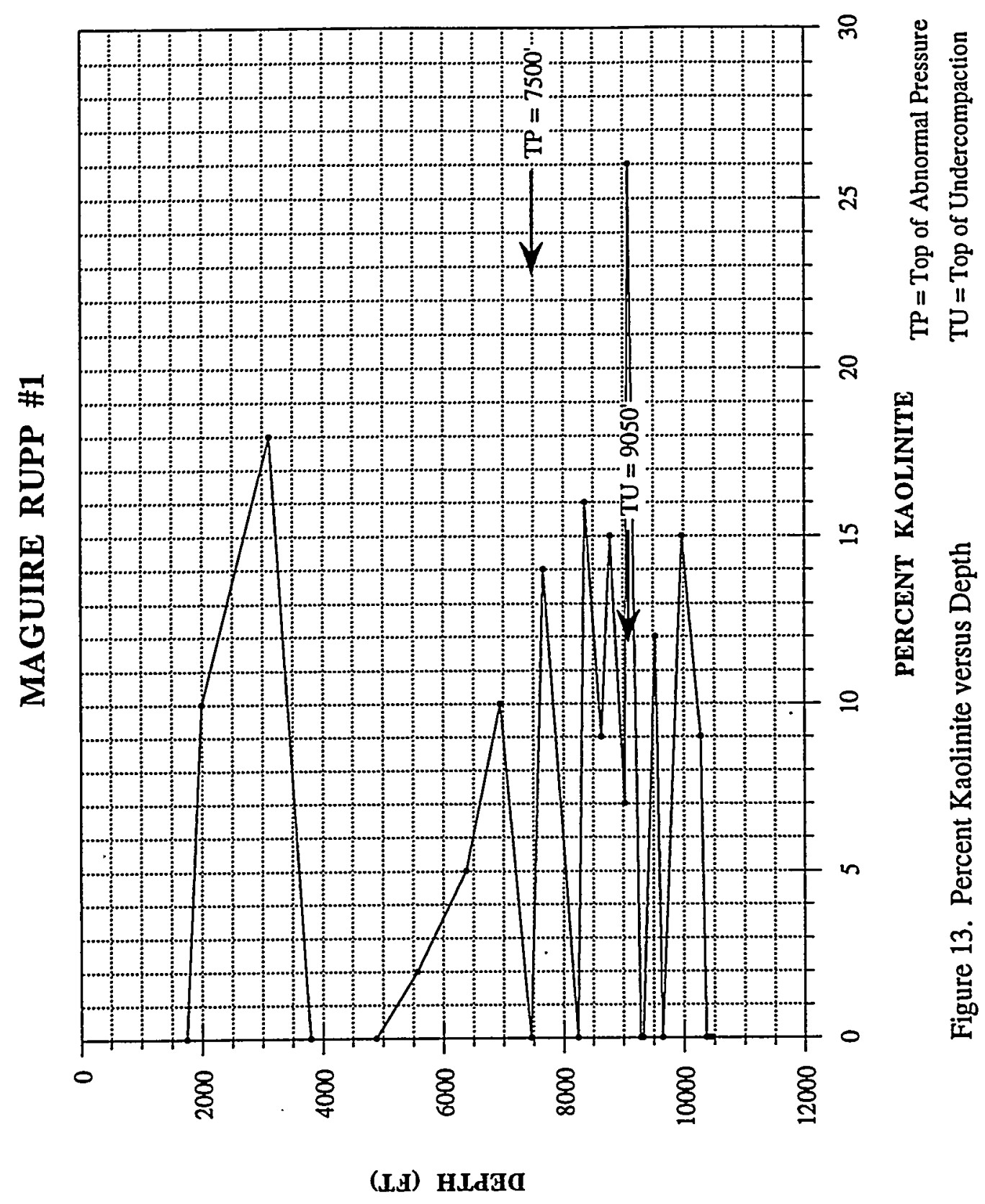




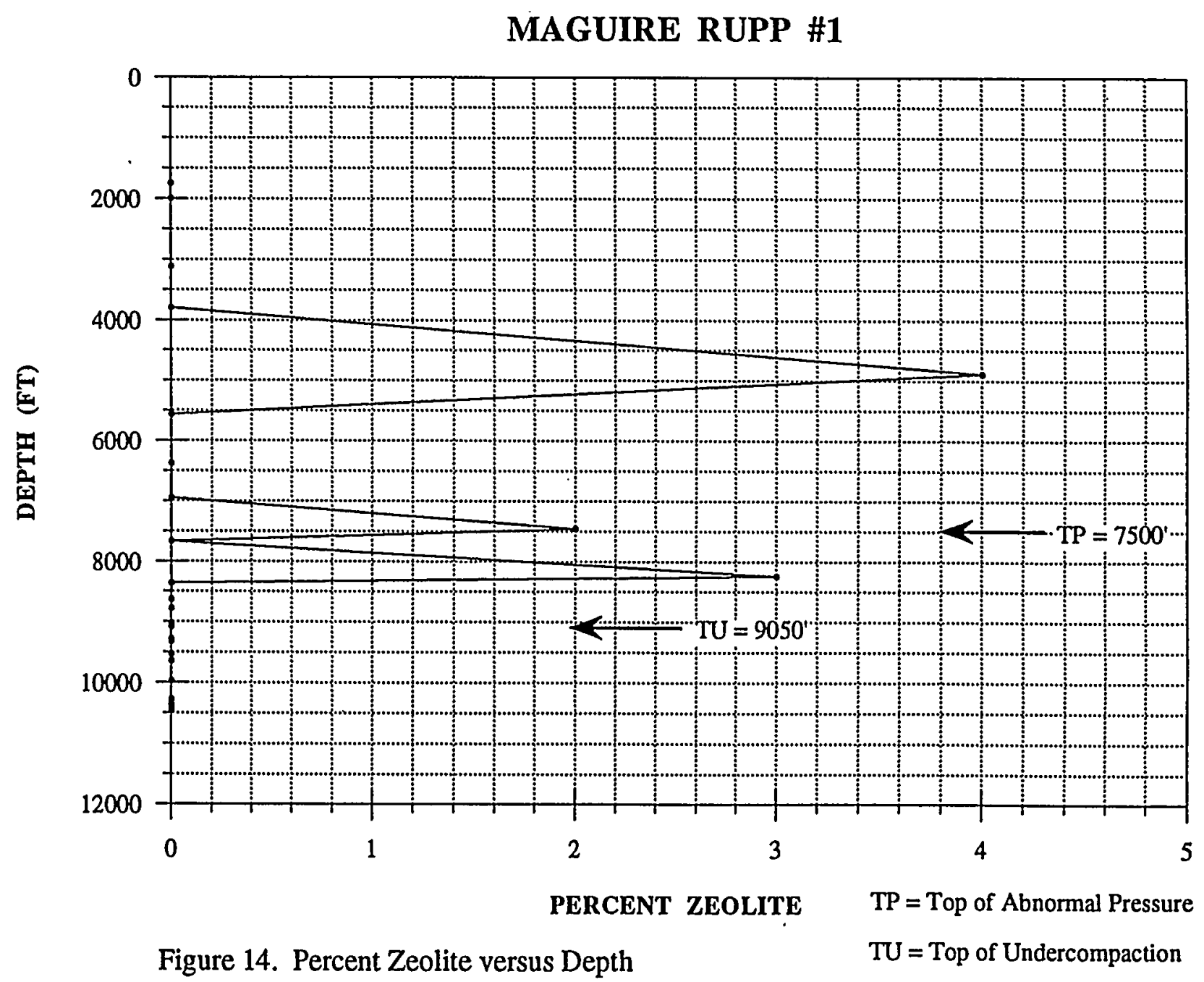




\section{SEMI-QUANTITATIVE X-RAY ANALYSIS FOR CLAY AND OTHER MINERALS IN SHALES FROM HUMBLE OIL EAST FLOUR BLUFF D-9 AND STANDARD OIL OF TEXAS STATE TRACT 883, WELL \#1, SOUTH TEXAS}

\section{INTRODUCTION}

As was the case with the X-ray work in the Rupp \#1 well discussed in the preceding section the purpose of this research was to determine if a correlation exists between mineral trends with depth and the tops of abnormal pressure and undercompaction in various wells. The intent here was to make the same investigations on two other wells in a different field area of South Texas.

Again this study investigated in addition to illite and smectite, the distribution of other minerals (i.e., chlorite, kaolinite, vermiculite, quartz, feldspar, calcite, dolomite and amphibole) relative to the tops of abnormal pressure and undercompaction.

\section{METHODS AND DATA}

Semi-quantitative XRD analysis was performed on 23 shale cuttings samples from the Humble Oil Company East Flour Bluff D-9 well and 24 samples from the Standard Oil State Tract 883, well \#1.(Detailed methodology is outlined in Appendix B). The samples range in depth from $945 \mathrm{~m}(3100 \mathrm{ft})$ to $3969 \mathrm{~m}(13,020 \mathrm{ft})$ in the Standard 883, \#1 well and from $1280 \mathrm{~m}(4200 \mathrm{ft})$ to $3597 \mathrm{~m}(11,800 \mathrm{ft})$ in the Humble D-9. Each sample.was analyzed for relative amounts of illite, smectite, and other minerals. These data were then used to construct mineral abundance versus depth trends for each mineral (See figures in this section). The mineral trend data were then compared to the depths to the tops of abnormal pressure and undercompaction and studied to determine relationships.

\section{OBSERVATIONS}

Results are somewhat mixed but indicate that there are distinct changes in mineralogy that can be correlated with both the tops of abnormal pressure and undercompaction.

\section{CONCLUUSIONS}

As was the case with the Rupp \#1 well, observations in these two wells also suggest that significant changes in mineral trends occur at or near the top of abnormal pressure rather than near the top of undercompaction. 

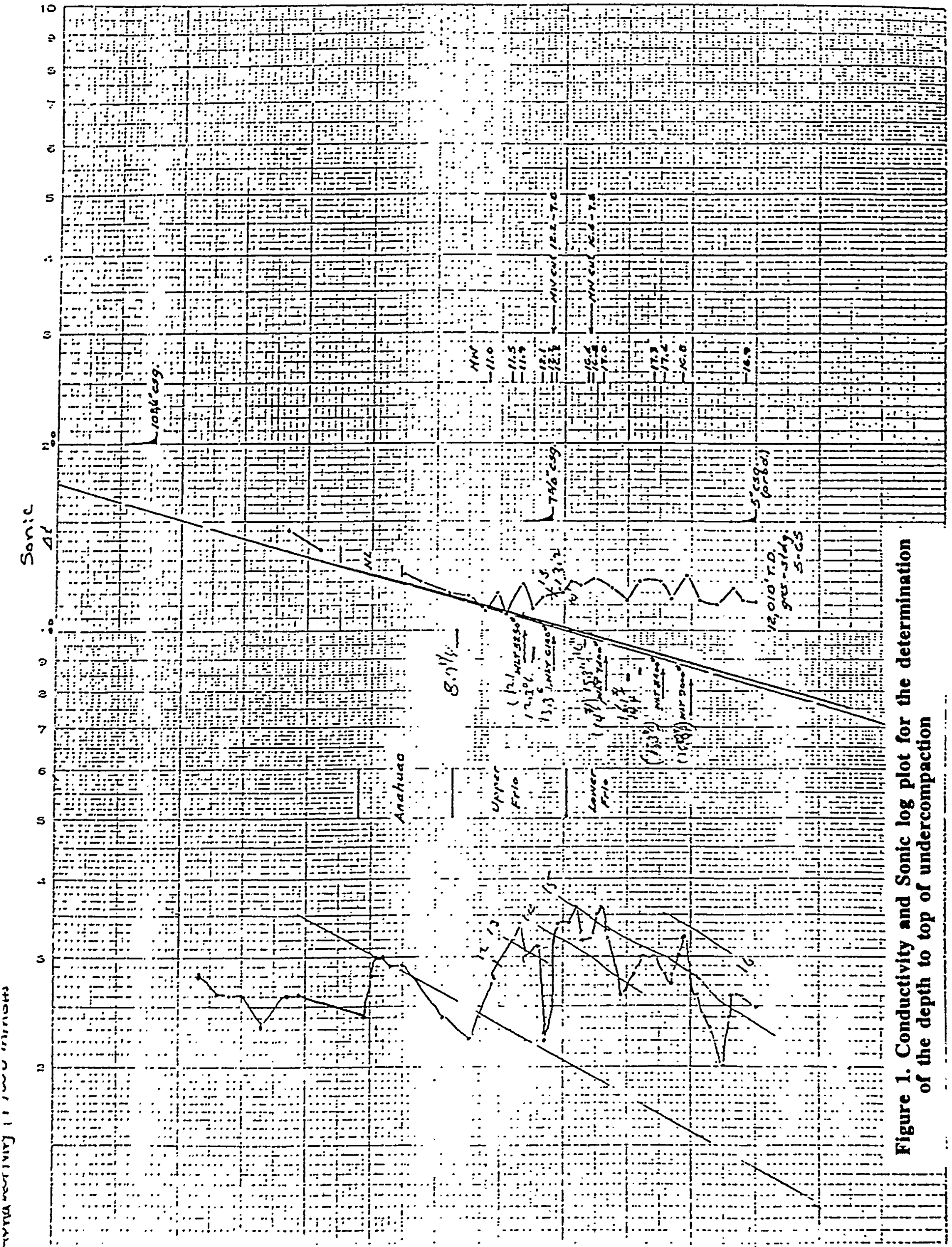


\section{RED FISH BAY/FLOUR BLUFF FIELD}

TEMPERATURE (F)

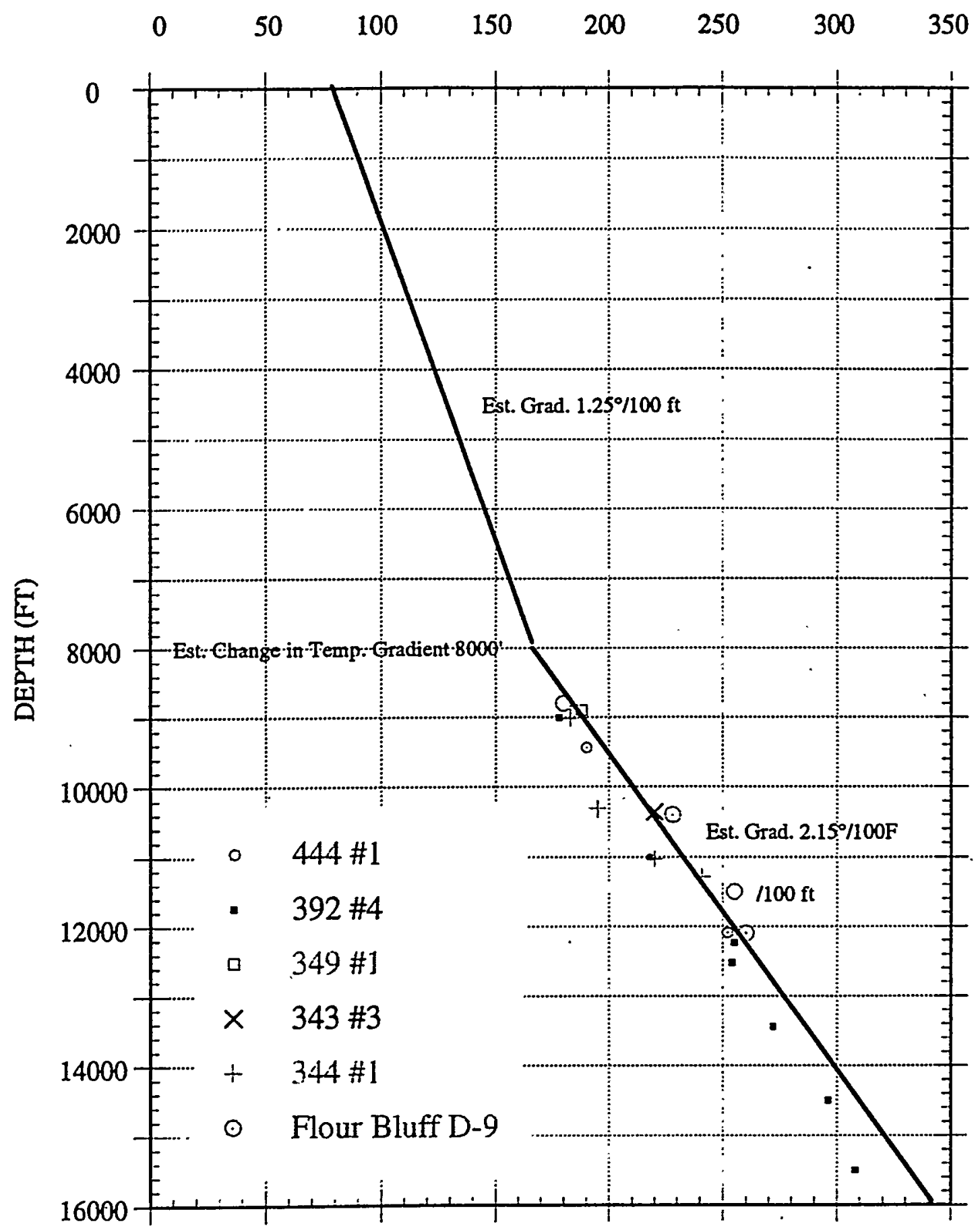

Figure 2. Temperature versus Depth plot for the Red Fish Bay/Flour Bluff Field areas 


\section{FLOUR BLUFF FIELD}

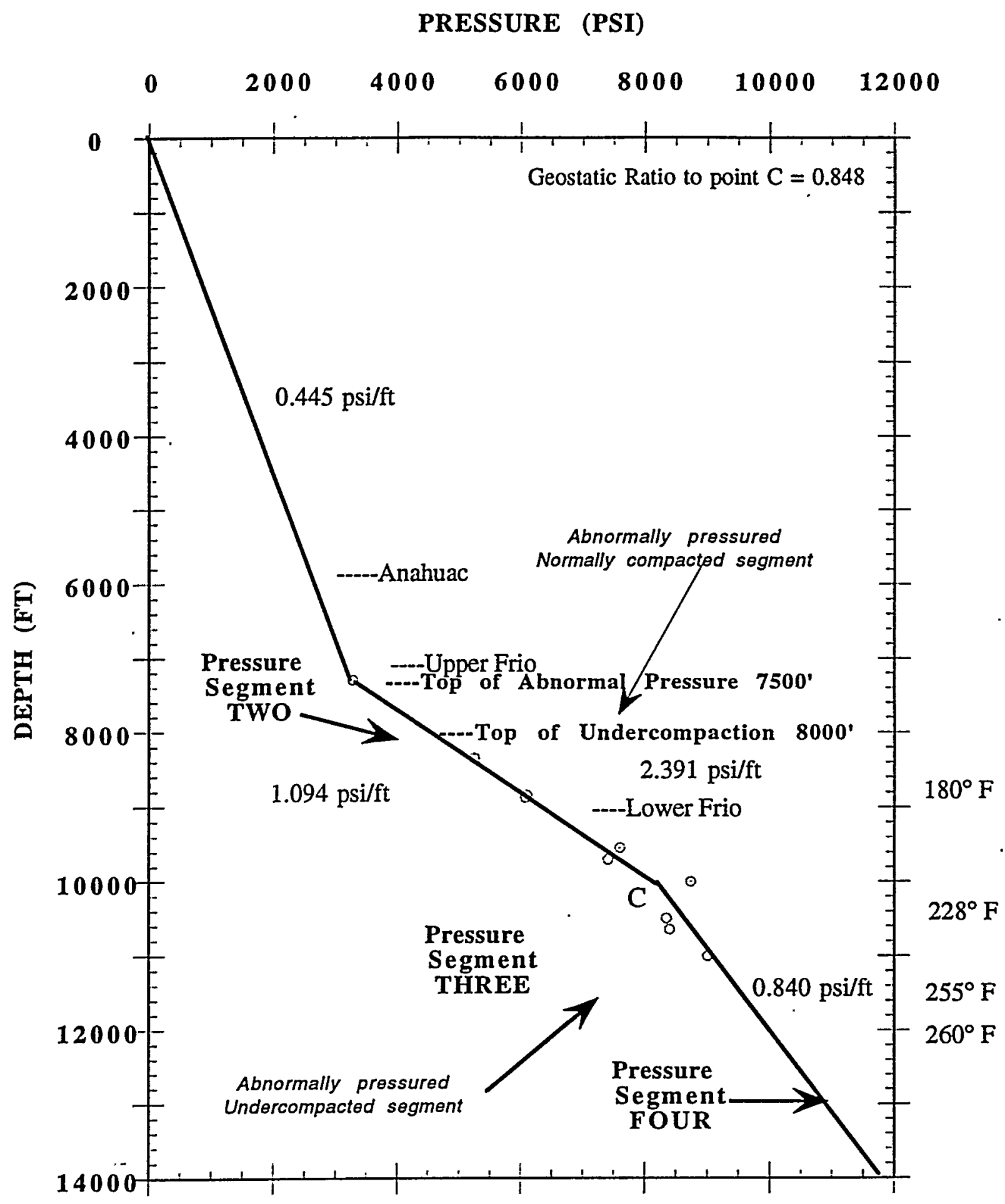

Figure 3. Pressure versus Depth plot Flour Bluff Field 


\section{Humble East Flour Bluff D-9}

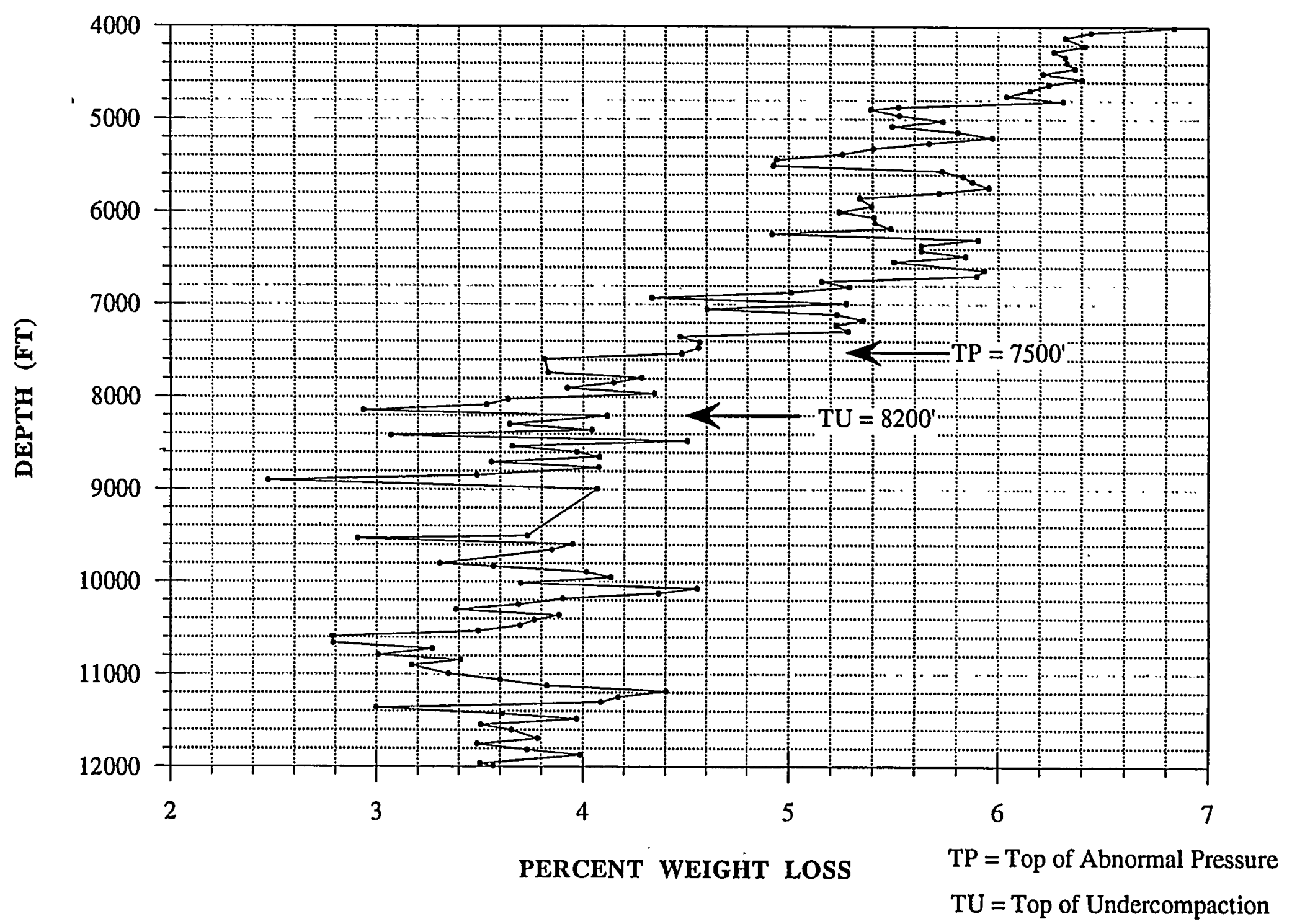

Figure 4. Water Loss versus Depth Humble East Flour Bluff D-9 
MINERAL TRENDS WITH DEPTH VERSUS THE TOPS OF ABNORMAL PRESSURE AND UNDERCOMPACTION 


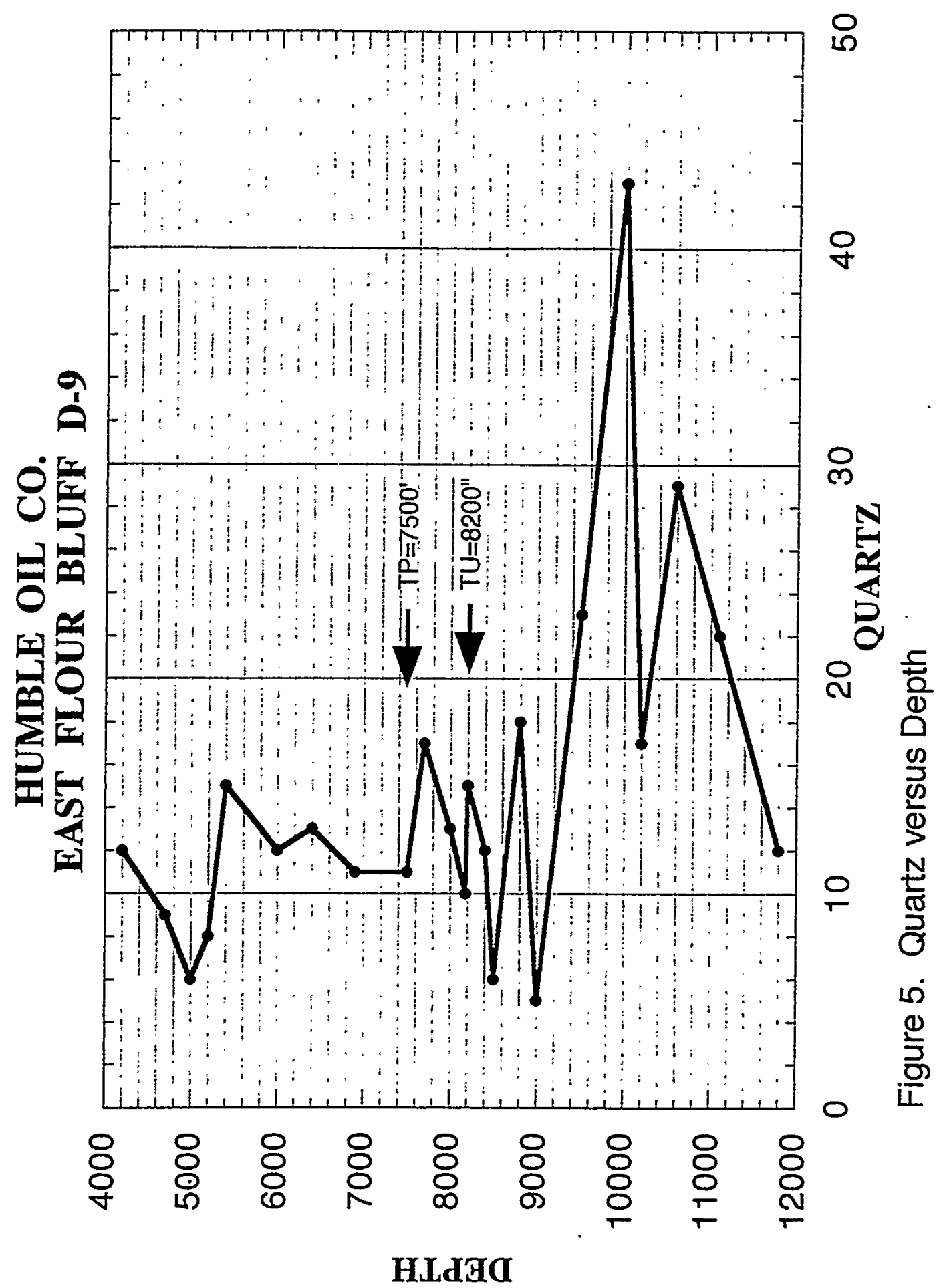




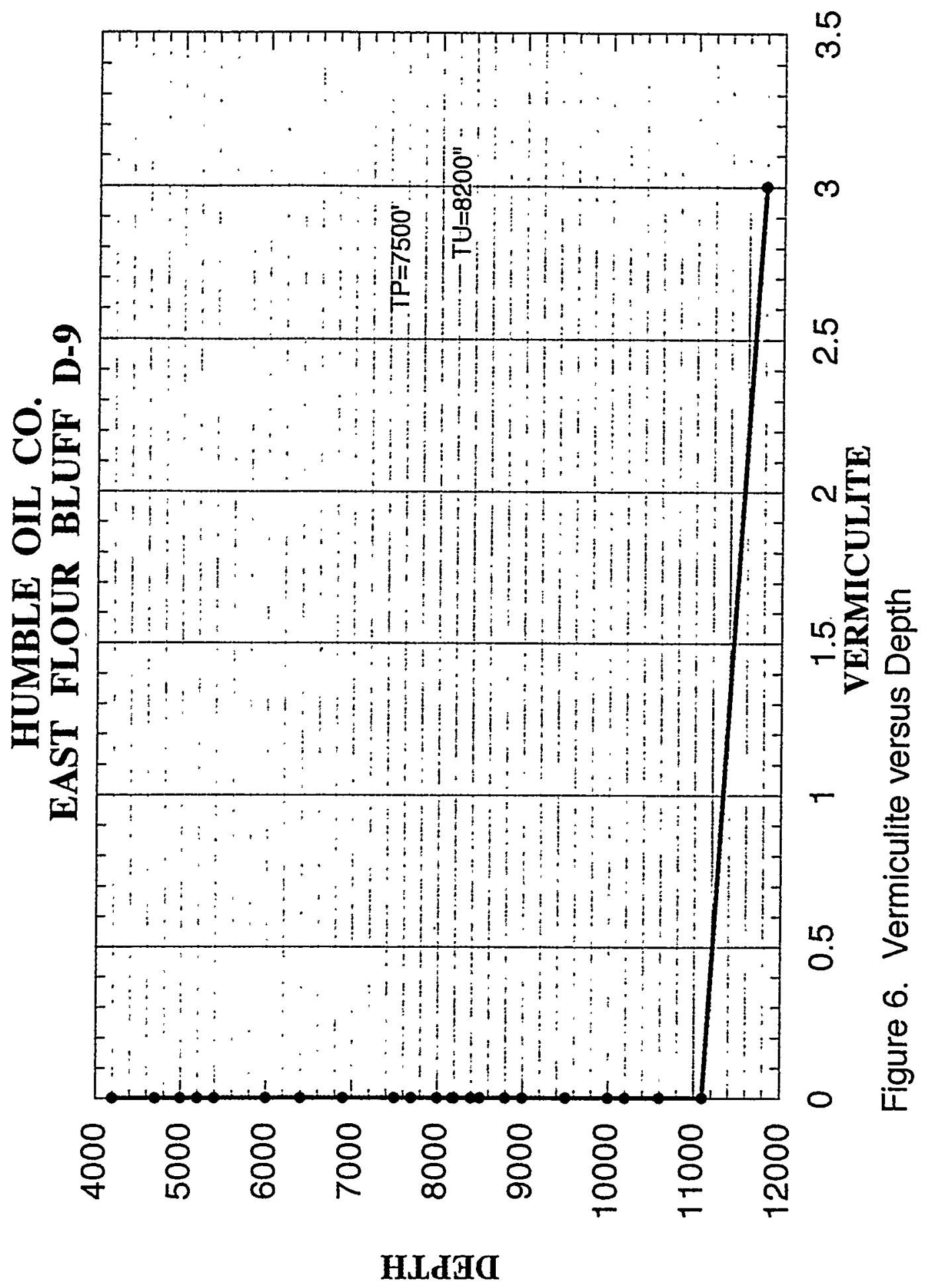




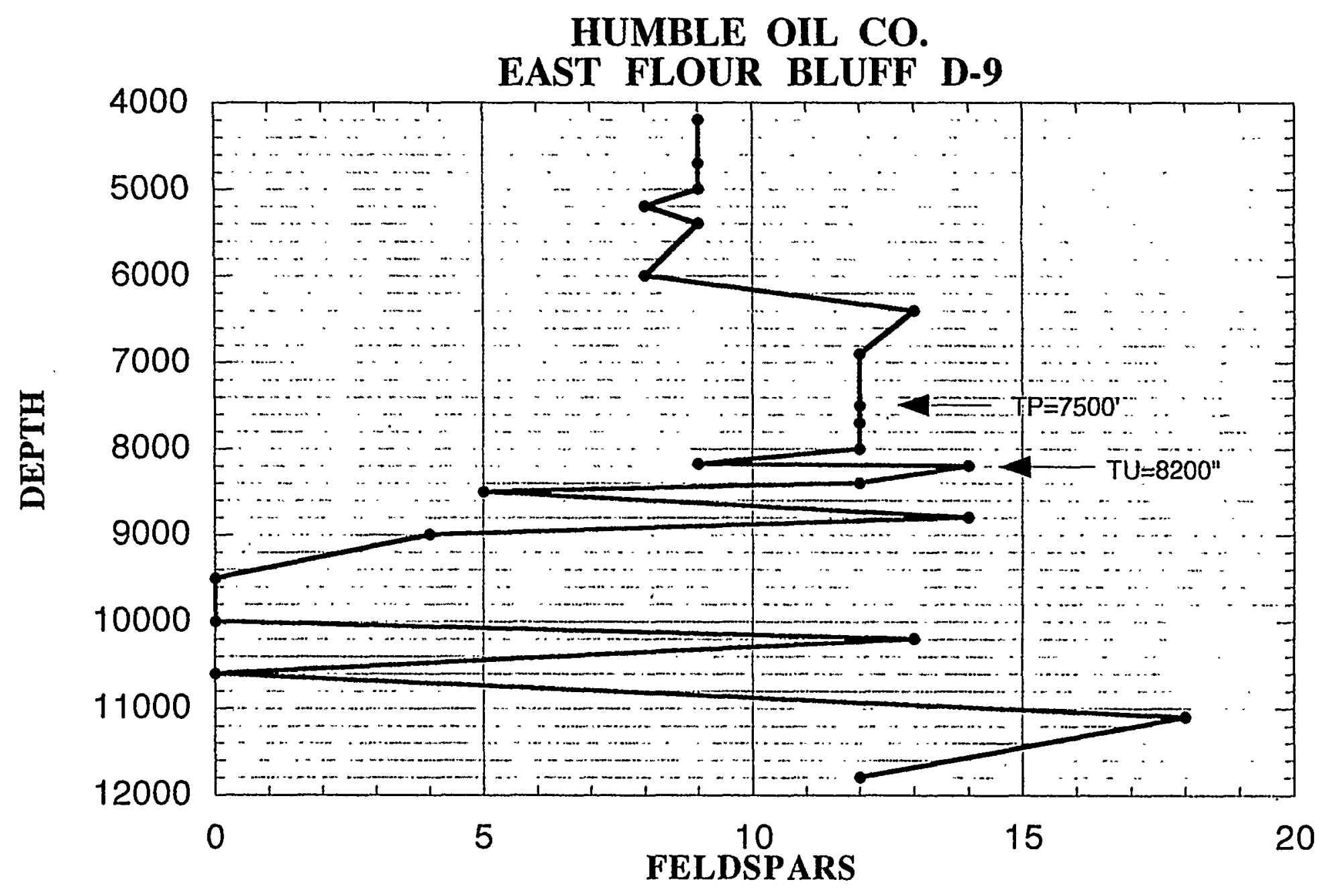

Figure 7. Feldspar versus Depth 


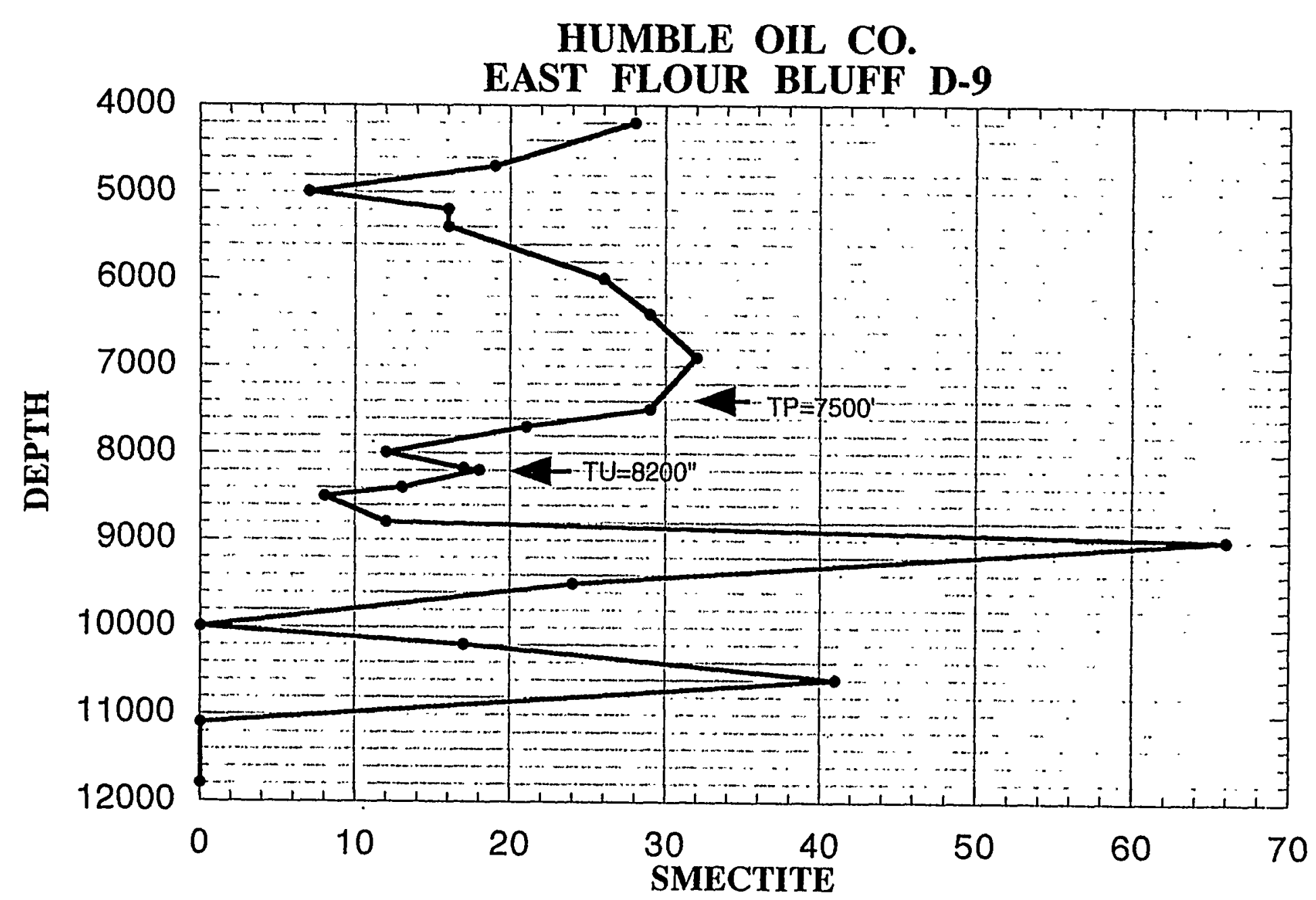

Figure 8. Smectite versus Depth 


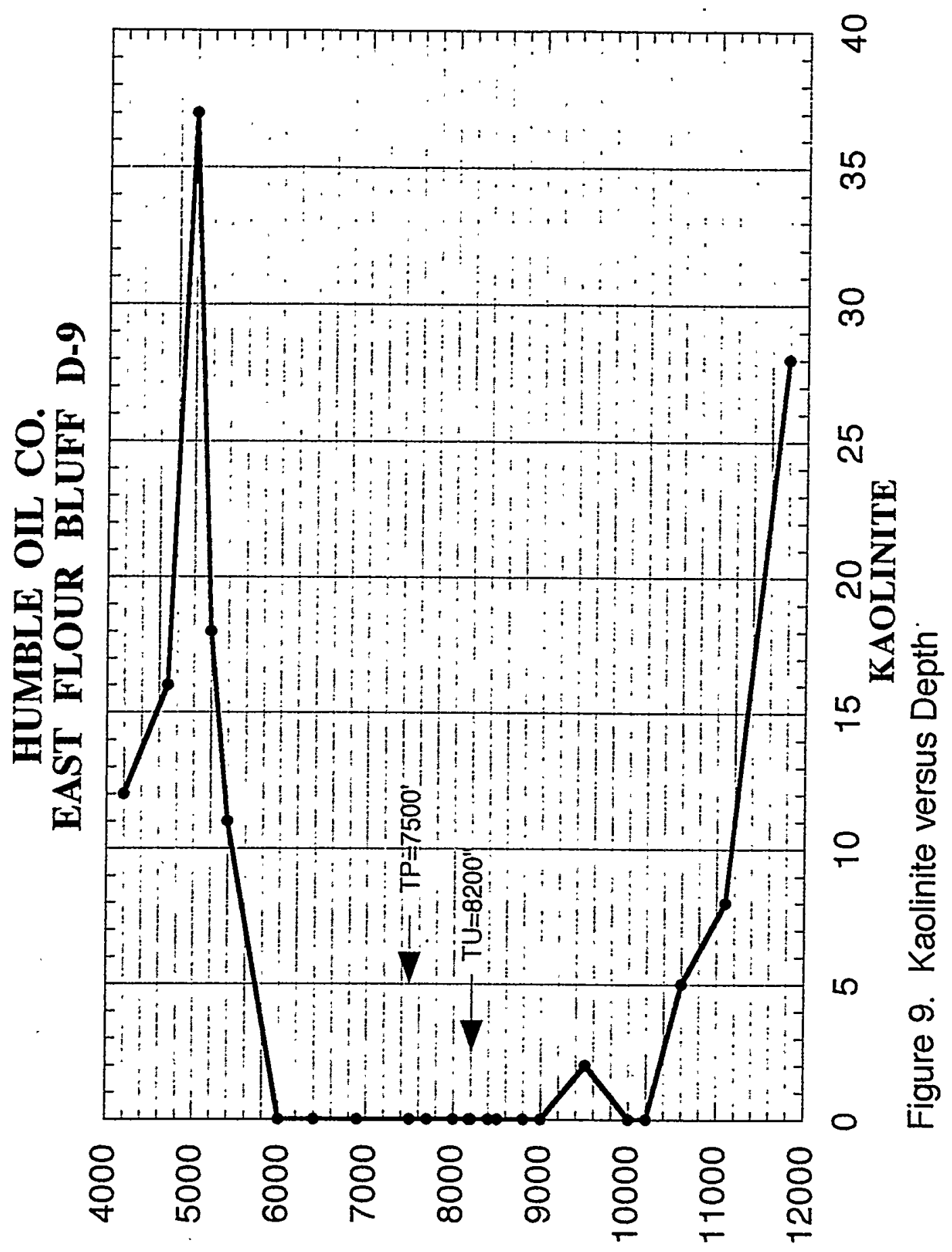

HLd'G 


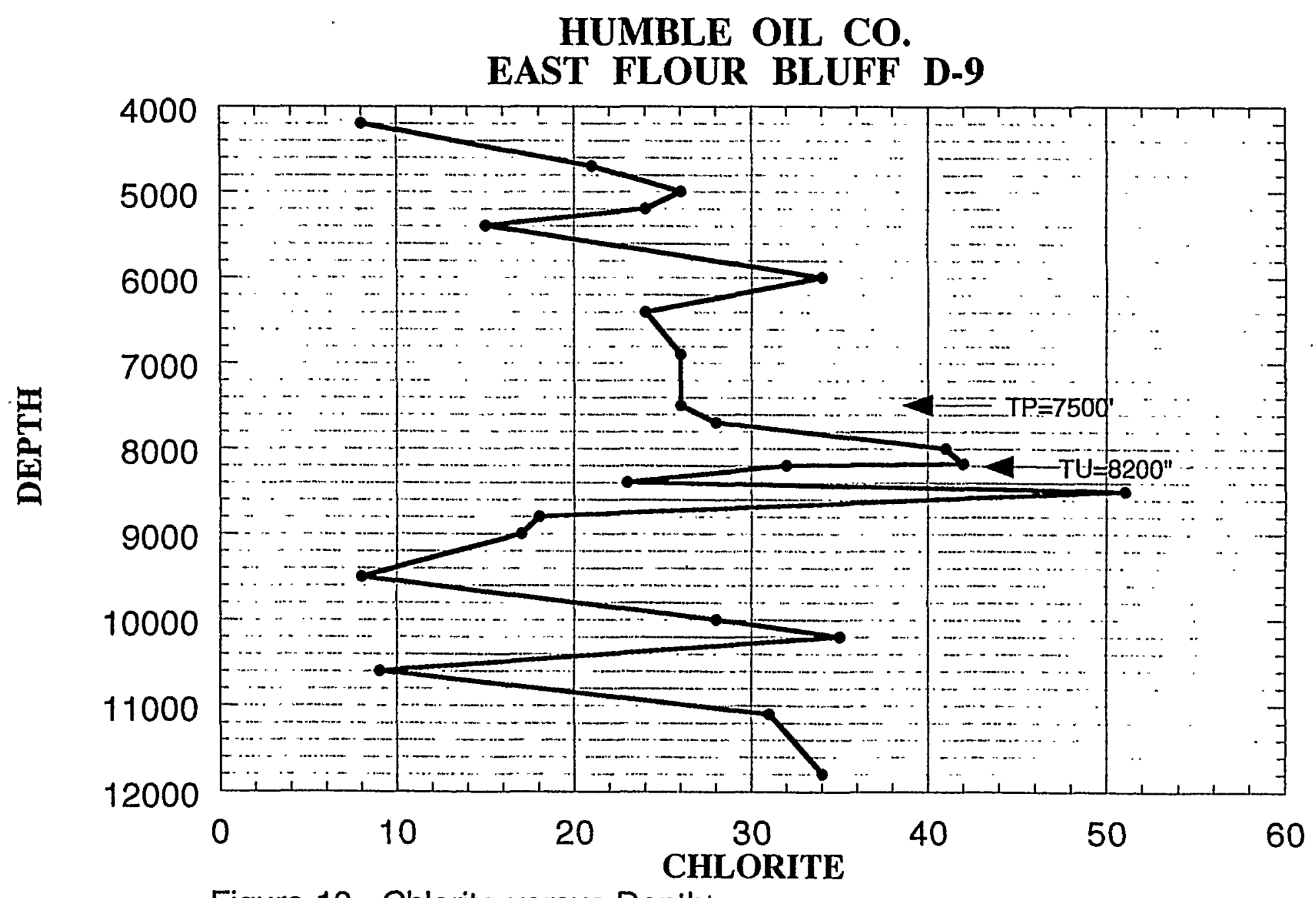

Figure 10. Chlorite versus Depth' 


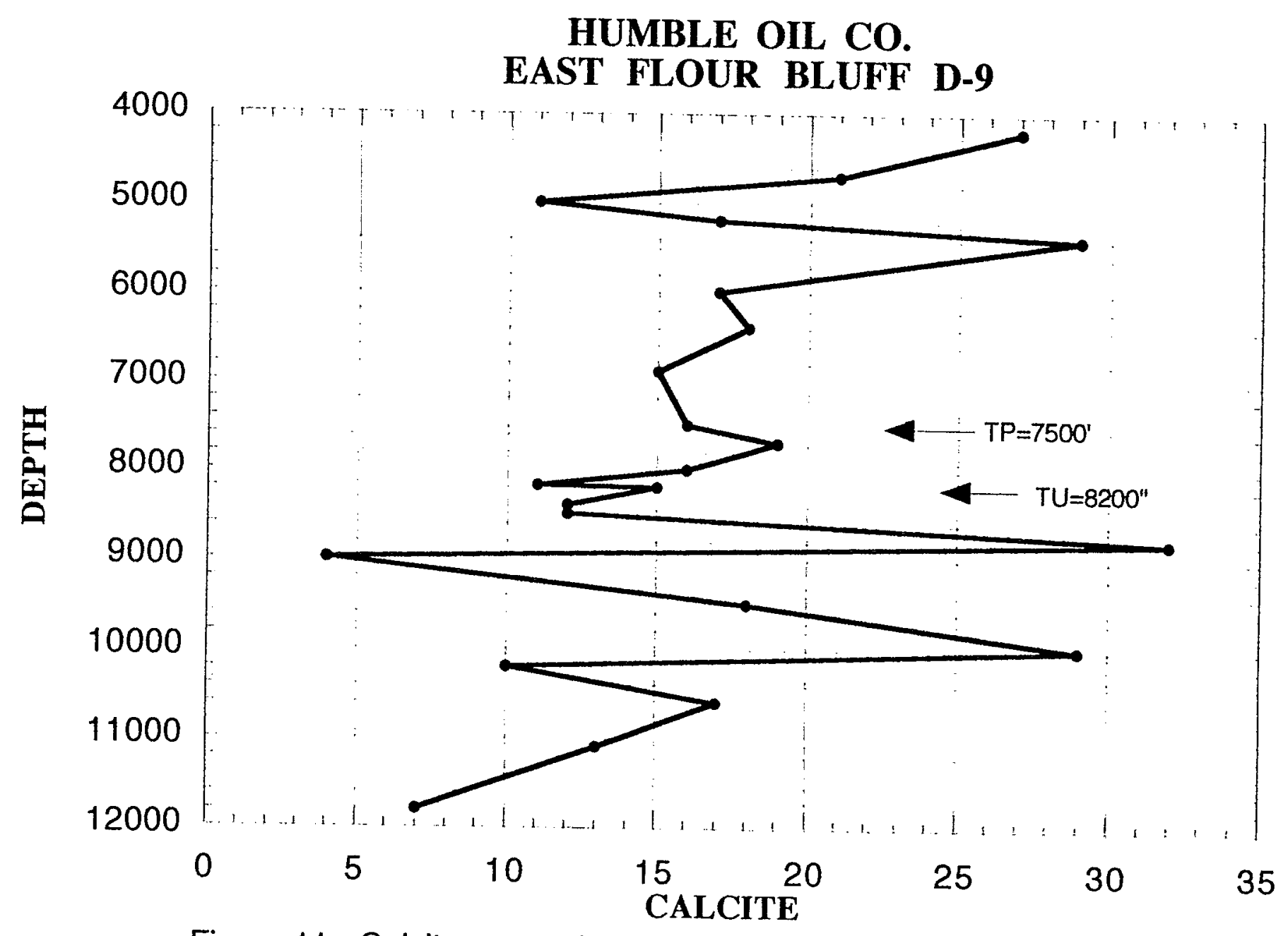

Figure 11. Calcite versus Depth 


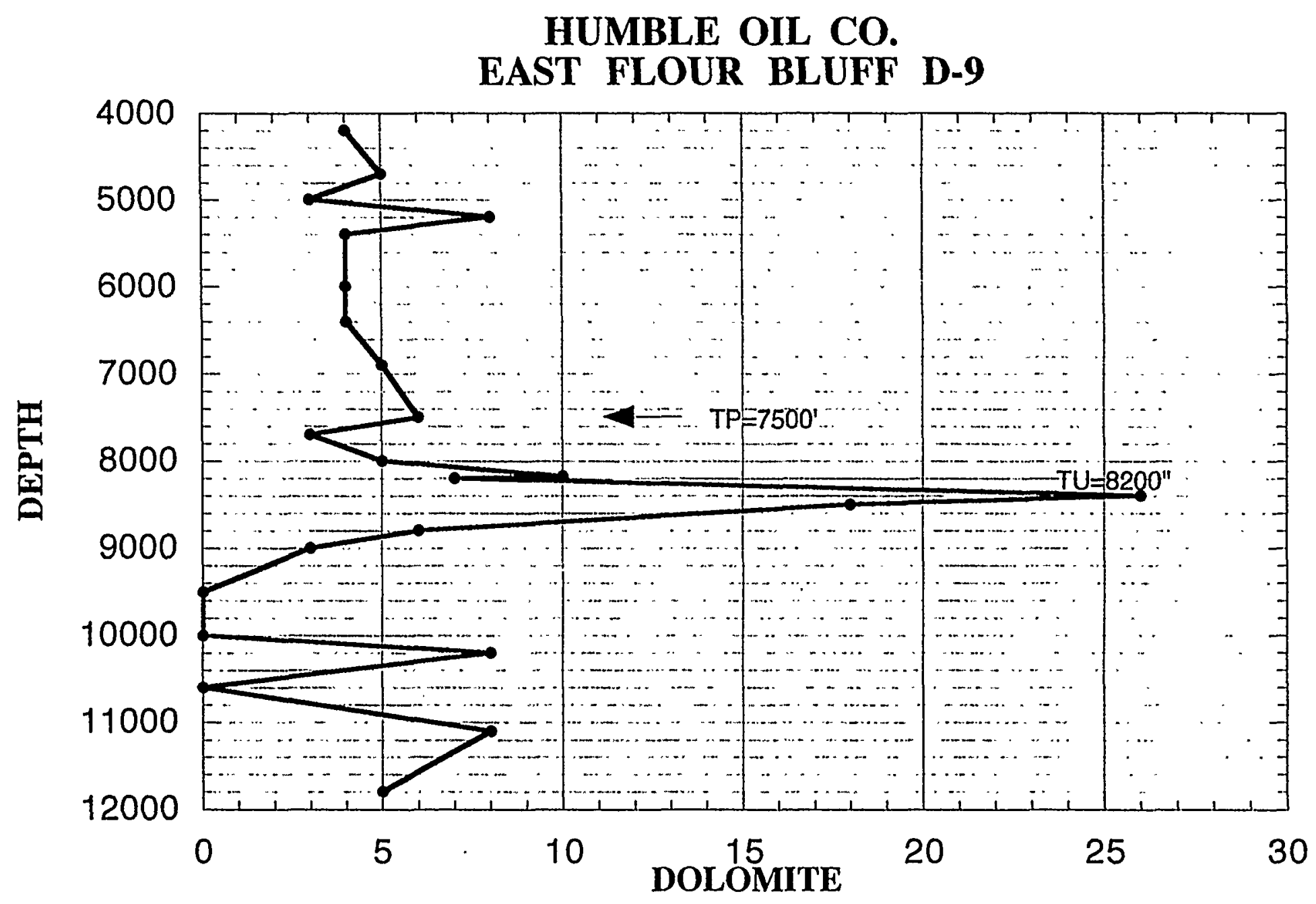

Figure 12. Dolomite versus Depth 


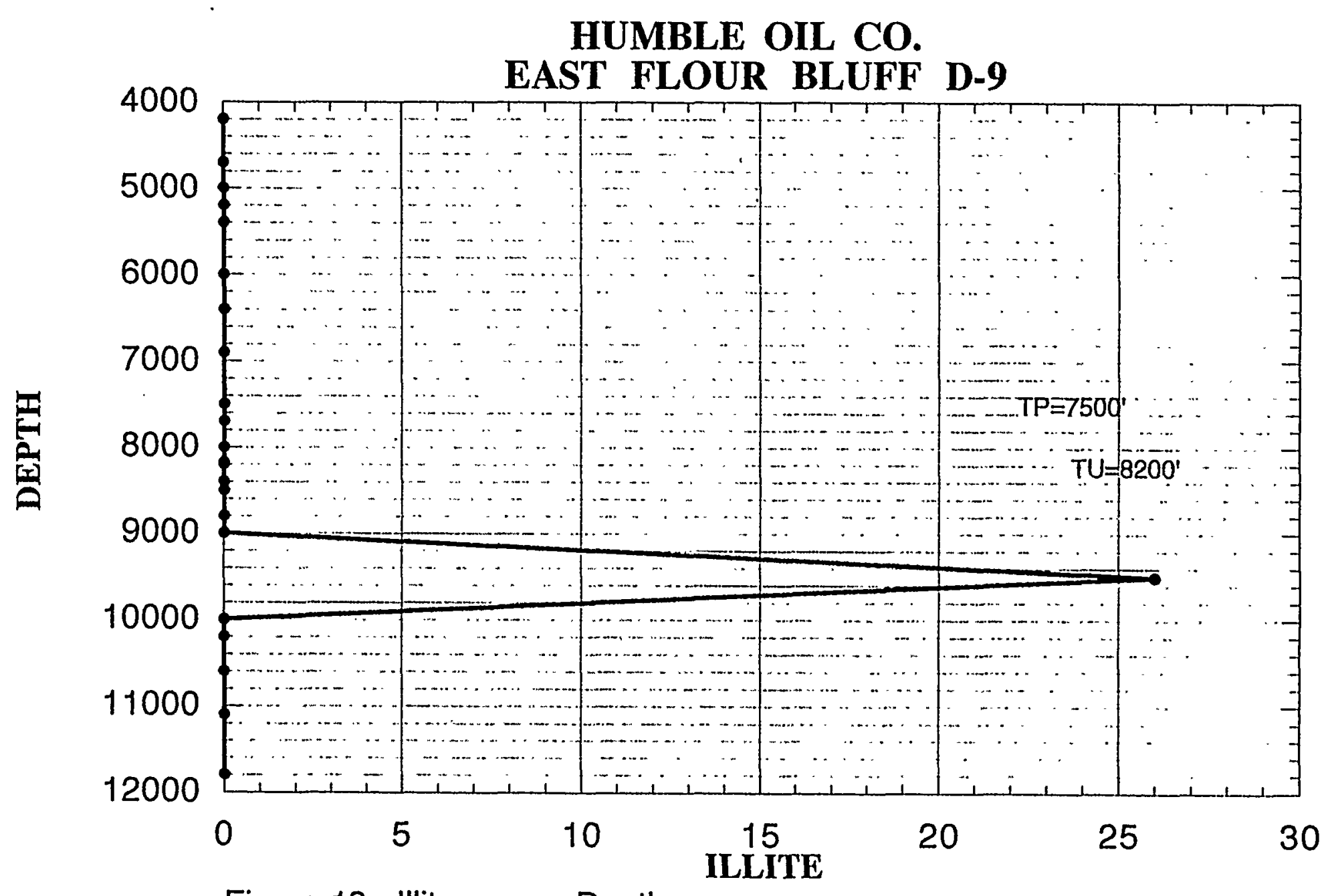

Figure 13. Illite versus Depth 
MINERAL TRENDS WITH DEPTH VERSUS THE TOPS OF ABNORMAL PRESSURE AND UNDERCOMPACTION

STANDARD OIL COMPANY OF TEXAS

STATE TRACT 883, WELL \# 1 


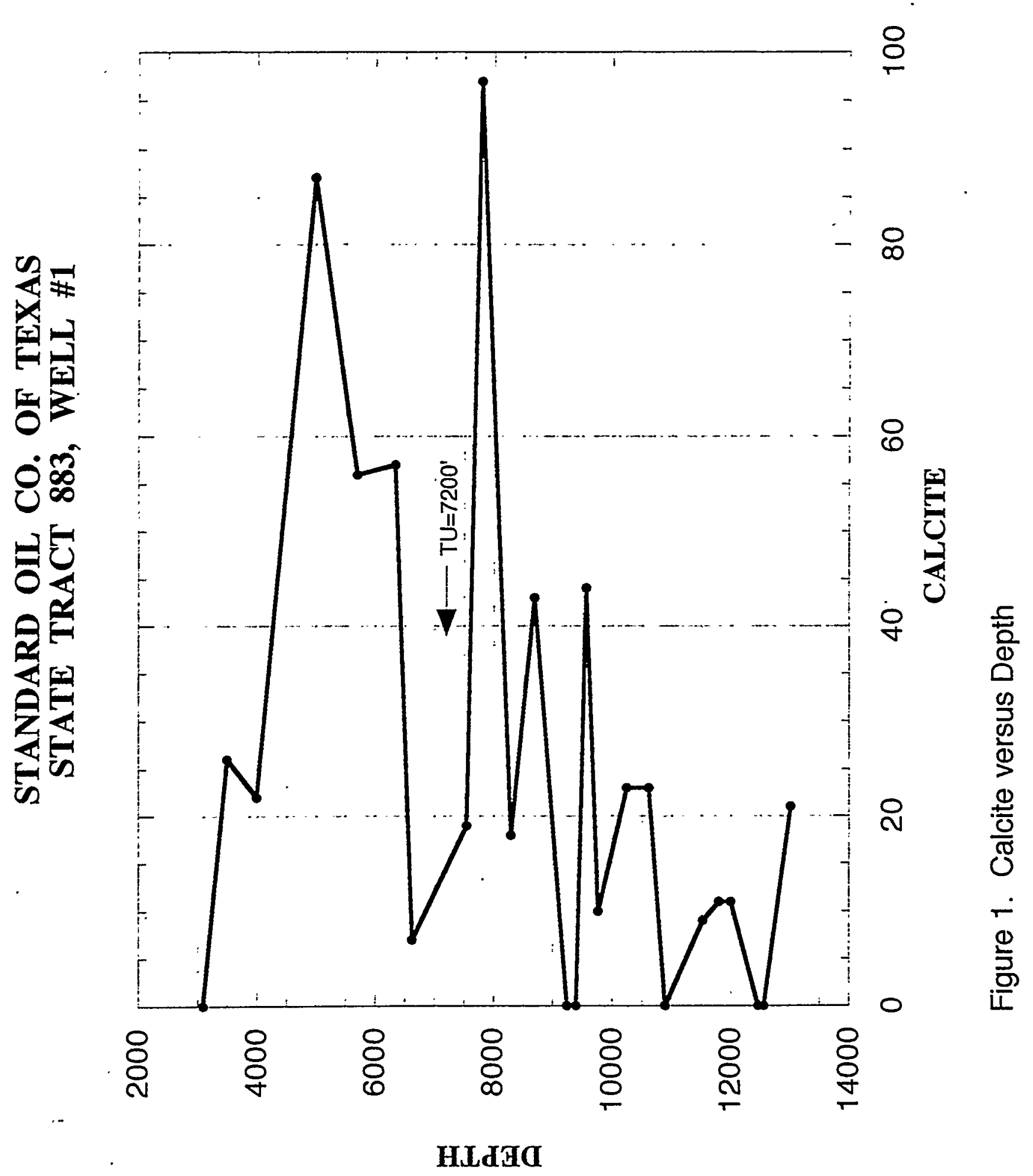




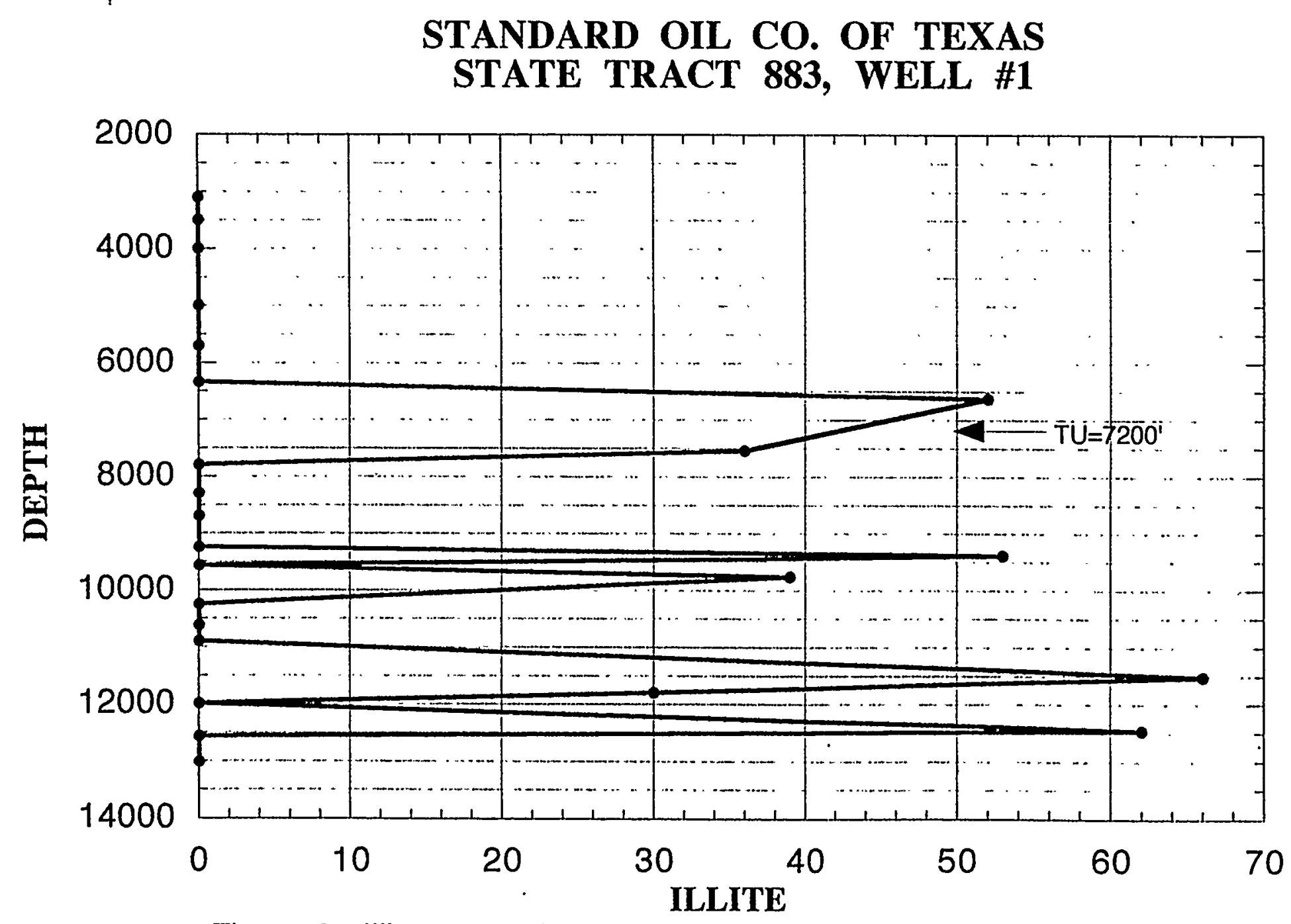

Figure 2. Illite versus Depth 


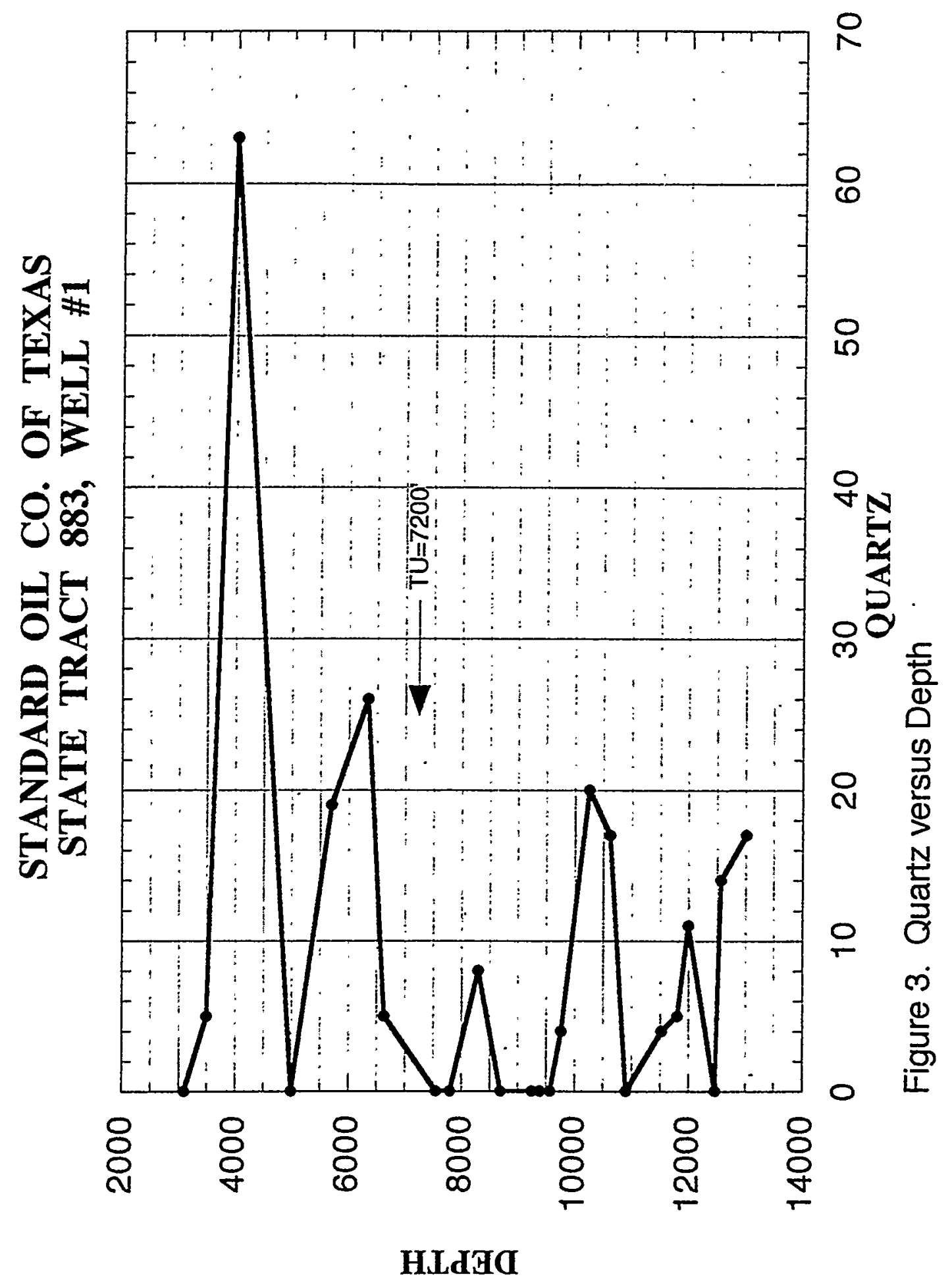




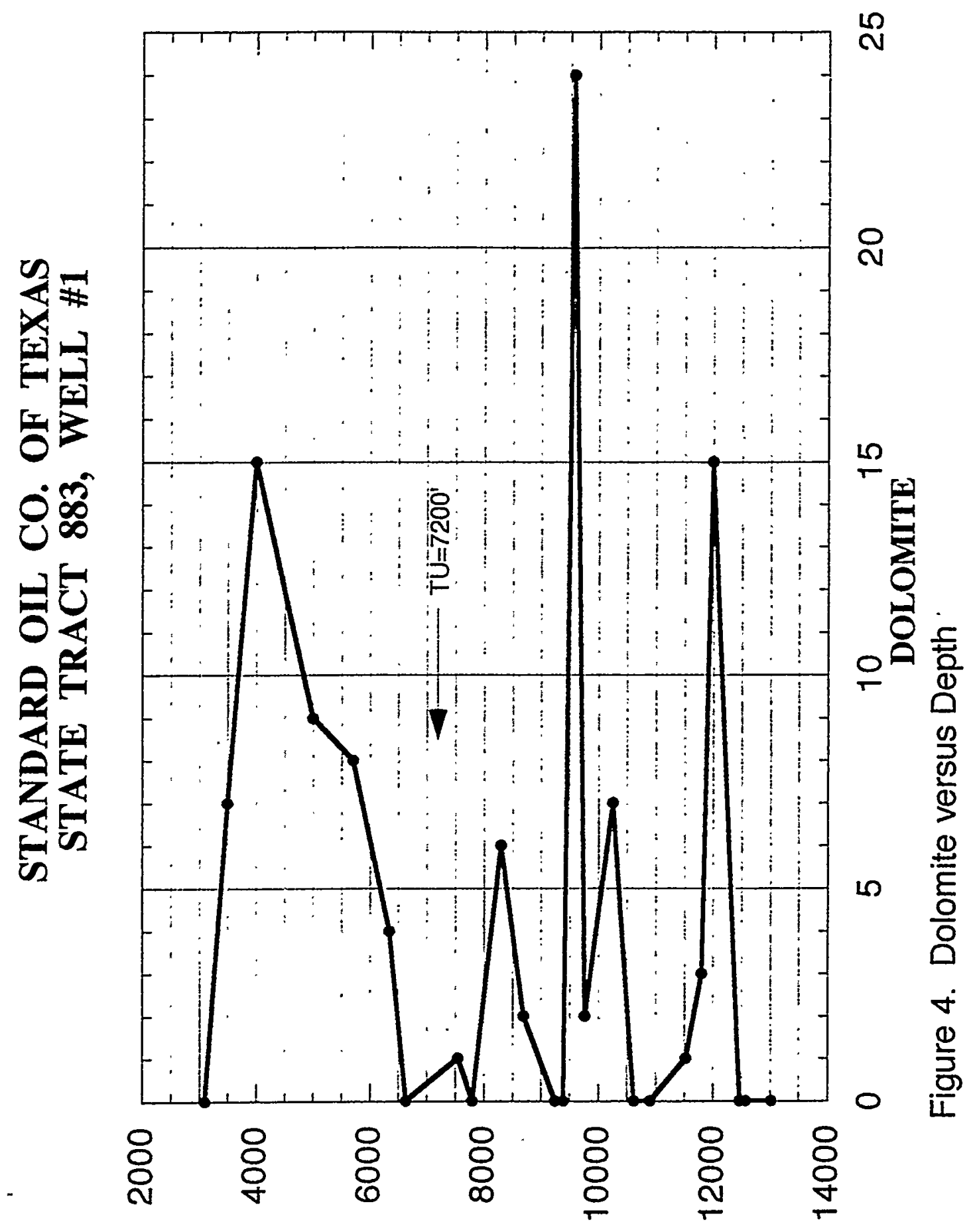

HLdGA 


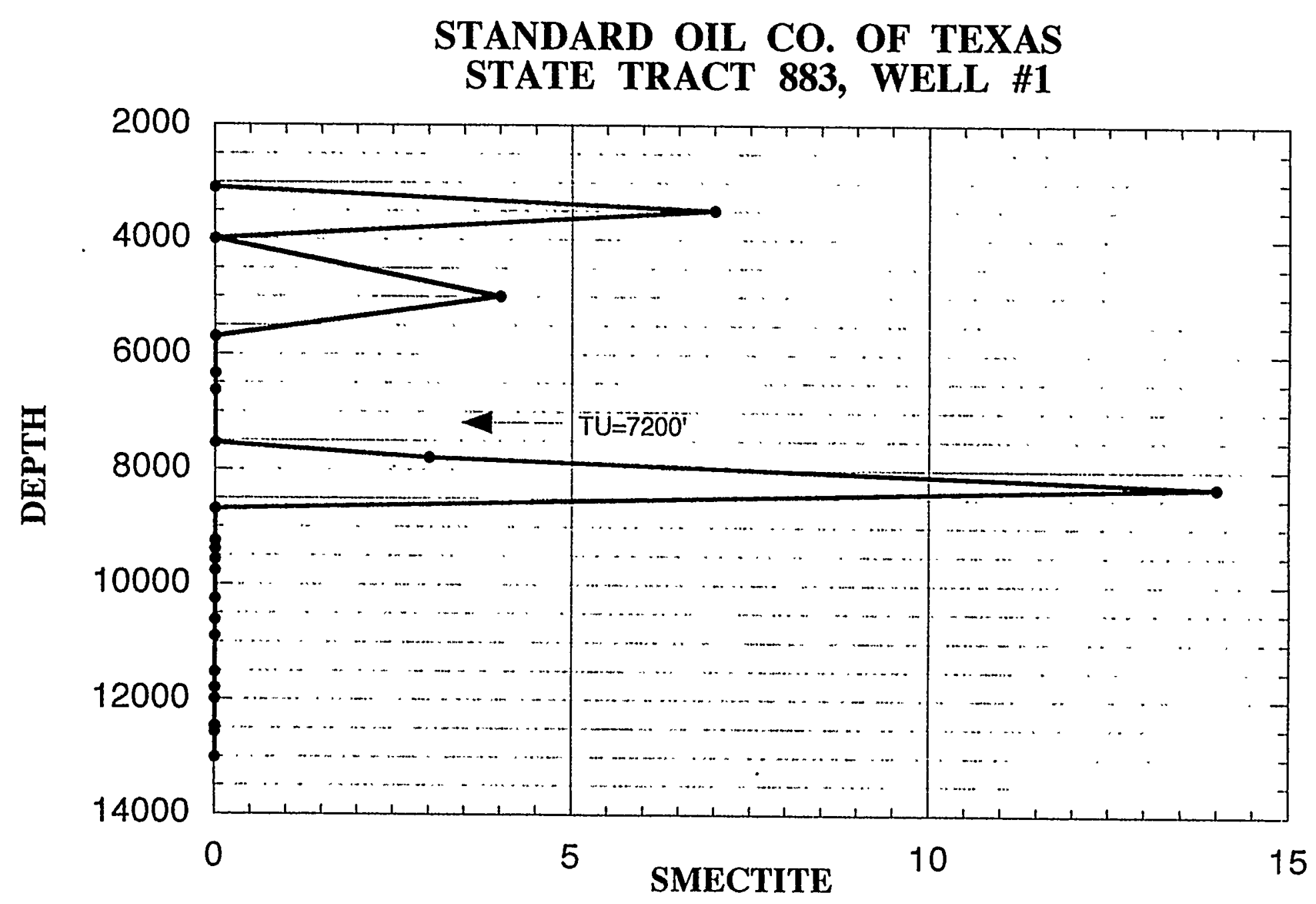

Figure 5. Smectite versus Depth 


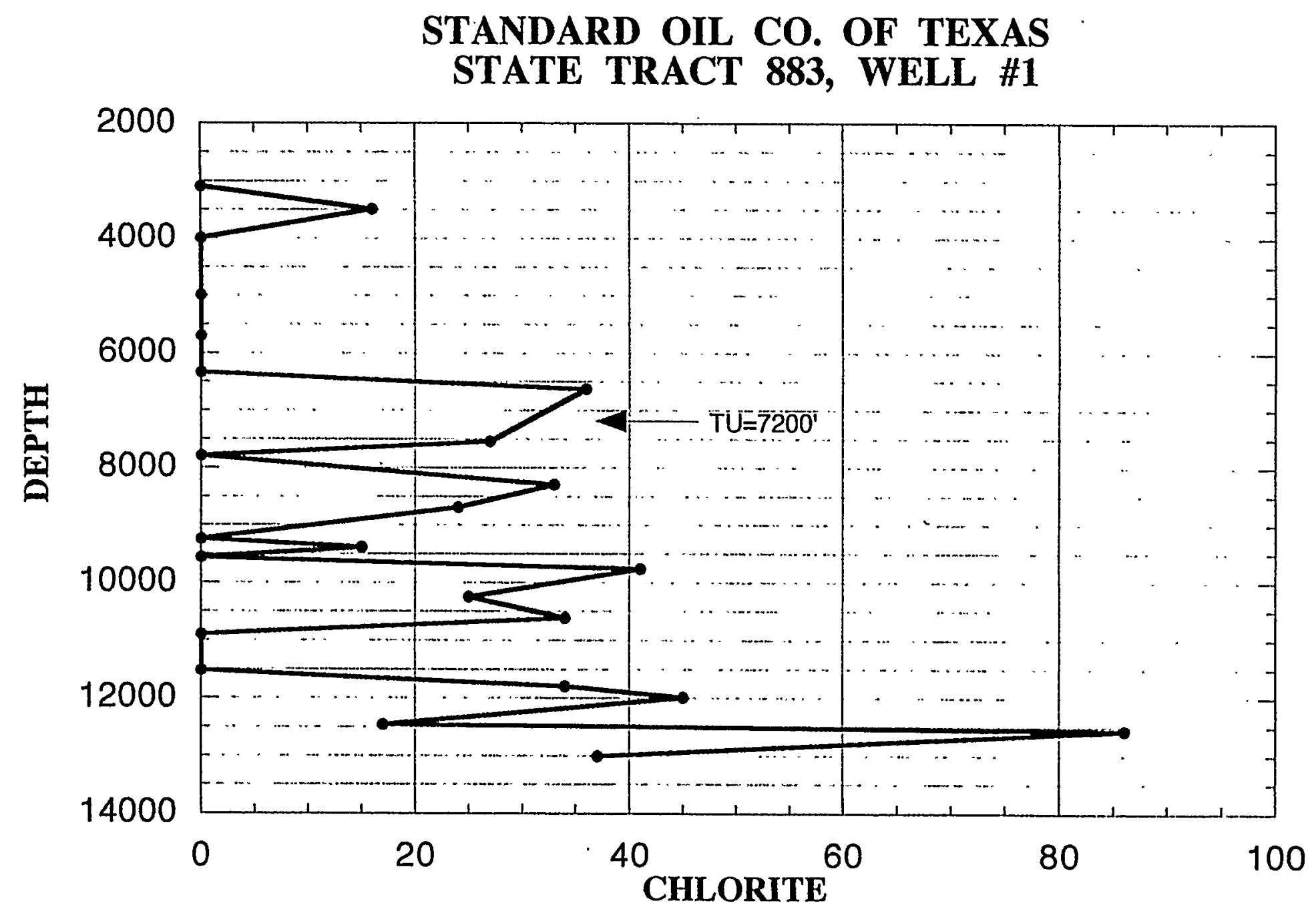

Figure 6. Chlorite versus Depth 


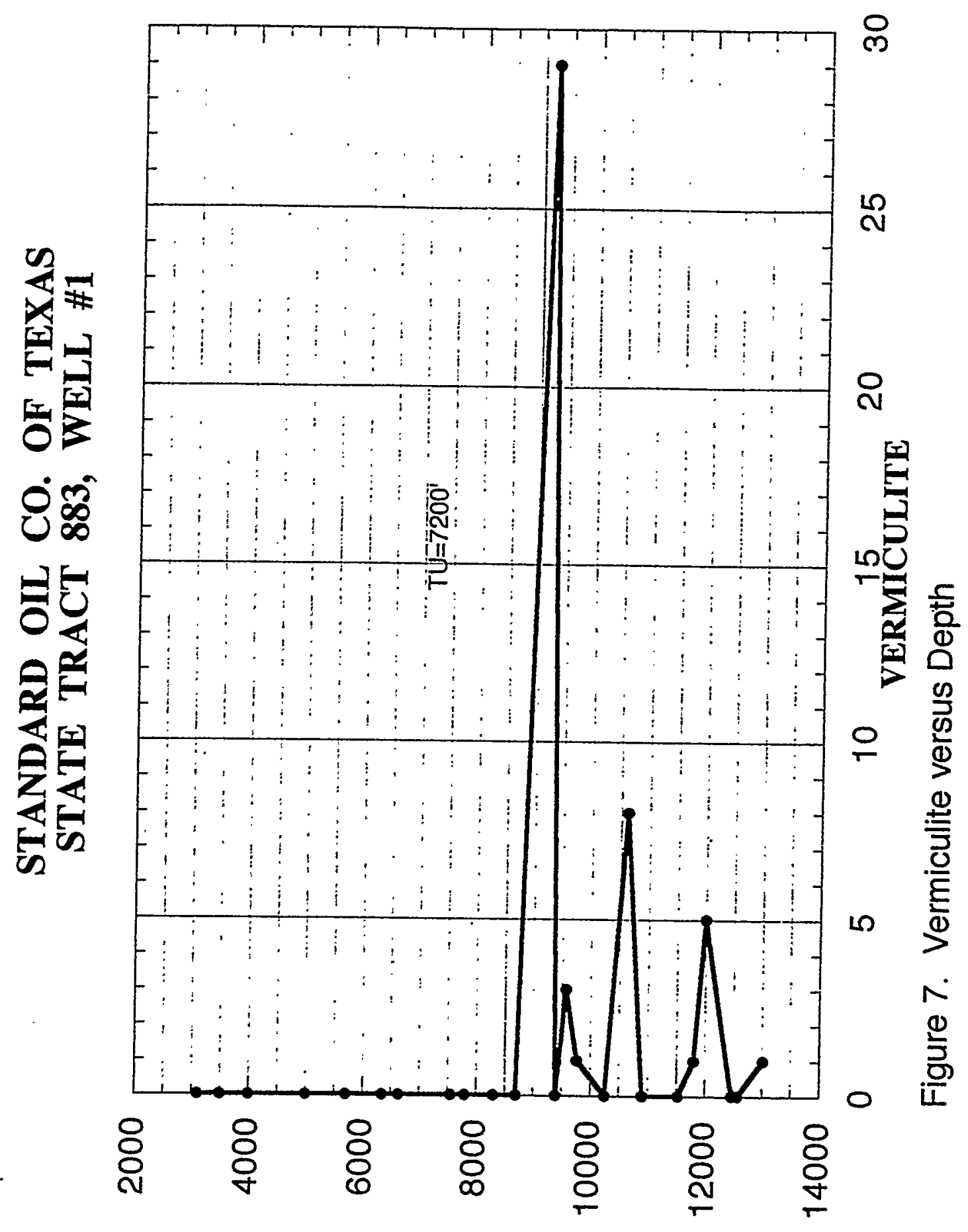

HLd'A 


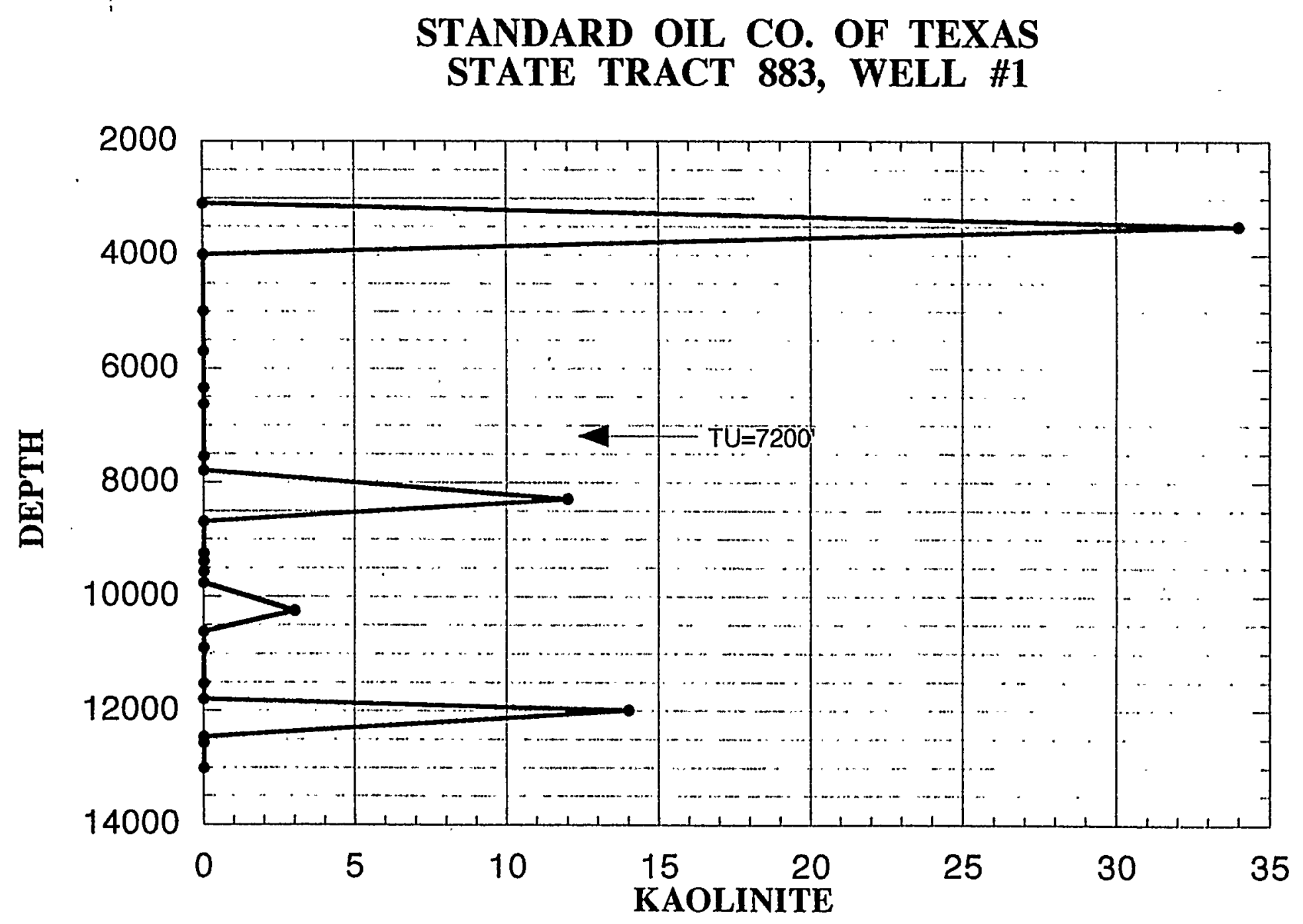

Figure 8. Kaolinite versus Depth. 
STANDARD OIL CO. OF TEXAS

STATE TRACT 883, WELL \#1

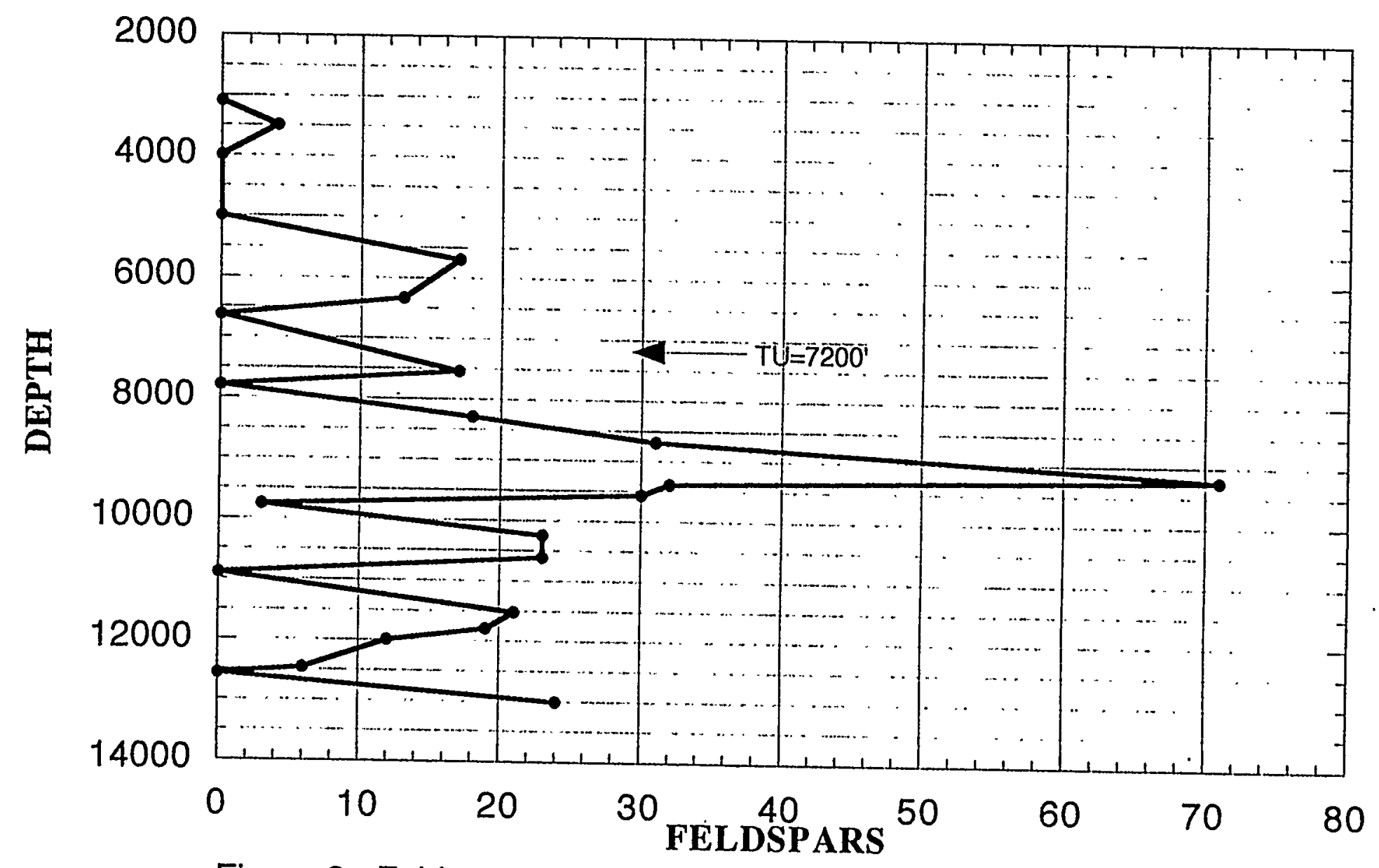

Figure 9. Feldspars versus Depth 


\section{RELATIONSHIP OF HYDROCARBON ZONES TO THE TOPS OF ABNORMAL PRESSURE AND UNDERCOMPACTION IN THE ANN MAG AND EL PAISTLE FIELDS, SOUTH TEXAS}

\section{INTRODUCTION}

Investigations of geopressure and undercompaction in Gulf Coast fields have revealed that the top of abnormal pressure and the top of undercompaction do not always occur at the same depth (Leftwich, 1993; and Leftwich and Engelder, 1995).

The purpose of this research was to determine if a correlation exists between the depths to oil and gas zones and the tops of abnormal pressure and undercompaction in the Ann Mag and El Paistle fields of South Texas.

\section{METHODS}

Dwight's Energydata records were used to obtain information on depths of upper and lower perforation of productive oil and gas zones in the Ann Mag and El Paistle fields. Perforation data were plotted on the actual 1" induction logs and also recorded in a Microsoft Excel 2.0 spreadsheet file. The Excel 2.0 file was imported into Golden Software's Grapher for Windows and a graph of depth versus perforations for each well was constructed. Previously determined (Leftwich, 1993) depths to the tops of abnormal pressure and undercompaction were plotted on this same graph.

\section{DATA AND OBSERVATIONS}

Tables 1 and 2 show the depths of perforated oil and gas zones in Ann Mag and El Paistle field wells used in this study.

At Ann Mag 17 productive zones from ten different wells were plotted (Figure 1). This figure shows that there was one perforated zone in the normally pressured, normally compacted segment (segment 1) of the field. Seven perforated zones in the abnormally pressured normally compacted segment (segment 2 ), and nine in the abnormally pressured undercompacted segment (segment 3 ) of the field.

At El Paistle nine productive zones from seven different well are shown in Figure 2. This figure shows that seven of the productive zones from five of the wells are perforated in segment 1 . The remaining two zones are perforated in segment 3.

\section{CONCLUUSIONS}

We conclude that there is no correlation between productive zones and the tops of abnormal pressure and undercompaction. Rather, it appears that oil and gas pay zones might occur in any field segment. 


\section{BIBLIOGRAPHY}

Leftwich Jr., J. T., 1993, The Development of Zones of Undercompacted Shale Relative to Abnormal Subsurface Pressures in Sedimentary Basins. Ph.D. diss., The Pennsylvania State University.

Leftwich, J.T., and Engelder, T., 1995, The characteristics of geopressure profiles in the Gulf of Mexico Basin: in Orteleva, P., ed., Pressure Compartments, American Association of Petroleum Geologists Memoir, (in press). 


\begin{tabular}{|l|l|l|}
\hline Well Name & Upper Perf (feet) & Lower Perf (feet) \\
\hline Rupp Deep \# 1 & 8172 & 8184 \\
\hline Rupp Deep \# 1 & 9544 & 9558 \\
\hline Sullivan \# 4 & 8376 & 8385 \\
\hline Sullivan \# 4 & 9034 & 9042 \\
\hline Sullivan J1 & 8760 & 8770 \\
\hline Sullivan \# 3 & 8540 & 8545 \\
\hline Sullivan \# 3 & 8604 & 8612 \\
\hline Sullivan \# 3 & 9740 & 9759 \\
\hline Sullivan \# 5 & 7000 & 7008 \\
\hline Sullivan H-1 & 10180 & 10246 \\
\hline Sullivan H-1 & 9620 & 9668 \\
\hline Maguire-Sullivan & 9792 & 9808 \\
\hline Sullivan Deep Unit \# 1 & 9792 & 9808 \\
\hline Sullivan N1 & 7969 & 7982 \\
\hline Sullivan N1 & 9954 & 10000 \\
\hline Flores Chamberlain & 8202 & 8208 \\
\hline Flores Chamberlain & 9152 & 9158 \\
\hline
\end{tabular}

Table 1.--Ann Mag Field wells showing upper and lower perforations of productive intervals.

\begin{tabular}{|l|l|l|}
\hline Well Name & Upper Perf (feet) & Lower Perf (feet) \\
\hline Kennedy J-9 & 13868 & 14728 \\
\hline Kennedy \# 13 & 11522 & 11875 \\
\hline Kennedy \# 32 & 8889 & 8896 \\
\hline Kennedy \# 32 & 8660 & 8665 \\
\hline Kennedy 3H & 8380 & 8385 \\
\hline Kennedy 3F & 8434 & 8439 \\
\hline Kennedy 3D & 8713 & 8718 \\
\hline Kennedy \# 6 & 6749 & 6771 \\
\hline Kennedy \# 6 & 6070 & 6080 \\
\hline
\end{tabular}

Table 2.--El Paistle Field wells showing upper and lower perforations of productive intervals. 


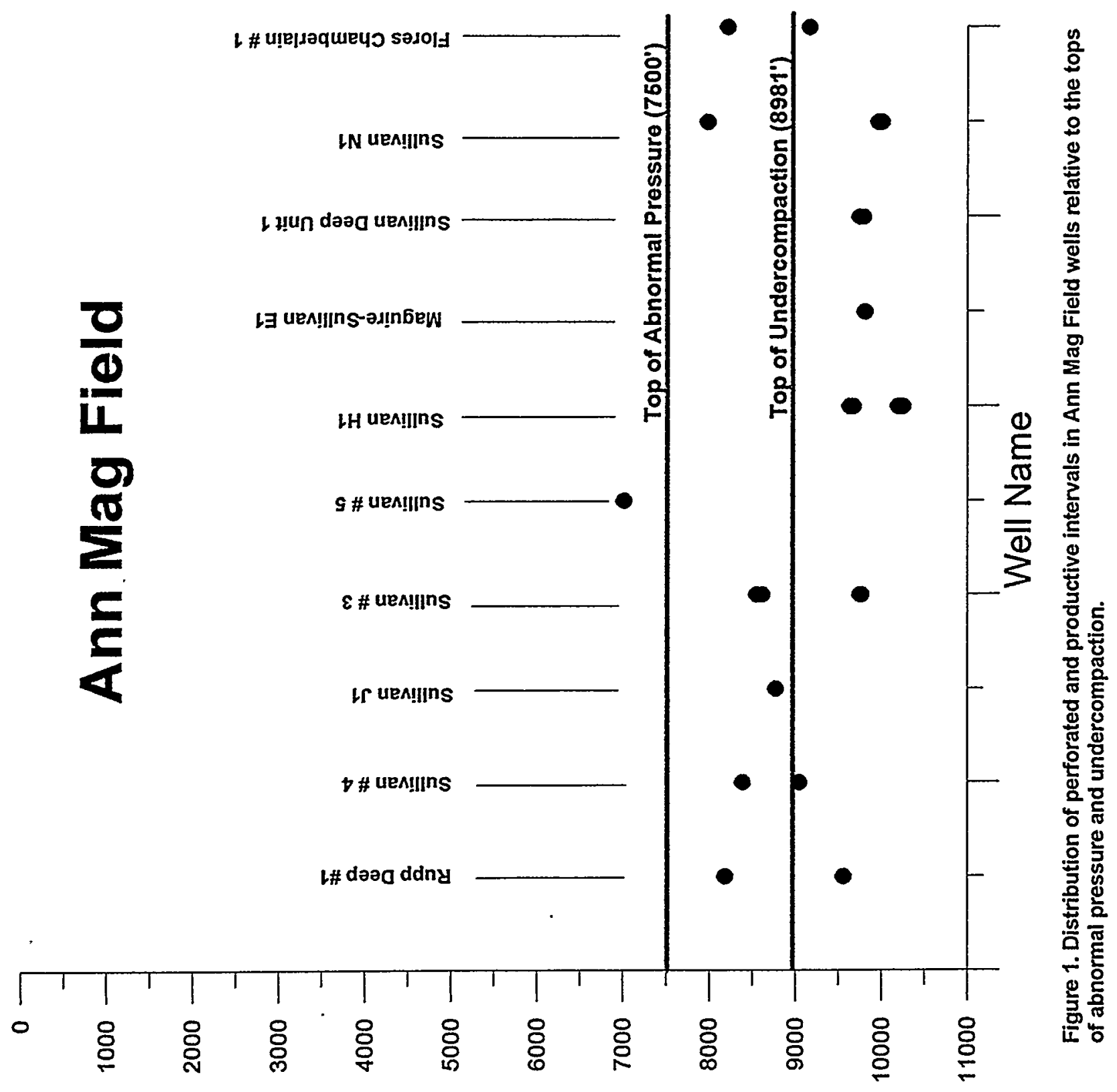

(ओ) yldəa 


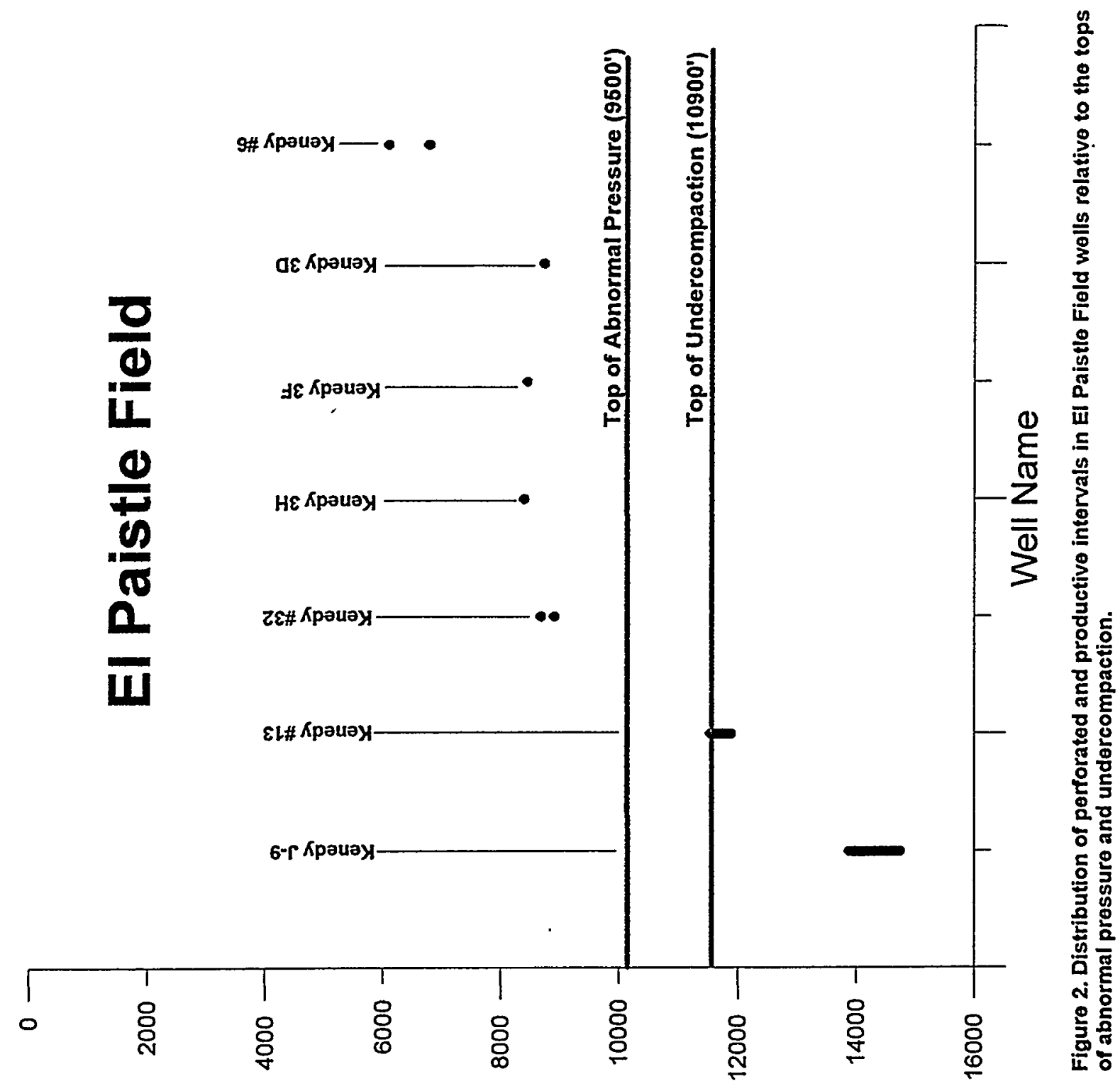

(H) पldəa 


\section{SUMMARY OF MAJOR FINDINGS}

This research has helped to confirm one rather significant discovery.

The top of undercompaction in sedimentary basins is essentially the same as the smectite-illite transformation point of Hower et. al., 1976. The changes we observe in water loss with depth are related to shale interlayer water and not simply shale pore water. Since this phenomenon is interlayer water controlled it is not compaction because you cannot compact interlayer water out of shale. The exchange of interlayer water is a chemical process and not just physical compaction. The term undercompaction is a misnomer. The water loss, $\mathrm{X}$-ray analysis and methylene blue experiments clearly support this conclusion.

Hower J., Eslinger E., Hower M. E. and Perry E. A. (1976): Mechanism of Burial metamorphism of argillaceous sediments--1. Mineralogical and Chemical Evidence. Bulletin of Geological Society of America 87, 725-737. 


\section{STUDENT DEVELOPMENT AND EDUCATION}

As a result of this U. S. Department of Energy grant several students had the opportunity to be involved in interesting scientific research and to broaden their education. This project has changed their academic perspectives, as they have a much better understanding of research, technology and how scientific research is done. As they continue their education in graduate school in the near future they will continue to develop and learn scientific research skills.

As a direct result of this project Kelly Doswell, Delano King, Miyoshi Stith applied to Old Dominion University (ODU) for graduate school and all were accepted.

Kelly Doswell was awarded a $\$ 8500$ Research assistantship by our department and is continuing to work on research that is an outgrowth of this project for her Masters degree.

Delano King has just finished his undergraduate work and will likely attend graduate school. I am presently seeking an assistantship to help him further his education.

Melanie Turner a student not directly involved in this project, but whom I met through my interaction with DOE entered our graduate program this fall and has done excellent work. I am very pleased to say that Melanie was also awarded an $\$ 8500$ Research assistantship.

In addition to supporting active petroleum research, your support of this program has done much to enhance students development and education. 


\section{GENERAL COMMENTS}

\section{Kelley Doswell}

This project have given me a good hands on experience view on what some subsurface geologists do in the laboratory and what they look for. The smetite- illite experiment have broaden my skills in working in a laboratory on a professional level. The methylene blue experiment has helped me to understand the purpose and importance of cation exchange in clay minerals.

Being a graduate student at Old Dominion University, is very challenging as well as exciting. Without the help of Dr. Leftwich, my research assistant position would not have been possible. Because of his time and patience, subsurface geology has become my field of interest. I hope to become a subsurface geologist and work abroad. The knowledge that I will gain from Old Dominion University will help me to become a successful subsurface geologist. 


\section{COMPUTER EQUIPMENT FOR VIRGINIA STATE UNIVERSITY}

The following computer equipment was donated to the Department of Geology at Virginia State University to enable the students to accomplish their component of the research.

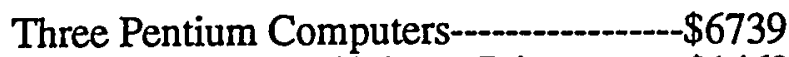

Tectronix Phaser 140 Laser Printer------\$1463

Total $\$ 8202$

This donation of computer equipment to the students at Virginia State University is quit significant to their program. Before the donation they only owned one very small out dated machine. The three new machines have had a tremendous impact on there program and they are very much appreciated.

\section{COMPUTER EQUIPMENT FOR OLD DOMINION UNIVERSITY}

The following is the major computer equipment purchased for Old Dominion University for use in this research project:

Two Macintosh Computers ------ \$5109

Epson Color Printer--

Gateway Pentium 166 (Dos) Computer ----\$2431

Total $\$ 9562$ 


\section{Appendix A}

A paper by Leftwich et.al

THE CORRELATION BETWEEN INTERLAYER WATER CONTENT IN

SHALE AND ABNORMAL PRESSURE IN THE ANN MAG FIELD 


\title{
THE CORRELATION BETWEEN INTERLAYER WATER CONTENT IN \\ SHALE AND ABNORMAL PRESSURE IN THE \\ ANN MAG FIELD, SOUTH TEXAS
}

\author{
JOHN T. LEFTWICH, JR., TERRY ENGELDER and GEORGE H. KACANDES \\ Department of Geosciences, The Pennsylvania State University, \\ University Park, Pennsylvania 16802
}

\begin{abstract}
Gravimetric data on the interlayer water content in Oligocene shales from the Ann Mag field, Brooks County, Texas were used to evaluate the relationship of overpressure to the development of undercompaction and the illitization of smectite. The relative amount of mineral-bound interlayer water content in the shale samples was estimated by comparing the densities of dessicated shales before and after heating to $115^{\circ}$ C. X-ray analyses of shale gave a measure of the amount of smectite in mixed-layer clays and with these data a qualitative relationship between interlayer water content and the smectite/illite ratio was developed. Starting at a depth of $2 \mathrm{~km}$ (6562 ft) in the Ann Mag field interlayer water is lost (by illitization of smectite) as a function of depth. This water loss trend is interrupted by a layer of illite-rich shale. The Ann Mag field is characterized by geopressure profile having four segments with distinct pressure gradients: the top segment is normally pressured whereas three segments are overpressured. Undercompacted shale, as indicated by resistivity and density measurements, is found immediately below the prominent illite-rich layer. This illite-rich layer may be a seal as indicated by its location at the break between two pressure segments. The undercompacted shale is smectite-rich which means that illitization is not the mechanism for undercompaction as some have proposed. Our model for undercompaction suggests that the illite-rich shale layer is detrital and is a seal relative to smectite-rich shales below.
\end{abstract}




\section{INTRODUCTION}

Geologists often speculate about the most important parameter controlling the depth at which abnormal pore pressure develops. Commonly, a correlation between the top of thicker shale sections and the upper boundary of abnormally pressured sections is noted (e.g., McCulloh, 1988) [Exceptions to this rule include seals around pressure compartments (e.g., Weedman, et al., 1992)]. Presumably, the lower permeability of the shales slows the upward fluid flow which might otherwise prevent the buildup of abnormally high pore-fluid pressures. Recent calculations suggest that the transition zone from normally to abnormally pressured rock develops near a hydraulic diffusivity minimum at depths of $2-4 \mathrm{~km}$ (Mello et al., 1994). However, the role of shales in constraining this transition zone is still poorly understood. Two common characteristics of shales in the transition zone bear further investigation: shales from the transition zone often have anomalously low densities (e.g., Hottman and Johnson, 1965) and the illitization of smectite often occurs at or near the transition zone (e.g., Hower et al., 1976).

The objective of this paper is to document the location of the transition from normal to abnormal pressures relative to both low density shale and to the smectite-illite transformation. Questions of interest include the possibility that the illitization of smectite leads to a seal which marks the top of abnormal pressure in shale-rich sections. A second question involves the role of illitization in generating the low density, undercompacted shale commonly found near the top of abnormal pressure (Magara, 1975). Among the many mechanisms for the generation of abnormal pressures (see Bradley, 1975), thermal loss of interlayer water from clay minerals remains a possible candidate (Burst, 1969). A third question concerns the connection between interlayer water loss during illitization and abnermal pressure.

Achieving the objectives of this study requires high quality pore pressure data, a good suite of electric logs, and a complete set of shale samples, all from the same field. In addition, a means of rapidly assessing the ratio of smectite to illite is desirable. The Texas 
Gulf Coast is a suitable case largely because of the presence of a section with abundant smectite-rich shales (Hower et al., 1976). We chose the Ann Mag field of Brooks County, Texas, because the nature of the pressure transition zone is well defined by high quality repeat formation tester (RFT) data (Leftwich and Engelder, 1995). In the Ann Mag field a zone of low density shales is well defined by sonic, density and resistivity data. Although $\mathrm{XRD}$ analysis is the most reliable means to characterize the clay mineralogy of shale samples, we wished to develop a new and faster technique for assessing the ratio of smectite to illite in samples. As an alternative, we will show that, a weight change of shale cuttings during dehydration by heating serves as a qualitative, if not a quantitative measure of the interlayer water (smectite) content of the shale.

\section{THE TEXAS GULF COAST}

Numerous gas producing fields along the Texas Gulf Coast are situated in the Vicksburg Trend, where the primary production is from Vicksburg sandstone reservoirs. Many of these Vicksburg sandstones were deposited as part of a wave dominated delta complex. These sand bodies are generally $5-10 \mathrm{~m}(16.4-32.8 \mathrm{ft})$ thick and are separated by as much as several hundred meters (hundreds of feet) of prodelta mudstone and shale. Above the Vicksburg is the Frio Formation, a unit dominated by interconnected sand bodies interrupted by considerably thinner mudstone and shale units. This is the situation in Maguire Oil Company's Ann Mag field (Brooks County, Texas), a field which produces from sandstone reservoirs in the shale-rich Vicksburg Formation (Figure 1).

The pore pressure transition zone in the Ann Mag field is particularly well characterized as a consequence of about 100 high quality RFT measurements from over two dozen wells. A composite geopressure profile from the Ann Mag field shows the top of abnormal pressure at a depth of approximately $2286 \mathrm{~m}(7500 \mathrm{ft}$ ) (Figure 1). Furthermore, the profile consists of four segments; each segment has a characteristic pressure gradient (Leftwich and Engelder, 1995). The top segment (1) follows the normal 
pressure gradient of $10.1 \mathrm{MPa} / \mathrm{km}(0.445 \mathrm{psi} / \mathrm{ft})$. Immediately below the top of abnormal pressure is a normally compacted segment (2) with a constant (at the resolution of the plot) pressure gradient of $24.7 \mathrm{Mpa} / \mathrm{km}$ (1.094 psi/ft). Below the top of undercompaction, as identified in electric logs by the presence of low resistivity shale (Figure 2), is a segment (3) with a pressure gradient of $54.1 \mathrm{MPa} / \mathrm{km}(2.391 \mathrm{psi} / \mathrm{ft})$ down to a depth of approximately $3200 \mathrm{~m}(10500 \mathrm{ft})$. The deepest segment (4) has a pressure gradient of about $18.9 \mathrm{MPa} / \mathrm{km}(0.84 \mathrm{psi} / \mathrm{ft})$ which is poorly constrained because of the small number of data points. These pressure-depth segments are labeled ONE through FOUR moving downward in the field.

Although all RFT measurements were taken in sand bodies, Leftwich and Engelder (1995) argue that the nearly linear increase in pressure of segments TWO and THREE supports the notion that fluid pressure has equilibrated to follow the same linear trend throughout the enclosing shale. If not, pressure in the individual sand bodies might not fall on such a linear trend. Obviously, the presence of less dense gas in some of the sand bodies means that pressure-depth curves will not be linear in detail but too few RFT data were taken to resolve this behavior in the composite pressure-depth curve at the scale of Figure 1.

The characteristic that makes the Ann Mag field particularly interesting is the location of a shale resistivity anomaly of the type used by Hottman and Johnson (1965) as an indicator of abnormal pressure. In the Ann Mag field this anomaly does not occur at the top of abnormal pressure, but rather well below the Frio-Vicksburg contact (Figure 2). Other log characteristics of the anomalous shale include a lower sonic velocity and lower density. Consequently, a subsidiary objective of this paper is to identify the clay mineralogy of the anomalous, low density shale. Some previous work in this area was done by Bott and Tieh (1987) where they studied Frio and Vicksburg shales in the Ann Mag field and compared mineralogic changes in the shales to high fluid pressure anomalies. 


\section{SHALE SAMPLES}

The shale samples examined in this study came from gas wells drilled in Maguire Oil Company's Ann Mag field, Brooks County, Texas (Figure 1). Four Ann Mag wells were investigated: the Maguire Oil Sullivan K-1, the Maguire Oil Sullivan L-1, the Maguire Oil Sullivan M-1, and the Maguire Oil Rupp \#1. All four wells were drilled into abnormal pressure and into the undercompacted zone which occurs below the Frio-Vicksburg contact (Figure 2). The shale samples were stored as cuttings (ambient conditions) at the offices of Maguire Oil, Dallas, Texas. Because some mixing of shale and sandstone clasts takes place within the well bore, we hand picked shale clasts from each sample envelope which contained representative cuttings from a three meter interval of a well. These shale chips were then used for our $\mathrm{XRD}$, density, and dehydration measurements.

In dealing with shale cuttings we make a distinction between desiccation and dehydration of shale. Desiccation is the lost of pore water (non-mineral-bound) from the rock samples on drying at room temperature. Dehydration is the lost of more tightly held, mineral hound water from clay minerals upon heating to $115^{\circ} \mathrm{C}$. Because the most abundant hydrated mineral in these shales is smectite, weight loss on heating is a relative measure of interlayer water content. Most of the formation fluids in shale is contained within the pore system and is readily exchangeable with the outside environment during desiccation of shale cuttings. When shale cuttings are brought to the surface by mud circulation during drilling the cuttings are saturated with formation fluid. We refer to these cuttings which are saturated with formation fluid as "fresh cuttings". Some of this original fluid saturation is lost on pressure release during the trip to the surface. Upon reaching the surface the chips continue to lose these pore fluids (mainly water) through evaporation so that after a few days or weeks in storage the cuttings become desiccated. 


\section{EXPERIMENTAL TECHNIQUES}

To map the transformation from smectite to illite and the depth to the low density shales in the Ann Mag field, we made three measurements. First, the density of shale chips was measured before and after desiccation. Second, the amount of interlayer water content was assessed by measuring the change in weight of shale samples before and after dehydrating. Finally, because the amount of interlayer water content is used as qualitative measure of the relative amount of smectite in a sample, the dehydration measurements were calibrated against the smectite/illite ratio obtained from XRD analyses.

\section{Density of shale chips}

Data on the density of fresh shale cuttings from the Sullivan K-1 well came from the mud log records at Maguire Oil in Dallas, Texas. These same samples (now desiccated) were retrieved from storage at Maguire Oil 20 months after the mud logger made his measurements. Desiccated densities were measured at $15.24 \mathrm{~m}$ (50 foot) intervals from a depth of $1981 \mathrm{~m}$ (6500 ft) to a depth of $3277 \mathrm{~m}(10,750 \mathrm{ft})$ in the Sullivan K-1 well.

Both sets of density data were collected using a variable density column method (Matthews, 1969). The column involves a graduated cylinder containing a mixture of two miscible fluids with different densities (bromoform and trichloroethane). Once the column is mixed, calibration beads of known density are dropped into the graduated cylinder and a calibration chart is prepared. Next several shale clasts were selected from each cuttings sample and dropped into the column. The settling depths at which each sample comes to rest was recorded and its density determined from the calibration curve. 


\section{Water of dehydration}

In pursuing the objectives of this paper our idea was that we could make a qualitative measure of the smectite content of shale chips by measuring the water of dehydration. We carefully picked a number of shale chips from the cuttings samples from the four wells mentioned above. Prior to dehydration of the shale, empty beakers were placed in an oven for 24 hours to drive off all surface moisture. After the beakers were removed and weighed, about two grams (pre measured) of shale sample was added to the beaker. The beaker containing the sample was again weighed. To dehydrate shale samples, carefully weighed shale cuttings were heated in an oven at $115^{\circ} \mathrm{C}$ for 24 hours after which they were removed and placed in a pre warmed desiccator containing phosphoric oxide and transported immediately to the balance for weighing while still warm. The relative amount of interlayer water was simply taken as the percentage weight loss during heating at $115^{\circ} \mathrm{C}$ for 24 hours.

\section{$X$-ray diffraction determination of smectitefillite ratio}

To calibrate our dehydration data, we determined the clay mineral compositions of the various shales using $\mathrm{X}$-ray diffraction (XRD) analyses of cuttings. Sixteen samples were selected at various depths [3 meter (10 foot samples)] in the Sullivan $\mathrm{K}-1$ well. $\mathrm{A}<2$ $\mu \mathrm{m}$ size fraction was obtained by sonicating ground cuttings in distilled water followed by centrifugation. Samples were calcium-saturated and analyzed in both the air-dried and ethylene glycol-solvated conditions. Iron-rich samples were additionally treated to remove iron oxides using the CBD method of Jackson (1975). The $<2 \mu \mathrm{m}$ size fraction of each of the euttings samples was examined by XRD to determine the percentage of smectite in mixed-layered smectite-illite. Oriented mounts were step-scanned from $2^{\circ}$ to $50^{\circ} 2 \theta$ with $\mathrm{Cu} \mathrm{K} \alpha$ radiation. The step interval and count time were $0.02^{\circ} 2 \theta$ and 1 second, respectively. Smectite-illite ratios were determined by the method of Srodon (1980) and by 
matching with theoretical patterns produced by the computer program, NEWMOD (Reynolds, 1985). The error in smectite-illite ratio estimates based on these methods is approximately $5 \%$.

\section{OBSERVATIONS}

\section{Density of shale chips}

The density of desiccated shale samples was determined for the Sullivan K-1 and plotted alongside the densities of fresh shale samples from the same well (Figures 3). The densities of fresh shale samples (curve A, Figure 3) range from $2.2 \mathrm{~g} / \mathrm{cm}^{3}$ at a depth of $1981 \mathrm{~m}(6500 \mathrm{ft})$ to $2.45 \mathrm{~g} / \mathrm{cm}^{3}$ at a depth of $3277 \mathrm{~m}(10,750 \mathrm{ft})$. Desiccated shale

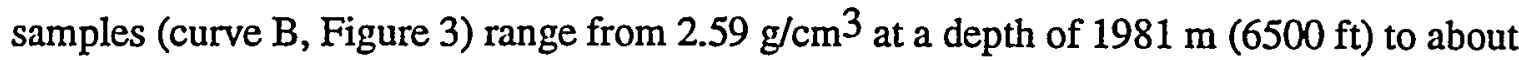
$2.62 \mathrm{~g} / \mathrm{cm}^{3}$ at $2743 \mathrm{~m}(9000 \mathrm{ft})$ and finally at a depth of $3277 \mathrm{~m}(10,750 \mathrm{ft})$ they equal $2.66 \mathrm{~g} / \mathrm{cm}^{3}$. Six interesting features appear in Figure 3.

First, the densities of the desiccated samples are significantly higher than those of the fresh samples. Because the density of fresh samples represents the density of the shales when they are still saturated with formation fluids, fresh shale densities may not equal in situ densities because of expansion on stress release. Evaluation of the amount of stress release expansion and the cause of densification upon desiccation was not attempted in the context of this study.

Second, the shale density curve for the desiccated shale cuttings shows less change with depth compared with the shale density curve recorded by the mud logger using fresh cuttings (Figure 3). A corollary is that changes in density during desiccation are smaller for samples from greater depths.

Third, the density of the fresh shale samples follows a trend indicative of compaction with depth. There is an offset in the trend at a depth of $2393 \mathrm{~m}(7850 \mathrm{ft})$, which correlates with a change in shale properties (e. g., density, and color change). Color 
changes are often observed in shale cuttings while drilling the Oligocene Frio-Vicksburg sections of the northern Gulf of Mexico basin. Shales of the Frio formation are usually red and green variegated in color with the green shale gradually becoming more predominant with depth. In the Ann Mag Field of South Texas red and green variegated Frio shales extend down to a depth of $2393 \mathrm{~m}$ ( $7850 \mathrm{ft}$ ), below which are gray shales.

Fourth, the fresh shale samples have a relatively lower density below the top of undercompaction in the Sullivan K-1 well. This trend correlates with the increasing conductivity and sonic travel time which are the logging parameters used to identify undercompaction (Figure 3).

Fifth, the low density shale indicative of the top of the zone of undercompaction is also preserved in the desiccated samples (Figure 3, curve B). The maximum undercompaction in the desiccated samples occurs at about $2987 \mathrm{~m}(9800 \mathrm{ft})$ and correlates with a maximum for conductivity and sonic travel time.

Sixth, some of the densest desiccated samples come from a zone at a depth between 2743 and 2804 meters ( 9000 and 9200 feet) where in situ shale has the shortest sonic travel time and lowest conductivity found anywhere in the Sullivan wells. This zone of high density shale was critical to our understanding of the geopressure profile within the Ann Mag field.

Interlayer water content in the shale of the Sullivan $K-1$ well

Shale from the Sullivan K-1 well was used to calibrate the quantity of interlayer water as a measure of the relative amounts of smectite and illite in a sample. In general, the . amount of interlayer water content, as determined by percent weight loss, decreases with depth starting at $2100 \mathrm{~m}$ (6890 ft) in the Sullivan K-1 well (Figure 4). The quasi-linear trend toward less interlayer water content with depth is interrupted by several samples in the $2743 \mathrm{~m}(9000 \mathrm{ft})$ to $2804 \mathrm{~m}$ (9200 ft) depth range showing considerably less interlayer water content. These low-weight loss samples fall near the boundary between pressure 
segments TWO and THREE of the Ann Mag geopressure profile (Figure 1) and correlate with the higher density fresh and desiccated shale from Sullivan K-1 (Figure 3). Shale from the zone of undercompaction at a depth between 2926 and 3048 meters (9600 and 10000 feet) show a weight loss which falls on the same quasi-linear interlayer water trend defined by samples shallower than $2743 \mathrm{~m}$ (9000 ft). Although samples between 2926 and $3048 \mathrm{~m}$ (9600 and 10000 feet) fall on a "normal" interlayer water trend (normal being defined by samples from less than $2743 \mathrm{~m}$ (9000 ft)), they have an abnormally low density. This observation points to the independence of compaction (shale density) and interlayer water content. Below $3048 \mathrm{~m}$, shale again displays a lower weight loss.

In summary, dehydration data from the Sullivan K-1 well are grouped into four depth-intervals. Note the position of the dehydration depth-intervals relative to the pressure segments from Ann Mag geopressure profile (Figure 4). In particular, depth-interval II is found at the base of pressure segment TWO and depth-interval III correlates with much of pressure segment THREE.

Correlation of smectite/illite ratio with water loss on dehydration in the Sullivan $K-1$ well

We used X-ray diffraction analysis to correlate the relative amounts of smectite to illite with the amount of water loss on dehydration. X-ray diffractograms of shale from each of 16 intervals are shown in Figure 5. A complete compilation of diffractograms is given in Leftwich (1993). The analysis reveals two populations of mixed layered clay minerals; one rich in smectite and the other relatively poor in smectite and rich in illite. Other minerals observed in the clay fraction include chlorite and minor amounts of quartz. The smectite-rich population contains between $40 \%$ and $60 \%$ smectite whereas the smectite poor zone contains less than $25 \%$ (Figure 6).

A plot of weight loss versus percentage of smectite shows a positive correlation which supports our interpretation that interlayer water was the source of weight loss during dehydration (Figure 7). We use this calibration curve from the K-1 well as a basis for a 
qualitative measure of the amount of smectite relative to illite in shale samples from other wells in the Ann Mag field.

Illite content as measured by gamma ray logs

Gamma ray logs give another qualitative check on the distribution of illite in the Ann Mag field. The gamma ray log responds to radioactivity (i.e., gamma rays) from naturally occurring radioactive elements (potassium, uranium, and thorium) within the formation. As illite is characteristically rich in potassium, a high concentration of illite can cause high gamma ray readings.

A plot of gamma ray intensity versus depth for shales in the Sullivan K-1 and Sullivan M-1 wells (Figure 8) show anomalously high gamma ray readings opposite the zones of illite. Based on the gamma ray intensity the following are important details concerning clay mineralogy. First, an illite rich interval interrupts the normal depth trend of gradually decreasing smectite. Second, the zone of dense shale in a depth range between 2743 and 2804 meters (9000 and 9200 feet) correlates with the illite rich interval II. Third, the low density shale of the undercompacted zone is smectite rich.

\section{Interlayer water of shale in four wells}

The weight loss curves for the Sullivan Rupp 1, Sullivan K-1, Sullivan L-1, and the Sullivan M-1 show that interlayer water content decreases with depth in all four Ann Mag wells (Figure 9). Unlike the Sullivan K-1, L-1, and M-1 wells, where shale samples were only collected below $1829 \mathrm{~m}$ (6000 ft), samples from the Sullivan Rupp 1 well were available from $549 \mathrm{~m}(1800 \mathrm{ft})$ and below. The Sullivan Rupp 1 shows a relatively large amount of interlayer water content from near the surface down to approximately $1829 \mathrm{~m}$ $(6000 \mathrm{ft})$, and less interlayer water content below this depth. Below $1829 \mathrm{~m}(6000 \mathrm{ft})$ we recognize the familiar quasi-linear trend going from $2.5 \%$ at $1829 \mathrm{~m}(6000 \mathrm{ft})$ to $1.3 \%$ at 
$3232 \mathrm{~m}(10000 \mathrm{ft})$. Just as in the K-1 well, less interlayer water content, hence an illiterich layer, is found at $2774 \mathrm{~m}(9100 \mathrm{ft})$ and at $3125 \mathrm{~m}$ (10250 ft) in the Sullivan Rupp 1 well. Likewise, shale from the Sullivan L-1 and M-1 show an illite-rich layer at these same depths. For reasons which are not clear to us the Sullivan M-1 showed less dehydration (1\% weight loss versus $2 \%$ weight loss) than the other three wells. This is the main reason we use the dehydration data as a qualitative measure of the smectite/illite ratio.

\section{DISCUSSION}

Origin of the Ann Mag geopressure profile

The geopressure profile of the Ann Mag field has four segments, each following a distinct pressure-depth gradient. The top of abnormal pressure at approximately $2280 \mathrm{~m}$ (7481 ft) is the boundary between pressure segments ONE and TWO. The mechanism placing the top of geopressure at $2280 \mathrm{~m}(7481 \mathrm{ft})$ is not clear. The closest geological feature, which might mark the top of pressure, is the boundary between reddish or greenish shales above gray shales at a depth of about $2390 \mathrm{~m}(7842 \mathrm{ft})$. Interestingly, the depth at which the section becomes predominantly shale occurs closer to the boundary between pressure segments TWO and THREE.

One possibility for the location of the top of geopressure is that sandstone bodies below $2280 \mathrm{~m}(7481 \mathrm{ft})$ are not interconnected whereas those sandstone bodies above are interconnected. Another possibility is that illitization by upward percolation of waters from the geopressured zone plays a role in determining the depth to abnormal pressure in the Ann Mag field. During illitization, silica-rich waters are released to move even further upward in the section. Silica may be carried upward and redeposited near the top of geopressure and well above the top of undercompaction. Although we have no evidence supporting it, a siliceous seal may in part be responsible for the development of the abnormal pressure in segment TWO. A third possibility is to call upon a diffusivity 
minimum (i.e., Mello et al., 1994) to explain the presence of abnormal pressures in pressure segment TWO. The interconnection of sandstone bodies or a diffusivity minimum are favored mechanisms for the top of geopressure largely because we did not detect a siliceous seal.

The illite-rich zone that occurs in the interval $2743 \mathrm{~m}-2819 \mathrm{~m}(9000 \mathrm{ft}-9250 \mathrm{ft})$ is situated just above the boundary between pressure segments TWO and THREE (Figures 1 and 4). This illite layer is found throughout the Ann Mag field as indicated by our dewatering measurements. This illite-rich layer may serve as a seal within overpressured shales because it has several characteristics consistent with a seal zone. First, it is located at the boundary between pressure segments; a seal will cause an abrupt jump in the pressure gradient (e.g., Weedman et al., 1992). Second, it is a zone of higher density as indicated by short sonic travel times $(\Delta t)$, low conductivity (i.e., low water content and porosity), and shale density measurements. Since the goals of this research do not include identifying the origin of the illite layer, no further attempt was made to analyze the shale of this illite-rich layer.

There is more than one possibility for the origin of the illite-rich layer. First, the illite-rich layer may be an artifact of an original depositional pattern favoring illite. Such illite-rich beds are known in the Louisiana Gulf Coast (Strickler and Ferrell, 1989) and in the North Sea (Pearson, 1990; Shaw and Primmer, 1991).

A second possibility arises because laboratory work suggests the transmission of large volumes of low silica saturated water is important in converting shale zones rich in smectite to highly illitized shales (Kacandes, et al., 1992). Ilitic-rich layers may occur immediately above the zone of undercompaction. As diagenesis and compaction proceeds in a subsiding basin, where sediments are undergoing rapid dewatering, large volumes of silica poor water are usually available from compacting and dehydrating shales below (i.e., thick marine shale sections). These fluids move upward and are transmitted through the smectite rich shales in response to increasing geopressures. If these large volumes of silica poor water pass through a specific smectite-rich shale zone, the smectite phases rapidly 
convert to illite (Kacandes, et al., 1992). As illitization proceeds the development of a diagenetic seal analogous to Al's Cap (Boatman, 1967) may occur. However, the reason of focused flow of silica poor water through the shale at $2743 \mathrm{~m}(9000 \mathrm{ft})$ in the Ann Mag field is not clear. As a consequence, we favor the detrital sediment origin as the most likely source of the illite-rich layer.

\section{The development of undercompaction}

Deeper in the Ann Mag field, shales in pressure segment THREE are undercompacted as indicated by anomalously low shale densities plus anomalously high conductivities and sonic travel times. The top of undercompaction is coincident with the boundary between pressure segment TWO and pressure segment THREE. The undercompacted zone is a smectite-rich zone on the normal smectite dehydration trend as defined by Figure 4. The contrast in physical properties between the illite-rich shales of interval II and the smectitic-rich shales of interval III define the top of undercompaction on electric logs. The electrical log and shale density anomalies associated with undercompaction are found in smectitic-rich shales.

The theory, that smectite-illite transformation is a cause of abnormal pressure and indirectly undercompaction, was based on measurements showing a predominance of smectite in the normally compacted section and illite in the undercompacted zone. Investigators state that undercompacted zone in the Gulf Coast are usually composed of illite rich clays, whereas the overlying compacted zones contain smectite rich clays (Kerr and Barrington, 1961; Powers, 1967; Burst, 1969; Freed and Peacor, 1989). However in many cases their sample intervals were widely spaced. Our analysis of interlayer water content from the four wells show that the clay minerals in the undercompacted zone of the Ann Mag field are more hydrated than the clay minerals just above the zone, the opposite from the observation reported in the literature. Hence, the distribution of interlayer water content in the Ann Mag field suggests that dewatering of smectite-rich shales is insufficient 
to cause abnormal pressure unless other parameters such as an external seal (i.e., Freed and Peacor, 1989; Powley, 1990) or a diffusivity minimum (i.e., Mello et al., 1994) come into play. Furthermore, we have shown the shale dehydration proceeds independently of compaction.

Compaction disequilibrium postulates an anomalously high porosity (pore water) in the undercompacted zone and our density data are consistent with the compaction disequilibrium model for undercompaction of smectite-rich shale of interval III. A consideration of possible mechanisms for undercompaction may also give an additional information on the origin of the overlying illite rich layer. The fresh shale density-depth curve has the general shape of the three curves shown in Figure 10 where the shale is undercompacted underneath the illite-rich layer. However, details of each curve differ as indicated by the path that shale take to arrive at their final density after starting at points $\mathrm{A}$, $\mathrm{B}$, and $\mathrm{C}$ on a normal compaction trend.

The first hypothesis is that the illite-rich layer formed at its present depth by transmission of a large volume of low silica saturated water. Suppose that a seal forms at a depth between points A and B; the seal and all rocks remain at that same depth (Figure 10, curve a). In order to arrive at the situation where shale at depths $B$ and $C$ are undercompacted relative to $\mathrm{A}$, the shale at $\mathrm{B}$ and $\mathrm{C}$ must decompact by transforming to $\mathrm{a}$ lower density. Decompaction is unlikely based on the smectite dehydration trend established for shale intervals I and III (Figure 4). At the depths of points B and C, smectite continues to convert to illite relative to point $\mathrm{A}$. This suggests that the shale at points $B$ and $C$ should have continued to increase in density. Furthermore, decompaction would require a mechanism such as microfracture dilation by several percent. Evidence for such a large volume of microfractures is not observed in thin section. Therefore, this model which states the illite seal formed at its present depth is unlikely.

The second hypothesis is that an illitic seal forms at a shallower depth possibly in a layer of detrital illite. Between points A and B, compaction stops instantaneously (time $t_{0}$ ). The shale at points $A, B$, and $C$ and seal all move down to the points $A^{\prime}, B^{\prime}$ and $C^{\prime}$ at time 
$t_{1}$ as the basin subsides under a large sediment load (Figure 10; curve b). Shale at point $A^{\prime}$ remain normally compacted whereas shale at points $\mathrm{B}^{\prime}$ and $\mathrm{C}^{\prime}$ become undercompacted because compaction is inhibited. This hypothesis does not apply because the final densitydepth curve shape does not match the actual electrical log or shale density plot profiles observed across the top of undercompacted zones.

For the third hypothesis, an illitic seal forms in a layer of detrital illite-rich shale. At a shallower depth the detrital layer starts to act like a seal and compaction below the seal stops between points A and B (time to in Figure 10c), but in this case partial compaction continues as the shale at points $\mathrm{A}, \mathrm{B}$, and $\mathrm{C}$ and seal subside. At time $\mathrm{t}_{1}$ the configuration of $A^{\prime}, B^{\prime}$ and $C^{\prime}$ is such that $A^{\prime}$ is normally compacted and rocks such as $B^{\prime}$ and $C^{\prime}$ are undercompacted (Figure 10c). B is partially compacted to $\mathrm{B}^{\prime}$ during further burial whereas compaction at $C$ is completely arrested so that compaction at $C$ and $C$ are equal. This hypothesis allows a shape of the density-depth curve at time $t_{1}$ which agrees with observations of electrical logs and shale density plot profiles across the tops of undercompacted zones.

\section{CONCLUSIONS}

Interlayer water content, as measured by water loss during heating shale cuttings to $115^{\circ} \mathrm{C}$ serves as a qualitative measure of the relative amounts of smectite and illite. In the Oligocene shales of the Ann Mag field, Texas Gulf Coast, the distribution of interlayer water with depth suggests that smectite starts to loose significant water at $2 \mathrm{~km}$, a depth which in most cases is somewhat shallower than the top of abnormal pressure. Within the Oligocene section there are illite-rich layers interpreted to be detrital. One such illite-rich layer acts like a seal below which is found undercompacted smectite rich shale. The correlation between undercompaction and smectite-rich shales suggests that illitization of smectite has little to do with the development of undercompacted shale. 


\section{ACKNOWLEDGEMENTS}

The writers are especially indebted to and wish to extend special thanks to Maguire Oil Company for their significant contributions to this study by providing logs, lithologic samples and other subsurface information on wells in their Ann Mag field located in Brooks County, Texas.

\section{REFERENCES}

Boatman WA. 1967. Measuring and using shale density to aid in drilling wells in high pressure areas. J Petrol Tech 19:1423-1429.

Bott WF, Tieh TT. 1987. Diagenesis and high fluid pressures in the Frio and Vicksburg shales, Brooks County, Texas. Transactions of the Gulf Coast Association of Geological Societies 37:323-333.

Bradley JS. 1975. Abnormal formation pressure. Am Assoc Petrol Geol Bull 59:957973.

Burst JF. 1969. Diagenesis of Gulf Coast clayey sediments and its possible relation to petroleum migration. Am Assoc Petrol Geol Bull 53:73-93.

Freed RL, Peacor DR. 1989. Geopressured shale and sealing effect of smectite to illite transition. Am Assoc Petrol Geol Bull 73:1223-1232.

Hottman CE, Johnson RK. 1965. Estimation of formation pressures from log-derived shale properties. J Petrol Tech 17:717-722.

Hower J, Eslinger EV, Hower ME, Perry EA. 1976. Mechanism of burial metamorphism of argillaceous sediment: 1. Mineralogical and chemical evidence. Geol Soc Am Bull 87: 725-737.

Jackson ML. 1975. Soil chemical analysis--advanced course. Published by the author, Madison, Wisconsin.

Kacandes GH, Barnes HL, Kump LR. 1992. Experimental study on the reaction of smectite to illite in silica deficient input fluids. (abstr.) The V. M. Goldschmidt Conference, Reston, Virginia, May 8-10.

Kerr PF, Barrington J. 1961. Clays of deep shale zone, Caillou Island, Louisiana : Am Assoc Petrol Geol Bull 45:1697-1712.

Leftwich $\mathrm{Jr}_{\mathrm{r}} \mathrm{JT}$. 1993. The development of zones of undercompacted shale relative to - abnormal subsurface pressures in sedimentary basins. Ph.D. diss., The

- Pennsylvania State University.

*Leftwich Jr JT, Engelder T. 1994. The characteristics of geopressure profiles in the Gulf of Mexico Basin. in Orteleva P., ed., Pressure Compartments, Am Assoc Petrol Geol Memoir 61:119-129. 
Matthews WR. 1969. Drilling variables show transition zone. Oil and Gas J 67:69-76.

Magara K. 1975. Reevaluation of montmorillonite dehydration as cause of abnormal pressure and hydrocarbon migration. Am Assoc Petrol Geol Bull 59:292-302.

McCulloh RP. 1988. Some implications of regional lithofacies control of Gulf Coast geopressures. Transactions of the Gulf Coast Association of Geological Societies:38:133-137.

Mello UT, Karner GD, Anderson RN. 1994. A physical explanation for the positioning of the depth to the top of overpressure in shale-dominated sequences in the Gulf Coast basin, United States. J Geophys Res 99:2775-2789.

Pearson MJ. 1990. Clay mineral distribution and provenance in Mesozoic and Tertiary mudrocks of the Moray Firth and northern North Sea. Clay Miner 25:519-541.

Powers MC. 1967. Fluid release mechanisms in compacting marine mudrocks and their importance in oil exploration. Am Assoc Petrol Geol Bull 51:1240-1254.

Powley DE. 1990. Pressures and hydrogeology in petroleum basins. Earth-Science Reviews 29:215-226.

Reynolds Jr RC. 1985. NEWMOD (c) a computer program for the calculation of onedimensional diffraction patterns of mixed-layered clays. R. C. Reynolds, Jr., 8 Brooks Dr., Hanover, New Hampshire.

Shaw HF, Primmer TJ. 1991. Diagenesis of mudrocks from the Kimmeridge clay formation of the Brae area, UK North Sea. Marine and Petrol Geol 8:270-277. .

Srodon J. 1980. Precise identification of illite-smectite interstratifications by X-ray powder diffraction. Clays and Clay Miner 28:401-411.

Strickler ME, Ferrell RE. 1989. Provenance and diagenesis of Upper Wilcox Formation clay minerals: Abstr 28, 9th International Clay Conference, Strasbourg. 379p.

Weedman SD, Guber AL, Engelder, T. 1992. Pore pressure variation within the Tuscaloosa trend: Morganza and Moore-Sams Fields, Louisiana Gulf Coast. J Geophys Res 97:7193-7202. 


\section{FIGURE CAPTIONS}

Figure 1. Formation pressure versus depth for the Ann Mag field (adapted from Leftwich and Engelder, 1994). The plot includes both BHP and RFT data. Inset is an index maps showing location of the Ann Mag Field (27 $09^{\prime} 58^{\prime \prime} \mathrm{N}$ and $98^{\circ} 03^{\prime} 30^{\prime \prime} \mathrm{W}$ ) in Brooks County, Texas.

Figure 2. A typical electric log from the Ann Mag field, Brooks County, Texas showing the correlation between the top of undercompaction and the top of a thick marine shale sequence. This particular well is the Ginther, Warren, and Gulf Oil Company, Chamberlain Unit \#1.

Figure 3. Composite plot, Maguire Oil Co. Sullivan K-1 well. Data include conductivity and sonic travel time taken from electric logs. Shale density data were measured using a density column. All four data plotted on a log scale. The top of undercompaction and top of abnormal pressure are field averages. The top of undercompaction for the Sullivan K-1 well is $82.3 \mathrm{~m}$ ( 270 feet) deeper than the field average.

Figure 4. Percent weight (water) loss upon dehydration versus depth and $\mathrm{X}$-ray analysis for shales in the Maguire Oil Sullivan K-1 well. Smectite-illite proportions for mix layer clay minerals as determined by $\mathrm{X}$-ray for each sample and the corresponding sample depths are as follows. $\underline{X}$-ray Interval I (40\% Illite) Samples M (2042 m; $6700 \mathrm{ft}), \mathrm{F}(2118 \mathrm{~m} ; 6950 \mathrm{ft}), \mathrm{B}(2179 \mathrm{~m} ; 7150 \mathrm{ft}), \mathrm{P}(2271 \mathrm{~m} ; 7450 \mathrm{ft}), \mathrm{Q}(2316$ $\mathrm{m} ; 7600 \mathrm{ft}), \mathrm{K}(2332 \mathrm{~m} ; 7650 \mathrm{ft}), \mathrm{G}(2545 \mathrm{~m} ; 8350 \mathrm{ft}), \mathrm{R}(2591 \mathrm{~m} ; 8500 \mathrm{ft}), \mathrm{J}$ $(2606 \mathrm{~m} ; 8550 \mathrm{ft}$ ), and I (2667 m; $8750 \mathrm{ft})$. X-ray Interval II (83\% Illite) Samples $\mathrm{T}(2774 \mathrm{~m} ; 9100 \mathrm{ft})$, and $\mathrm{E}(2804 \mathrm{~m} ; 9200 \mathrm{ft})$. X-ray Interval II ( $54 \%$ Illite) Samples O (2926 m; $9600 \mathrm{ft}), \mathrm{C}(2941 \mathrm{~m} ; 9650 \mathrm{ft}), \mathrm{W}(2956 \mathrm{~m} ; 9700 \mathrm{ft}), \mathrm{S}$ (3002 $\mathrm{m} ; 9850 \mathrm{ft}), \mathrm{U}(3048 \mathrm{~m} ; 10,000 \mathrm{ft}), \mathrm{H}(3063 \mathrm{~m} ; 10,050 \mathrm{ft})$, and A (3109 m; $10,200 \mathrm{ft}$ ). X-ray Interval IV (84\% Illite) Samples L (3139 m; 10,300 ft), V (3155 m; 10,350 ft), and $\mathrm{N}(3200 \mathrm{~m} ; 10,500 \mathrm{ft})$. Sample D (3231 m; 10,600 ft).

Figure 5. X-ray diffractograms for shale intervals in Maguire Sullivan K-1 well.

Figure 6. Percent smectite in smectite-illite of shale from the Sullivan K-1 well.

Figure 7. A plot of weight loss percent versus percentage of smectite. 
Figure 8. Shale gamma ray versus depth , (a) Maguire Oil Sullivan K-1 and (b) Sullivan M-1 wells.

Figure 9. Percent weight loss upon dehydration versus depth for shales from the following wells, (a) Maguire Oil Sullivan Rupp \#1, (b) Maguire Oil Sullivan K-1, (c) Maguire Oil Sullivan L-1, and (d) Maguire Oil Sullivan M-1. All curves plotted at the same scale for ease of comparison.

Figure 10. Three models illustrating the depth of illite layer formation and the development of the zone of undercompaction. Model (a), seal formed instantaneously at its present depth across normally compacted rocks. Rocks below the seal subsequently decompact. In the second model, (b), the instantaneous illitic seal forms at a shallow depth followed by the rocks and seal sinking to a new depth. In the third model, (c), an instantaneous illitic seal forms at a shallow depth, compaction stops instantaneously, then the rocks and seal move down as the basin subsides. 


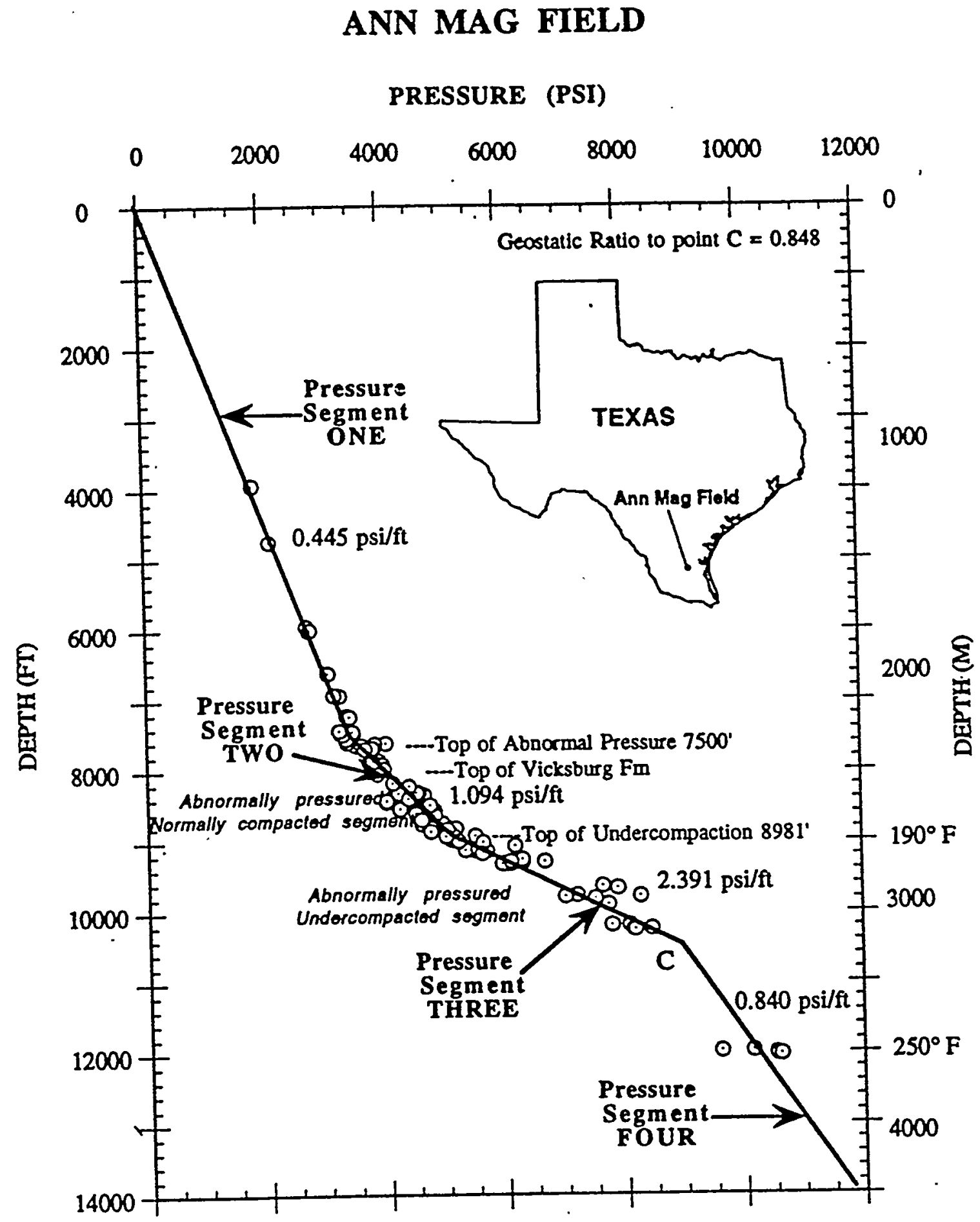

Figure 1. 


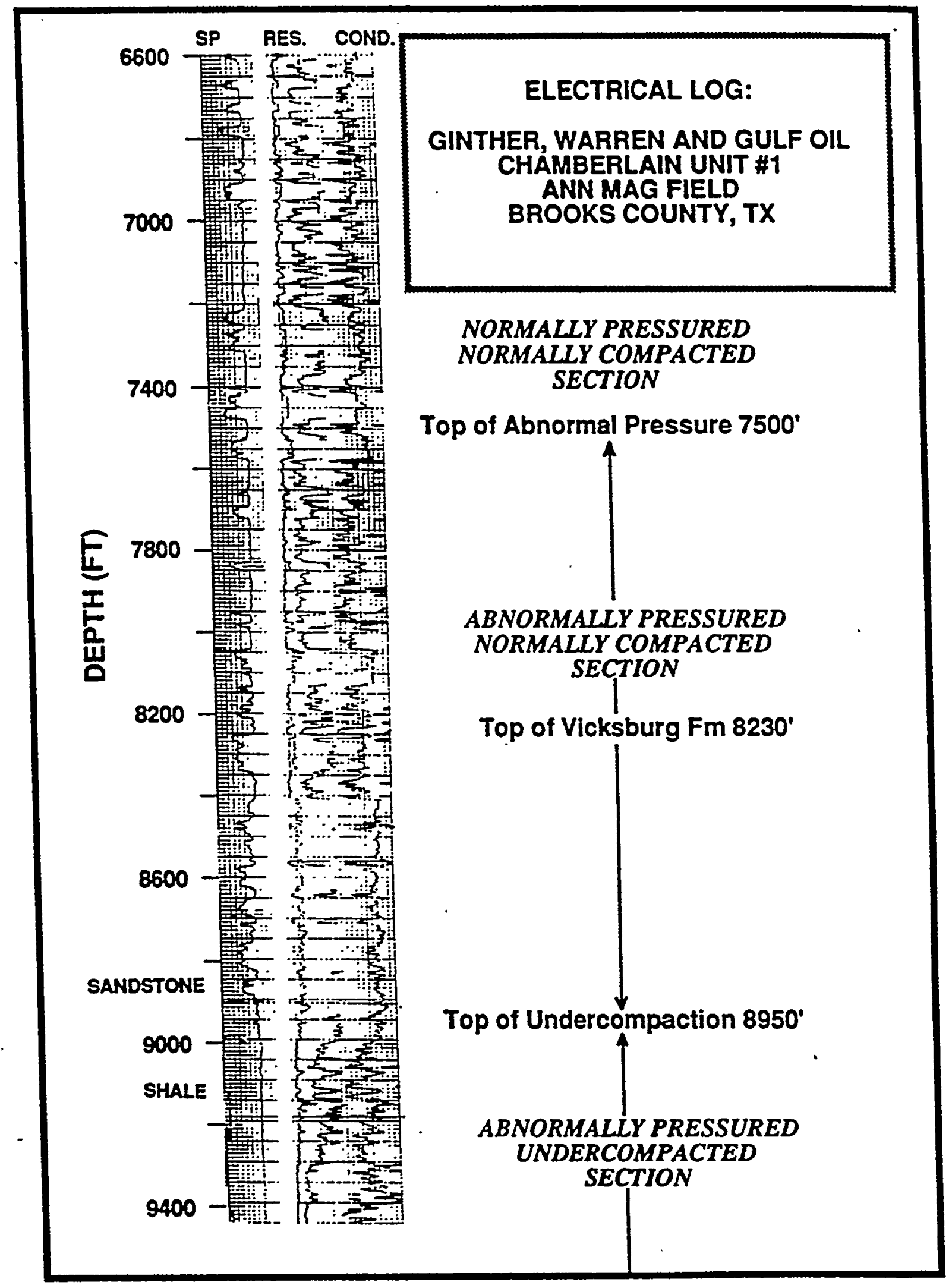

Figure 2. 


\section{COMPOSITE PLOT SULLIVAN K-1 WELL}

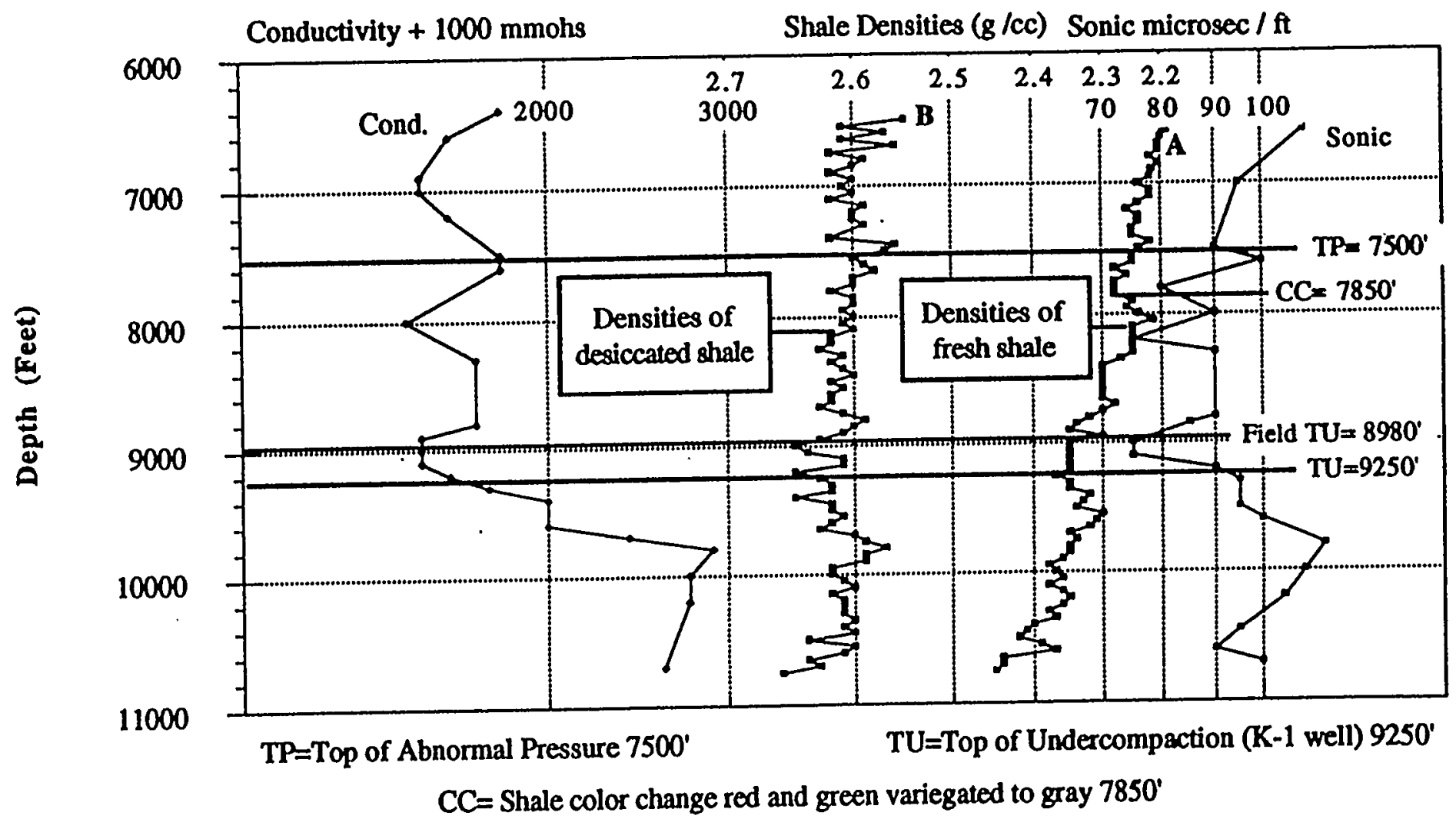

Figure 3. 
SHALE INTERLAYER WATER LOSS - MAGUIRE SULLIVAN K-1

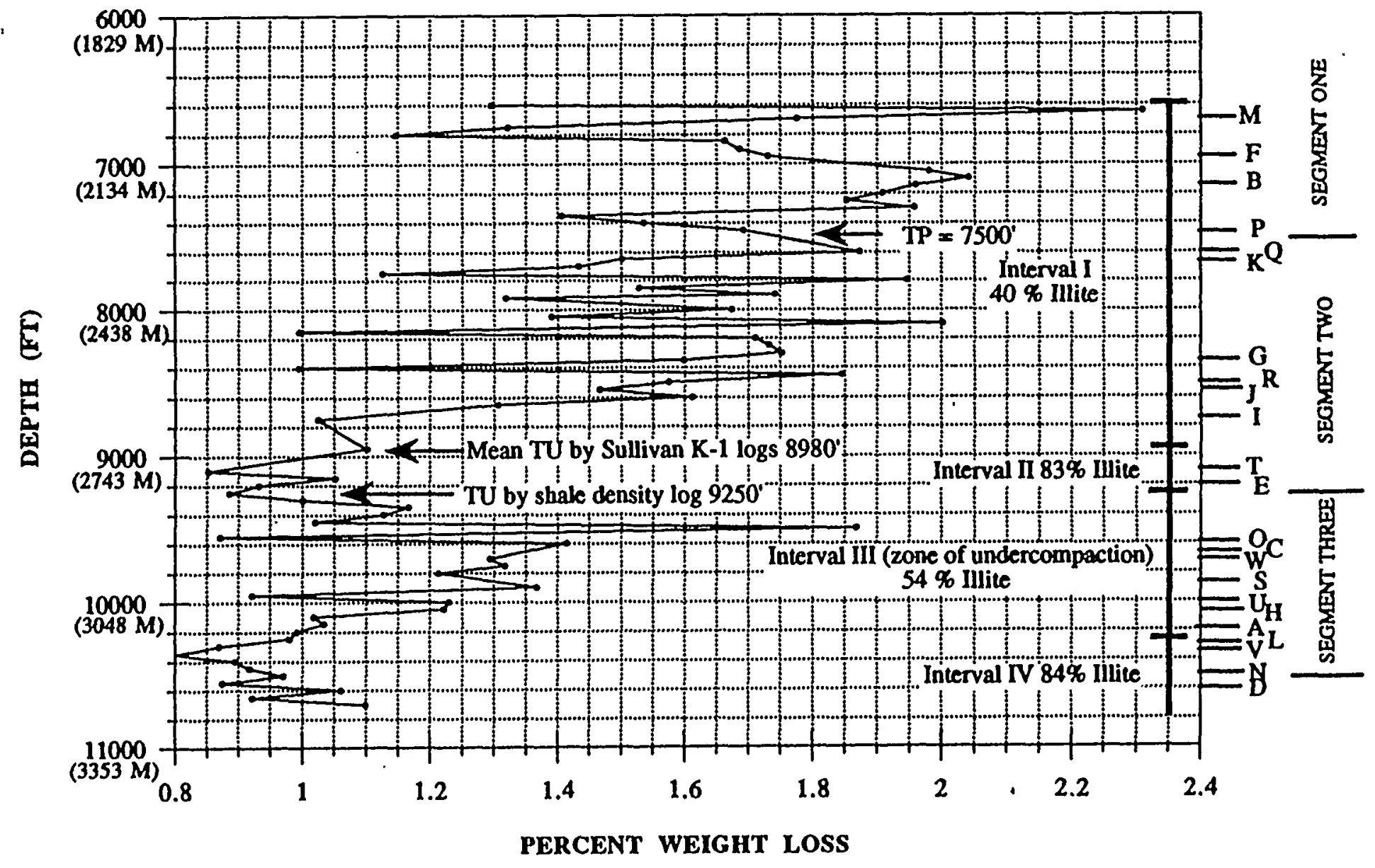

TP = Top of Abnormal Pressure

Deptbs in meters shown in parentheses

$\mathrm{TU}=\mathrm{Top}$ of Undercompaction

Figure 4. 


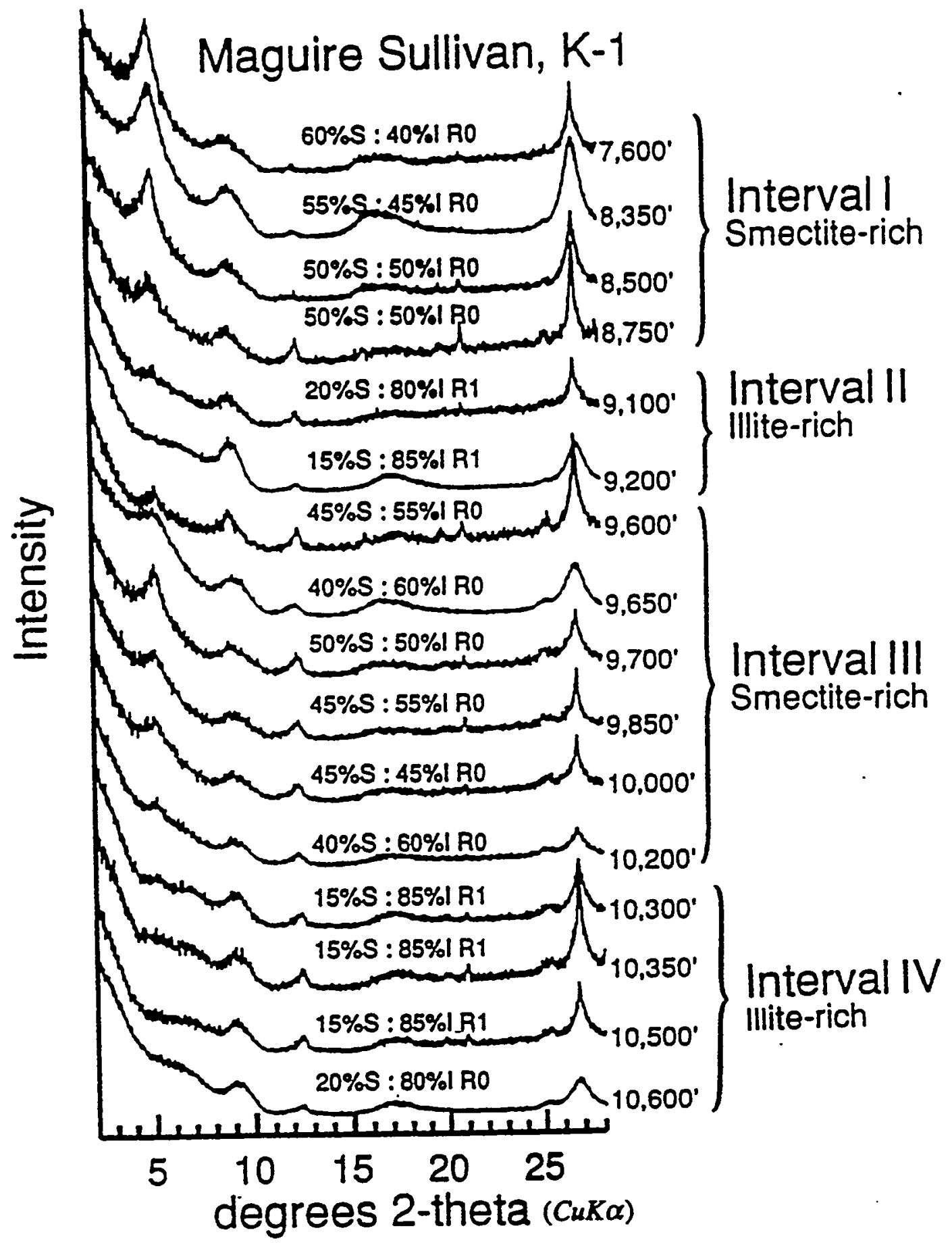

Figure 5. 


\section{MAGUIRE SULLIVAN K-1 WELL}

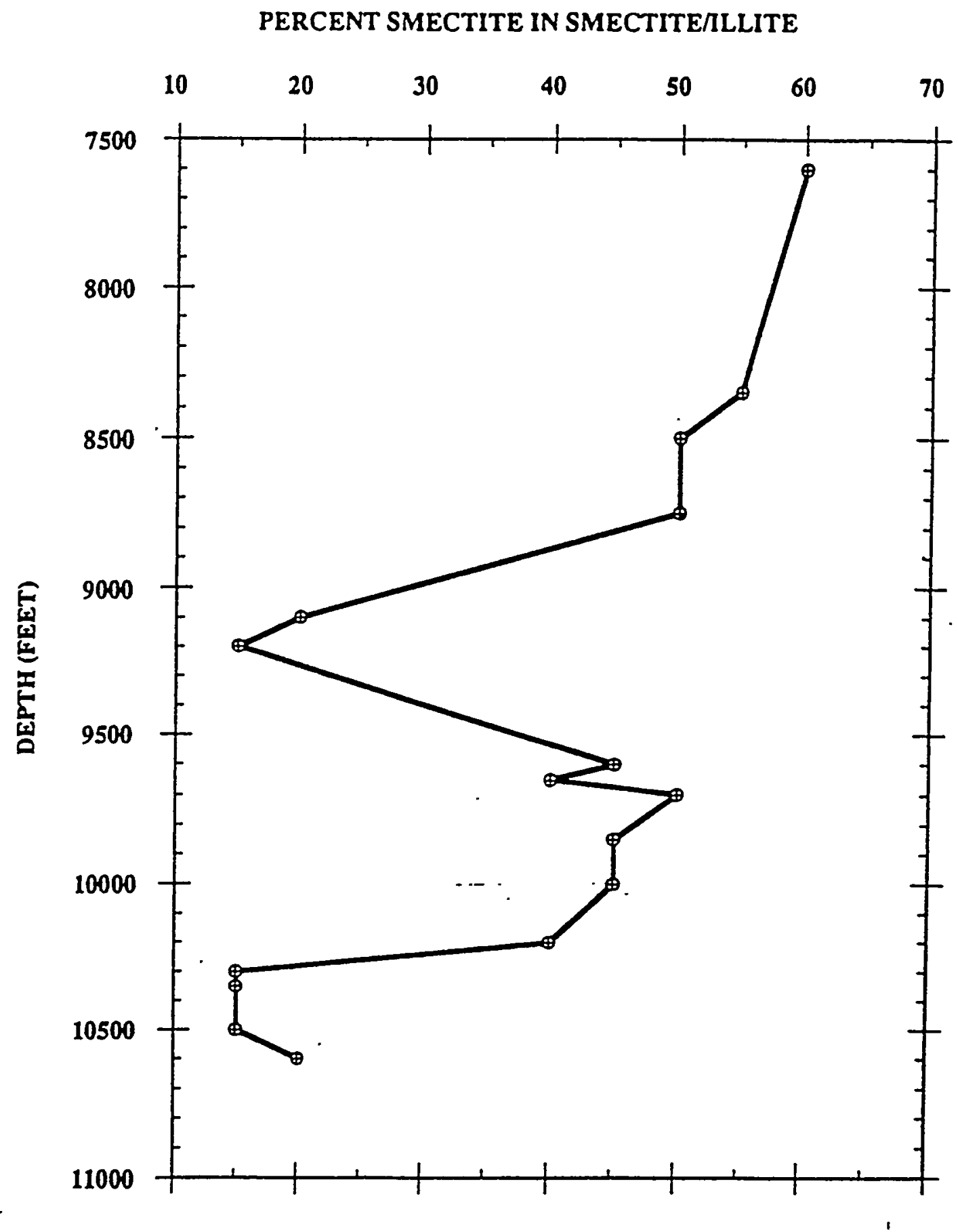

Figure 6. 
Sullivan $\mathrm{K}-1$

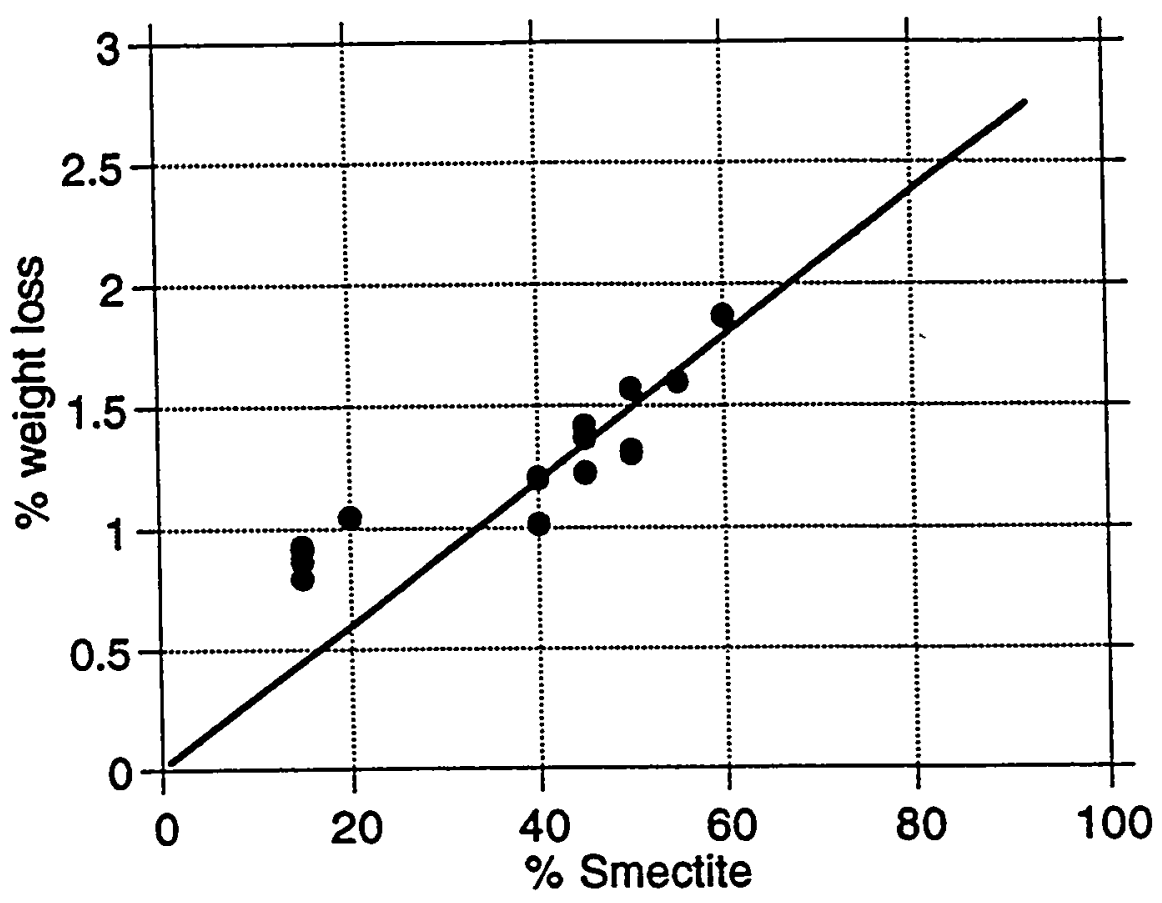

Figure 7. 


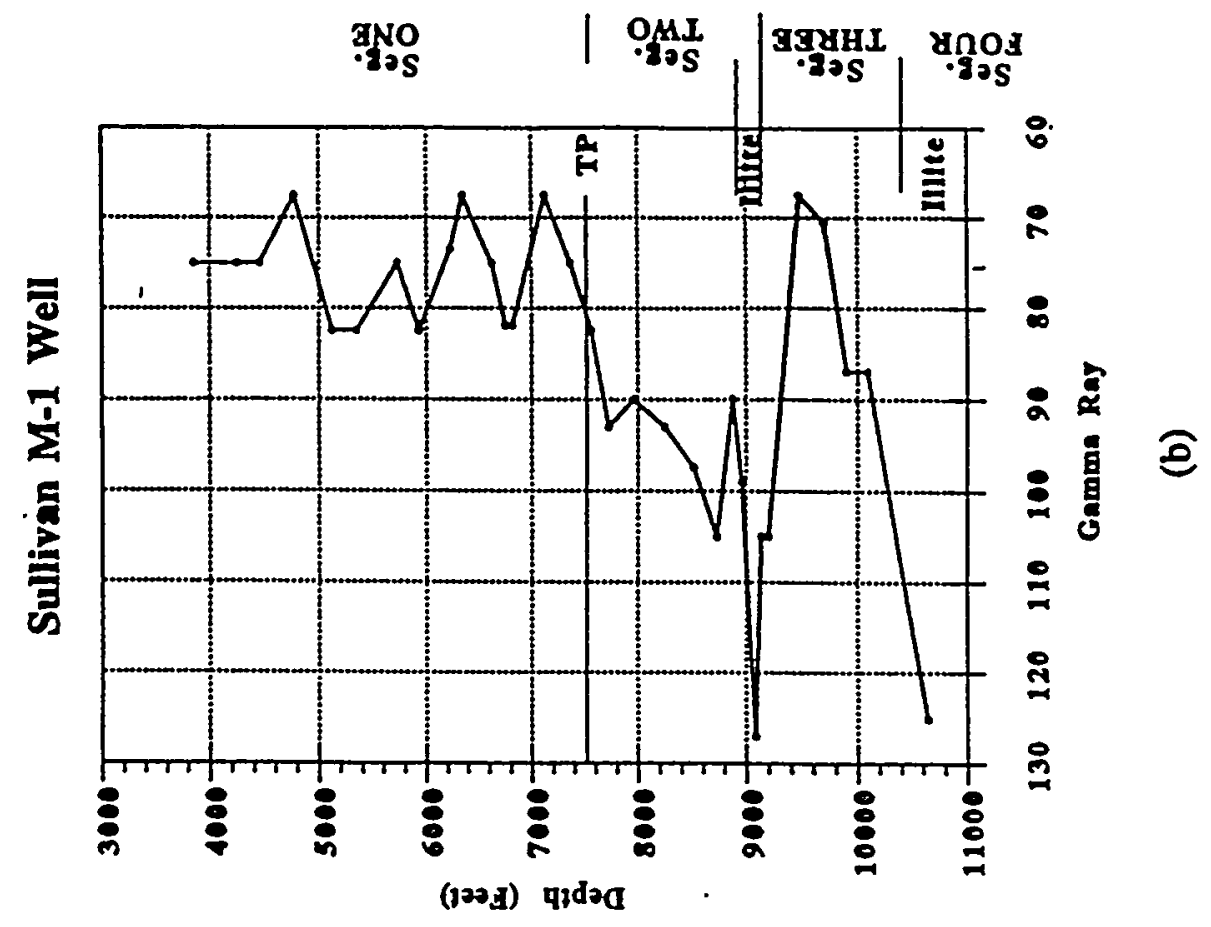

京

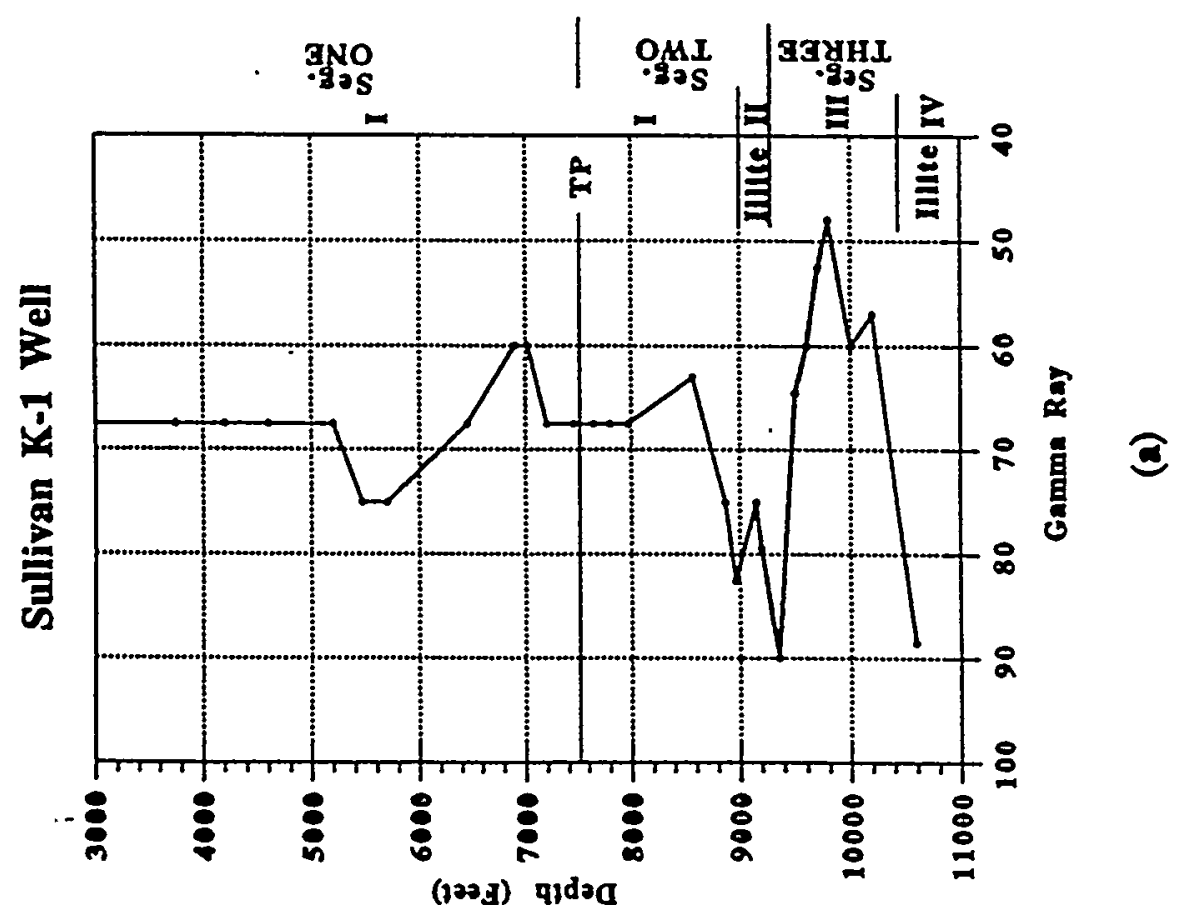




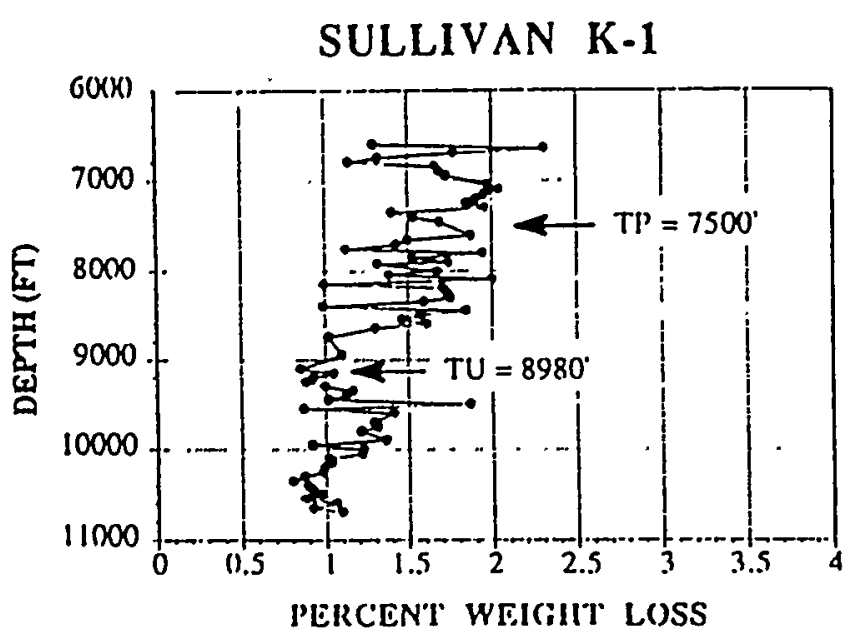

(a)

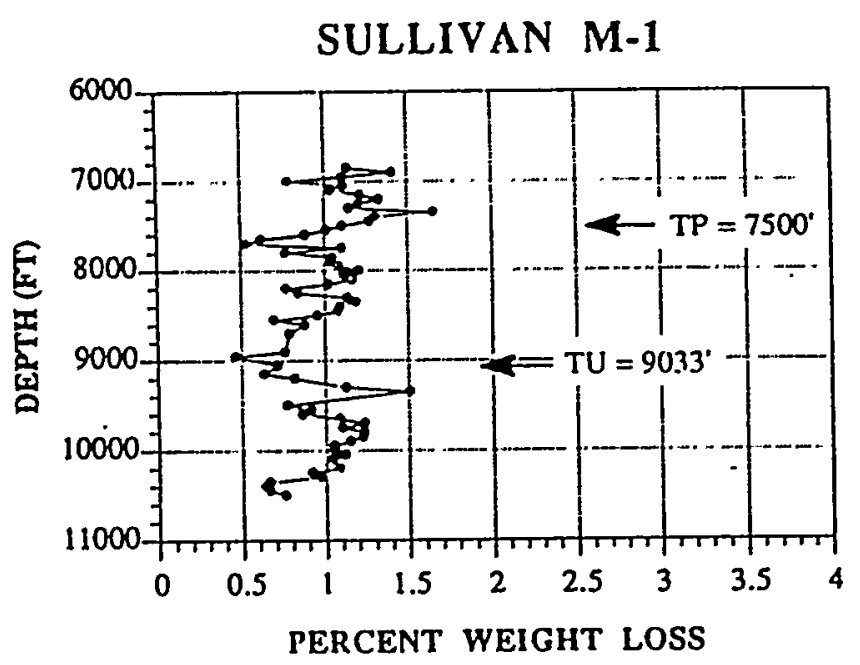

(c)

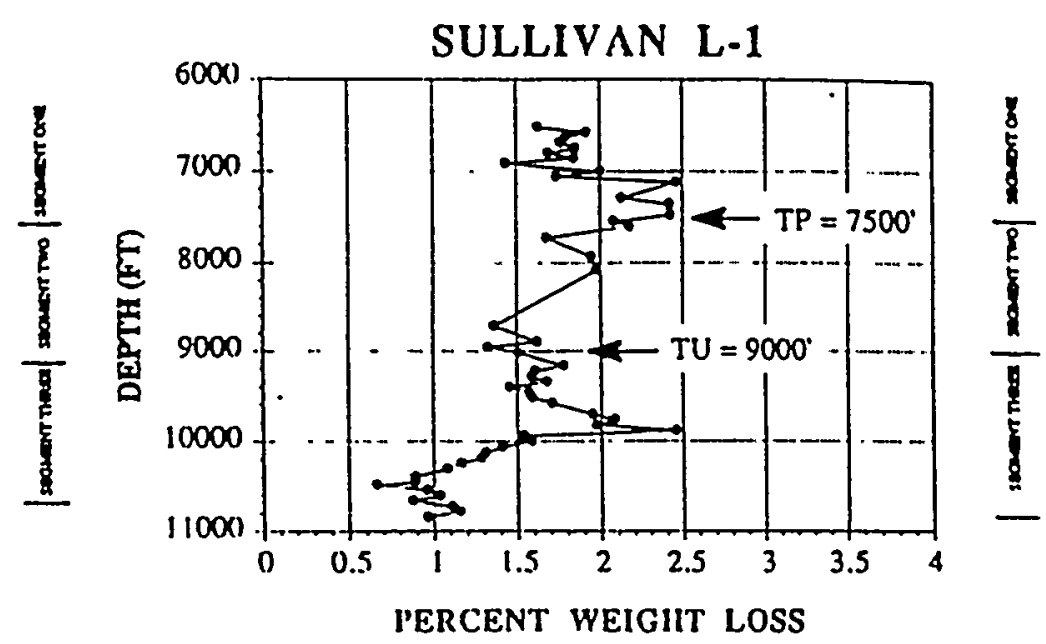

(b)

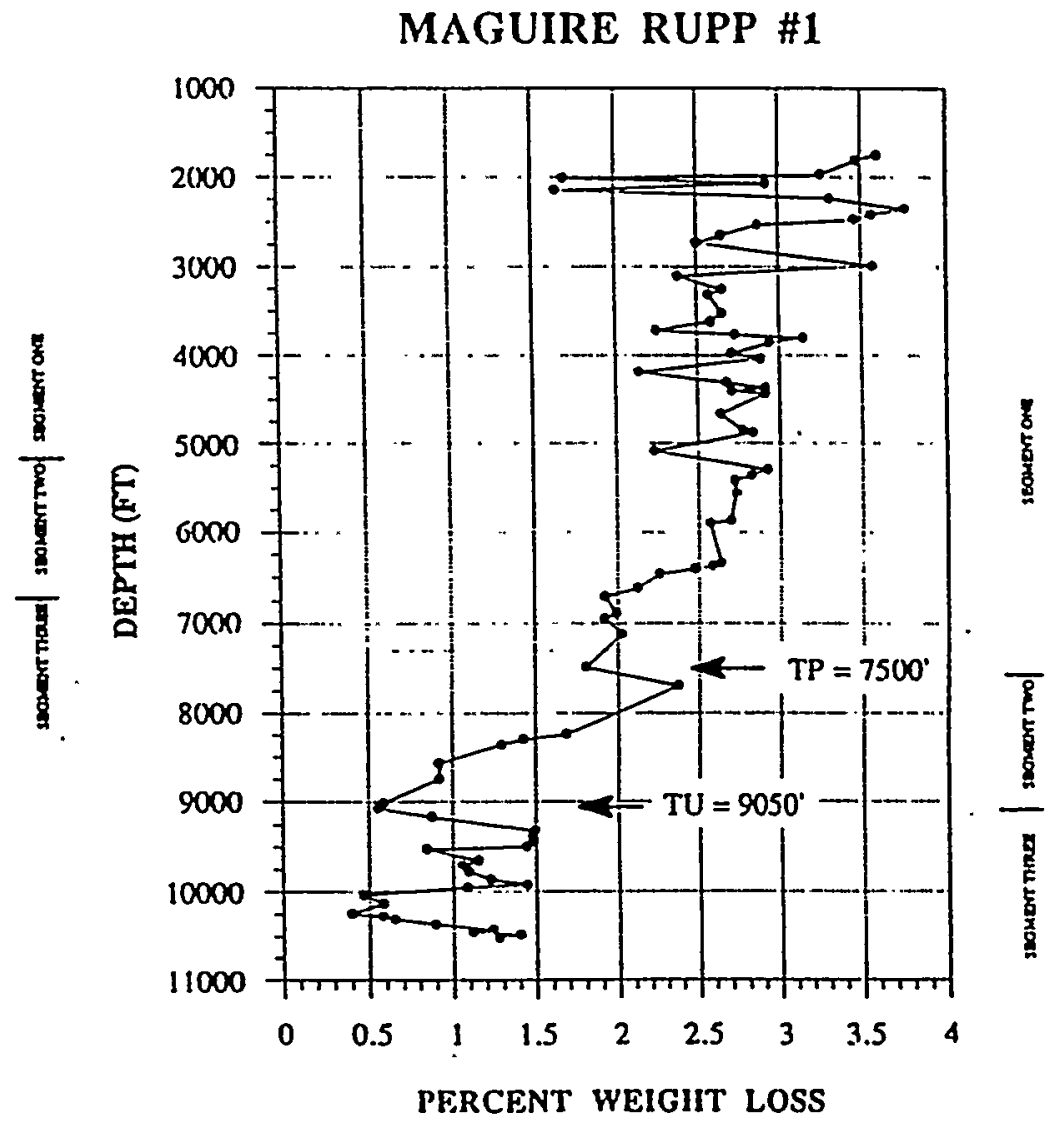

(d)

Figure 9. 


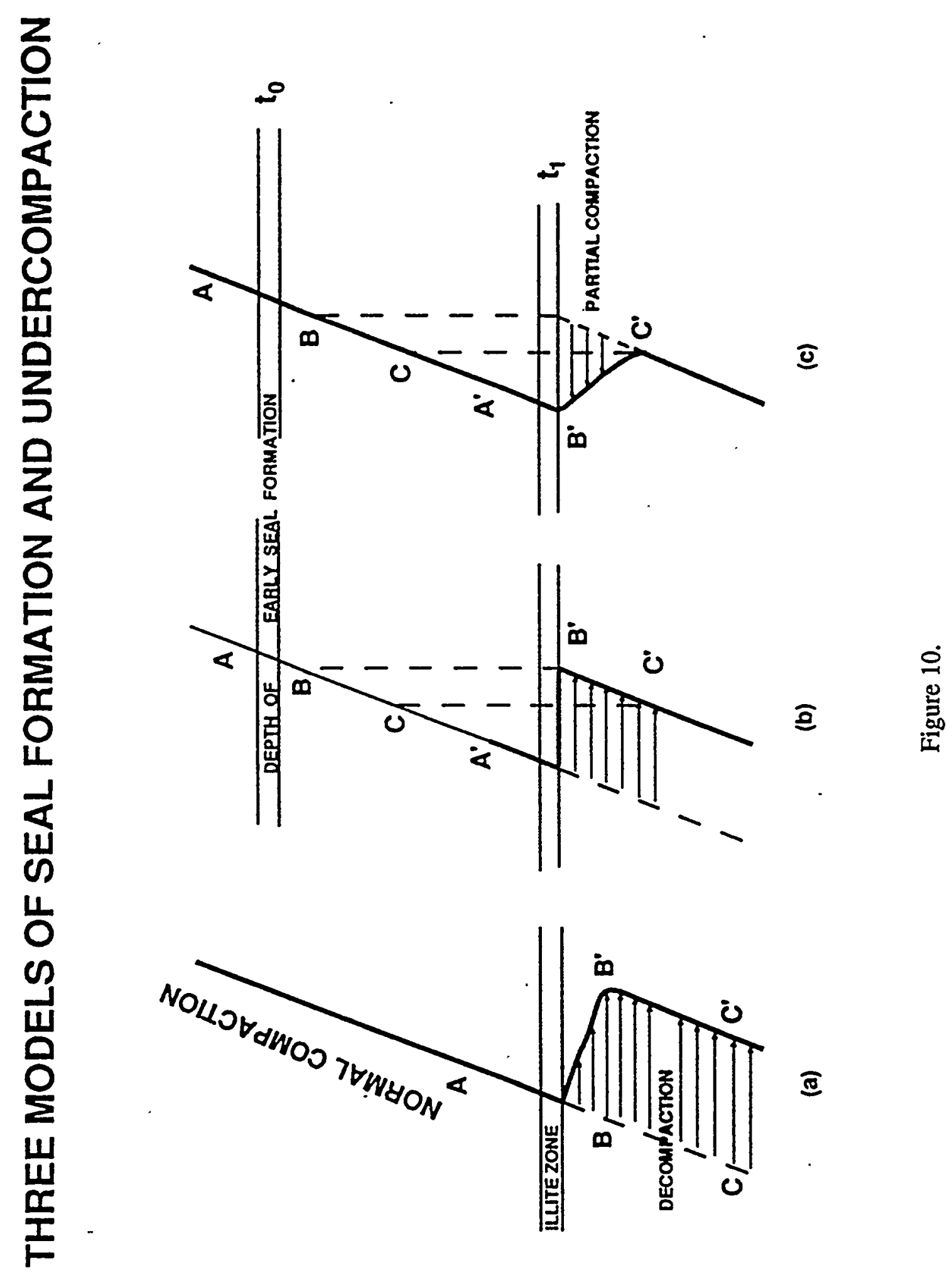


Appendix B

PREPARATION PROCEDURE FOR A SEMI-QUANTITATIVE ANALYSIS OF CLAY MINERALS FROM ANALYSIS OF SHALE CHIPS. DESCRIBED METHODS FOR X-RAYING CUTTINGS FROM MAGUIRE OIL COMPANY'S RUPP \#1 WELL. TECHNIQUE MODIFIED FROM METHODS BY DR. DENNIS DARBY 
Preparation procedure for a semi-quantitative analysis of clay minerals from analysis of shale chips Technique devised by Dr. Dennis Darby

\section{PROCEDURE}

1) Shale clippings were gently crushed via mortar and pestle into smalier sizes. Care was taken not to damage the crystal structure of any clay minerals that might be present.

2) Table listing the raw amount of sample used for the analysis. (1.e. sand + silt + clay fractions)

\begin{tabular}{|c|c|c|c|c|c|}
\hline 8ample & Noight & sample * & Nelght & Bample & Nolght \\
\hline $\begin{array}{l}1 \\
2 \\
3 \\
4 \\
5 \\
6 \\
7 \\
8\end{array}$ & $\begin{array}{l}2.21749 \\
2.18029 \\
2.12049 \\
2.11299 \\
2.12339 \\
2.11989 \\
2.19079 \\
1.83389\end{array}$ & $\begin{array}{l}9 \\
10 \\
11 \\
12 \\
13 \\
14 \\
15 \\
16\end{array}$ & $\begin{array}{l}2.1405 g \\
2.1368 g \\
2.11359 \\
2.06309 \\
2.10119 \\
1.82119 \\
1.75159 \\
2.14169\end{array}$ & $\begin{array}{l}17 \\
18 \\
19 \\
20 \\
21 \\
22 \\
23 \\
24 \\
25 \\
26\end{array}$ & $\begin{array}{l}2.61439 \\
2.16729 \\
2.29179 \\
3.10759 \\
2.19679 \\
2.40999 \\
1.99999 \\
2.02389 \\
2.2265 \mathrm{~g} \\
2.2535 \mathrm{~g}\end{array}$ \\
\hline
\end{tabular}

h

Talc is to be used as an internal standard and will be processed just as all the other samples. silde mounts of talc will undergo the same preparation as the sample slides for Xray analysis. This vill allow assessment of each of the preparations on the talc (i.e. how the talc peaks are affected by each slide preparation process).

* Yake sure the centrifuge tubes that are used can withstand $90^{\circ} \mathrm{C}$ and sonification at maximum setting. The heavier duty centrifuge tubes are recommended.

3) Samples were placed into centrifuge tubes with D.I. water and shaken for approximately five minutes by mechanical shaker.

4) The samples were then centrifuged at $700 \mathrm{rpm}$ for 3 minutes to segregate the sand and silt-sized fraction from the clay-sized fraction.

5) The suspended clay-sized frac along with the D.I. water was decanted into another centrifuge tube which was then centrifuged at $3,000 \mathrm{rpm}$ for three minutes to settle the clay-sized frac to the bottom of the tube. 
6) Processes 1-3 were repeated until there was sufficient clay frac to use for the $x$-ray diffraction analysis. At least $100 \mathrm{mg}$ of clay sample will be required for "full" clay analysis.

* I vould recommend having more than $100 \mathrm{mg}$.

7) Then enough clay frac was collected the samples were washed with $5 \mathrm{ml}$ of $1 \mathrm{~N} \mathrm{MgCL}_{2}$.

8) The clay frac were then centrifuged at 3000 rpm for 3 minutes and decanted.

9) Then the clay frac was washed 3 times with 2 ml of 1:1 ratio of methanol/D.I. water.

10) The clay frac and talc were then transferred into preweighed $50 \mathrm{ml}$ beakers and placed in an oven at $10^{\circ} \mathrm{C}$ to drive off the D.I. water.

11) After samples were free of water the beakers were reweighed to obtain the dry weight of the clay fraction. Dried clay weights are listed below.

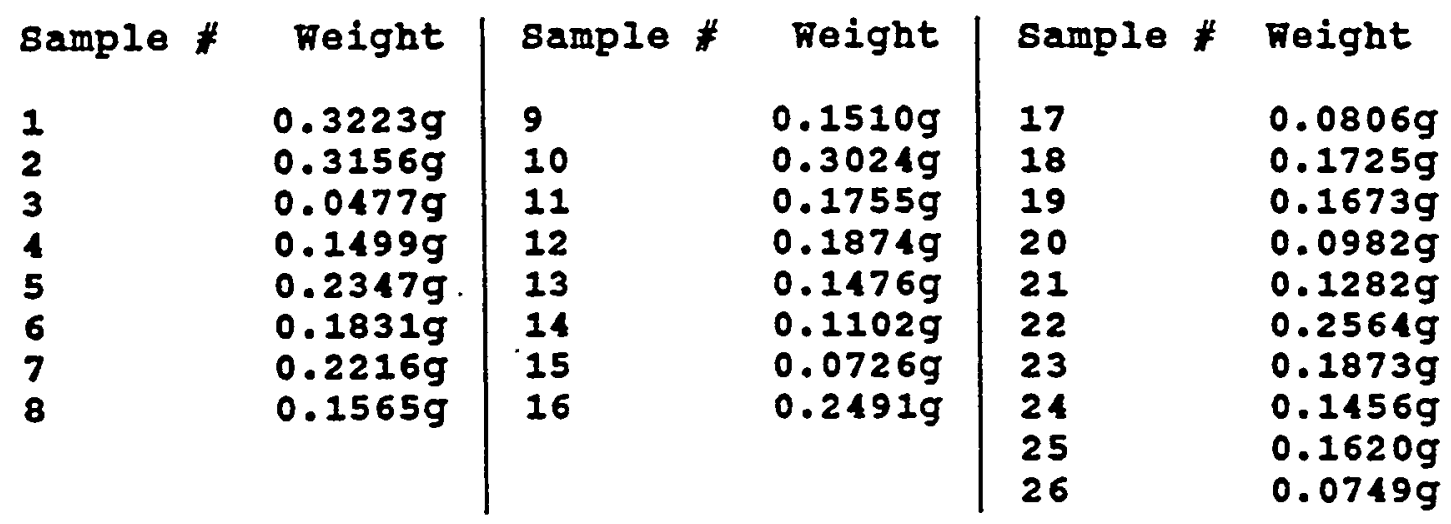

12) The percentage of the weight of each dry clay frac to the total weight of the "raw" sample (sand + silt + clay Eractions) are listed below.

\begin{tabular}{|c|c|c|c|c|c|c|}
\hline $\begin{array}{l}\text { 8ample } \\
1 \\
2 \\
3 \\
4 \\
5 \\
6 \\
7 \\
8 \\
9 \\
10\end{array}$ & $\begin{array}{r}\text { Teight } \\
15.0 \\
14.5 \\
2.2 \\
7.1 \\
11.1 \\
8.6 \\
10.1 \\
8.5 \\
7.1 \\
14.2\end{array}$ & $\begin{array}{l}\text { Sample } \\
11 \\
12 \\
13 \\
14 \\
15 \\
16 \\
17 \\
18 \\
19 \\
20\end{array}$ & $\begin{array}{r}\text { Weight } \\
8.3 \\
9.1 \\
7.0 \\
6.1 \\
4.1 \\
11.6 \\
3.1 \\
8.0 \\
7.3 \\
3.2\end{array}$ & $\begin{array}{l}q \\
q \\
8 \\
8 \\
8 \\
8 \\
8 \\
q \\
q \\
8 \\
q \\
q \\
q\end{array}$ & $\begin{array}{l}\text { Sample } \\
21 \\
22 \\
23 \\
24 \\
25 \\
26\end{array}$ & $\begin{array}{r}\text { Weight } \\
5.8 \\
10.6 \\
9.4 \\
7.2 \\
7.3 \\
3.3\end{array}$ \\
\hline
\end{tabular}


13) The talc standard was then added to each sample. The total amount of internal standard added to each sample was 10 of the dry weight of the clay frac.

13) The clay frac and internal standard (talc) were then saturated with D.I. water, placed in centrifuge tubes, and shaken for approximately 15 minutes.

14) The samples were then centrifuged at 3000 rpm for approximately 10 minutes to settle the material to the bottom of the centrifuge tube.

15) Approximately $0.05 \mathrm{~g}$ of the sample was then smeared onto a regular petrographic slide and run through the XRD machine using analysis program number 11 (CLAYANALYsI8) set up by $D r$. Darby and peaks were recorded.

16) 5 to $10 \mathrm{ml}$ of Dimethyl 8ulfoxide (DMsO) was then added to the rest of the sample in the centrifuge tube, sonified for 5 minutes (via a microtip sonifier set at maximum setting), and placed in a hot water bath $\left(90^{\circ} \mathrm{C}\right)$ for 24 hours. Note: Make sure that the tip on the sonifier is smooth and Eree of pits.

17) After 24 hours the samples were allowed to cool for approximately an hour and spun down via centrifuge for 10 minutes at $3000 \mathrm{rpm}$. The DMso was decanted and samples were capped until XRD analysis was ready to be performed.

18) XRD analysis was performed on samples using analysis program number 20 (DNSO) set up by Dr. Darby and peaks were recorded. (for Kaolinite \& Chlorite)

19) The untreated samples slides were then placed into an airtight film canister along with $10 \mathrm{ml}$ of ethylene glycol. The container was then placed into an oven set at $60^{\circ} \mathrm{C}$ for 24 hours.

20) XRD analysis was performed on samples using analysis program number 13 (GLYCOL) set up by Dr. Darby and peaks were recorded. (for smectite)

21) The glycolated sample slides were then set onto a flat homogeneous surface and placed into a furnace set at $300^{\circ} \mathrm{C}$ for 2 hours.

22) XRD analysis was performed on samples using analysis program number 19 (RSAT3OODEG) set up by Dr. Darby and peaks were recorded. (for vermiculite)

* suggestion: If the clay-sized fraction had proven to be to difficult to extact from the shale chips the sample could have been immersed directly into sodium hexametaphosphate and shaken gently for two days. 
CLAY CONTENT OF BHALE SAMPLES $1-26^{\circ}$

Mineralogy of samples less than two microns in size (clay)

(8ee Darby (1984) for equations used for mineral determination.)

\begin{tabular}{|c|c|c|c|c|c|c|c|c|c|}
\hline \multicolumn{10}{|c|}{ SAMPLES } \\
\hline INERALS & 1 & 2 & 4 & 5 & 6 & 7 & 8 & 9 & 10 \\
\hline $\begin{array}{l}\text { hlorite } \\
\text { aolin } \\
\text { meotite } \\
\text { li1te } \\
\text { ermiculite } \\
\text { uarts } \\
\text { eldspar } \\
\text { alcite } \\
\text { eolite } \\
\text { mphibole } \\
\text { olomite }\end{array}$ & $\begin{array}{rr}16 & t \\
0 & t \\
0 & t \\
62 & t \\
0 & t \\
7 & t \\
0 & t \\
15 & 7 \\
0 & t \\
0 & t \\
0 & f\end{array}$ & $\begin{array}{rr}17 & 7 \\
10 & f \\
11 & 7 \\
10 & 7 \\
0 & f \\
5 & 7 \\
5 & 7 \\
10 & 7 \\
0 & 7 \\
0 & 7 \\
2 & 7\end{array}$ & $\begin{array}{rl}22 & t \\
2 & f \\
58 & f \\
0 & t \\
0 & f \\
4 & t \\
1 & f \\
8 & t \\
0 & t \\
0 & t \\
2 & t\end{array}$ & $\begin{array}{rr}13 & f \\
5 & f \\
68 & f \\
0 & t \\
0 & 7 \\
4 & f \\
3 & t \\
6 & 7 \\
0 & 7 \\
0 & 7 \\
2 & 7\end{array}$ & $\begin{array}{rr}51 & 7 \\
0 & 7 \\
16 & 7 \\
0 & 4 \\
0 & 7 \\
10 & 7 \\
6 & 7 \\
10 & 7 \\
4 & 7 \\
0 & 7 \\
3 & 7\end{array}$ & \begin{tabular}{rr|}
3 & $t$ \\
10 & $t$ \\
25 & $t$ \\
41 & $t$ \\
0 & $t$ \\
15 & $t$ \\
3 & $t$ \\
0 & $t$ \\
0 & $t$ \\
0 & $t$ \\
0 & 7
\end{tabular} & $\begin{array}{rr}31 & t \\
0 & f \\
11 & t \\
0 & t \\
0 & t \\
18 & t \\
12 & t \\
17 & t \\
2 & t \\
2 & t \\
7 & f\end{array}$ & 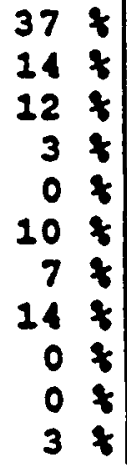 & 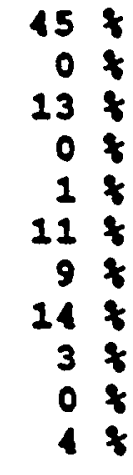 \\
\hline INERAIS & 11 & 12 & 13 & $\begin{array}{r}14 \\
14\end{array}$ & 15 & 16 & 17 & 18 & 19 \\
\hline $\begin{array}{l}\text { Chlorite } \\
\text { kaolin } \\
\text { smectite } \\
\text { Ililte } \\
\text { Vermiculite } \\
\text { Quartz } \\
\text { Foldspar } \\
\text { Calcite } \\
\text { geolite } \\
\text { Amphibole } \\
\text { Dolomite }\end{array}$ & $\begin{array}{rr}23 & f \\
16 & f \\
9 & 7 \\
15 & f \\
0 & f \\
12 & f \\
8 & 4 \\
13 & f \\
0 & f \\
0 & f \\
4 & 7\end{array}$ & 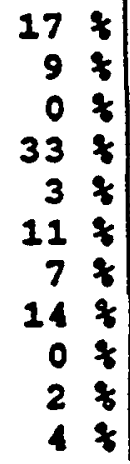 & 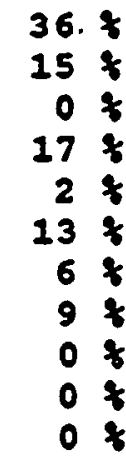 & $\begin{array}{rr}57 & 7 \\
7 & f \\
0 & f \\
0 & 7 \\
0 & f \\
12 & f \\
6 & 7 \\
13 & f \\
0 & f \\
2 & f \\
3 & f\end{array}$ & $\begin{array}{rr}44 & t \\
26 & f \\
2 & t \\
0 & t \\
0 & f \\
12 & f \\
5 & f \\
7 & t \\
0 & t \\
0 & f \\
1 & f\end{array}$ & $\begin{array}{rrr}51 & f \\
0 & f \\
13 & f \\
0 & t \\
0 & f \\
12 & f \\
10 & 7 \\
8 & 7 \\
0 & 7 \\
0 & 7 \\
6 & 7\end{array}$ & $\begin{array}{rr}36 & f \\
12 & f \\
7 & f \\
30 & f \\
0 & f \\
9 & f \\
5 & f \\
0 & f \\
0 & f \\
1 & f \\
0 & f\end{array}$ & 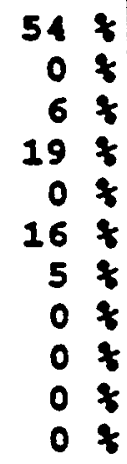 & $\begin{array}{r}11 \\
15 \\
2 \\
16 \\
0 \\
10 \\
8 \\
6 \\
0 \\
0 \\
2\end{array}$ \\
\hline
\end{tabular}

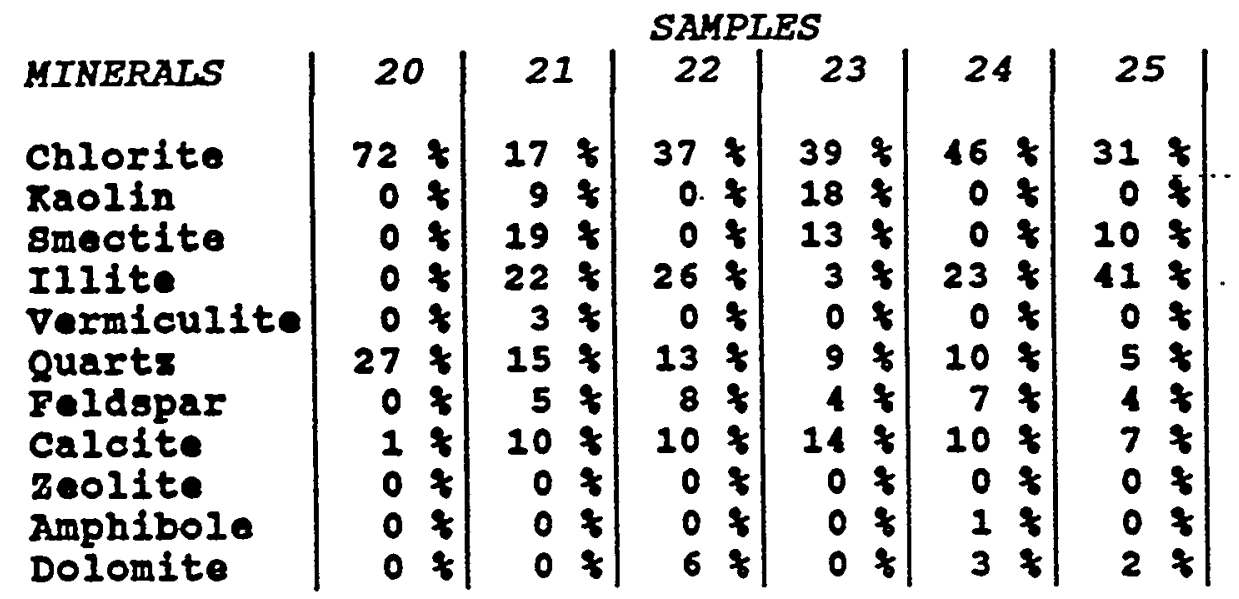

* . Note lack of data for samples 3 and 26. Insufficient amounts of clay-sized material was obtained to run these two samples. 